\title{
Fusion Materials Research at Oak Ridge National Laboratory in Fiscal Year 2017
}

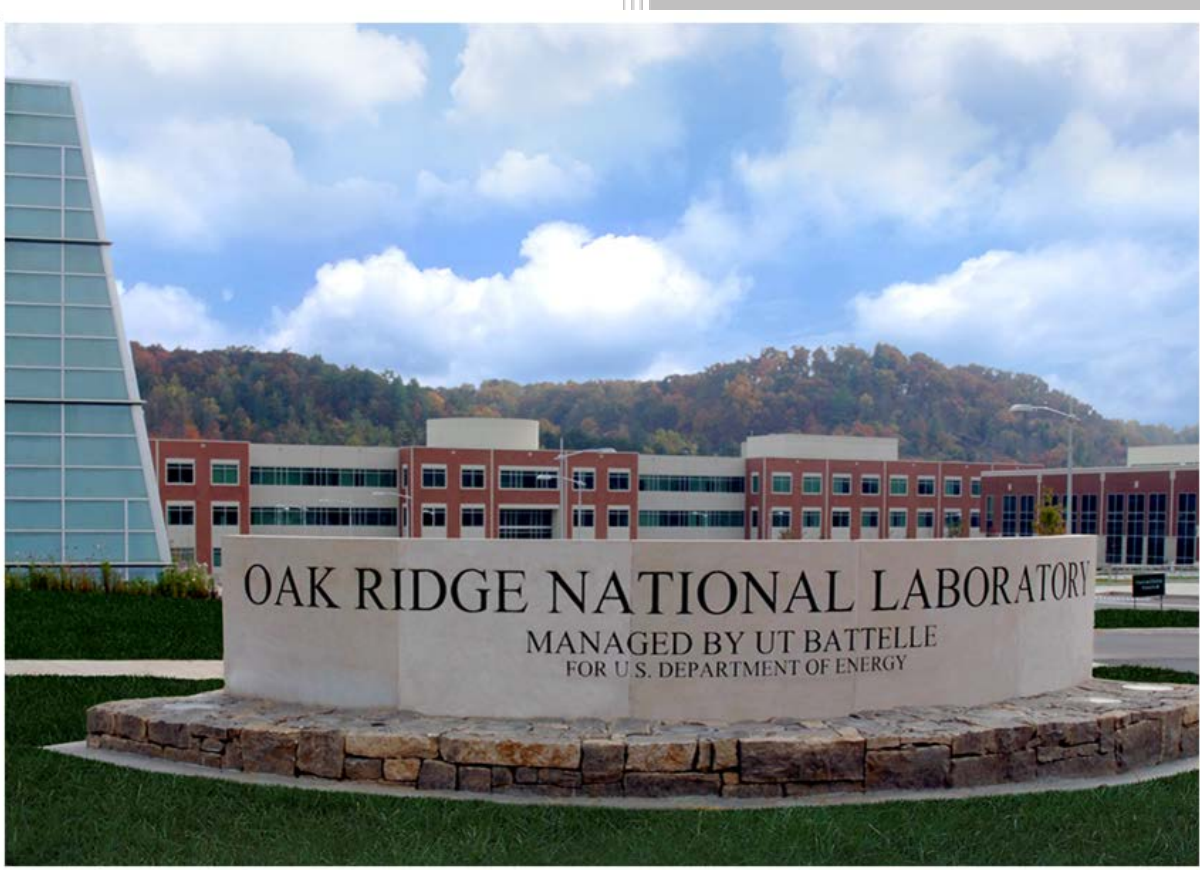

Compiled by:

F.W. Wiffen

Y. Katoh

S. Melton 


\title{
DOCUMENT AVAILABILITY
}

Reports produced after January 1, 1996, are generally available free via US Department of Energy (DOE) SciTech Connect.

\section{Website http://www.osti.gov/scitech/}

Reports produced before January 1, 1996, may be purchased by members of the public from the following source:

\author{
National Technical Information Service \\ 5285 Port Royal Road \\ Springfield, VA 22161 \\ Telephone 703-605-6000 (1-800-553-6847) \\ TDD 703-487-4639 \\ Fax 703-605-6900 \\ E-mail info@ntis.gov \\ Website http://www.ntis.gov/help/ordermethods.aspx
}

Reports are available to DOE employees, DOE contractors, Energy Technology Data Exchange representatives, and International Nuclear Information System representatives from the following source:

Office of Scientific and Technical Information

PO Box 62

Oak Ridge, TN 37831

Telephone 865-576-8401

Fax 865-576-5728

E-mail reports@osti.gov

Website http://www.osti.gov/contact.html

This report was prepared as an account of work sponsored by an agency of the United States Government. Neither the United States Government nor any agency thereof, nor any of their employees, makes any warranty, express or implied, or assumes any legal liability or responsibility for the accuracy, completeness, or usefulness of any information, apparatus, product, or process disclosed, or represents that its use would not infringe privately owned rights. Reference herein to any specific commercial product, process, or service by trade name, trademark, manufacturer, or otherwise, does not necessarily constitute or imply its endorsement, recommendation, or favoring by the United States Government or any agency thereof. The views and opinions of authors expressed herein do not necessarily state or reflect those of the United States Government or any agency thereof. 
Materials Science and Technology Division

FUSION MATERIALS RESEARCH AT OAK RIDGE NATIONAL LABORATORY IN FISCAL YEAR 2017

Compiled by:

F.W. Wiffen

Y. Katoh

S. Melton

Date Published: November 2017

Prepared by

OAK RIDGE NATIONAL LABORATORY

Oak Ridge, TN 37831-6283

managed by

UT-BATTELLE, LLC

for the

US DEPARTMENT OF ENERGY

under contract DE-AC05-00OR22725 


\section{CONTENTS}

CONTENTS iii

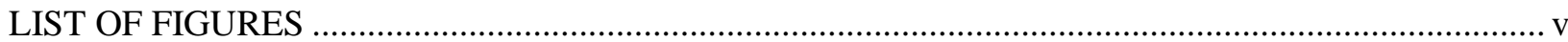

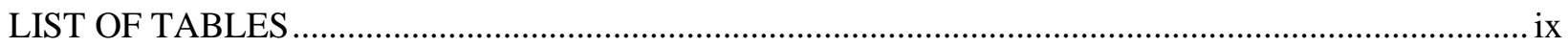

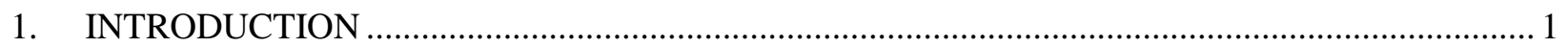

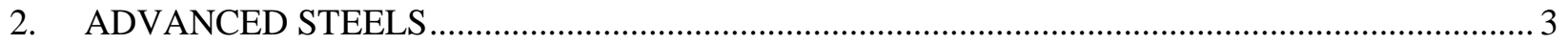

2.1 DEVELOPMENT OF ADVANCED RAFM STEELS - CNAs .......................................... 3

2.2 DEVELOPMENT OF TRANSFORMATION ENHANCED ODS Fe-Cr ALLOYS ................ 6

2.3 DEVELOPMENT OF ODS FeCrAl ALLOYS WITH Zr ADDITIONS FOR FUSION



2.4 BAINITIC STEEL DEVELOPMENT FOR FUSION APPLICATIONS ................................ 14

2.5 MECHANICAL PERFORMANCE OF RAFM AND ODS STEELS IN HFIR JP28

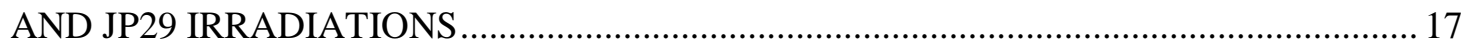



2.7 LIQUID METAL COMPATIBILITY IN STATIC Li, Sn AND Sn-Li .................................. 25

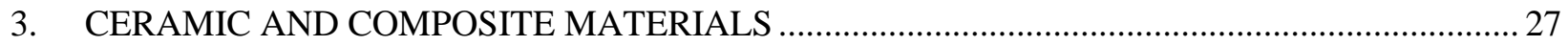

3.1 DEVELOPMENT OF SiC JOINING TECHNOLOGIES FOR FUSION .............................. 27

3.2 HIGH DOSE NEUTRON IRRADIATION EFFECTS ON MECHANICAL

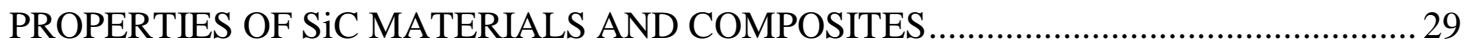

3.3 ADVANCED CHARACTERIZATION OF IRRADIATION DEFECTS IN SILICON

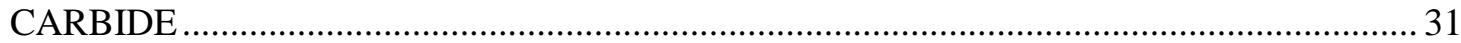

4. HIGH HEAT FLUX AND PLASMA FACING MATERIALS …................................................. 34

4.1 FABRICATION OF FUNCTIONALLY GRADED TUNGSTEN STEEL LAMINATES ..... 34

4.2 TUNGSTEN/SiC AND TUNGSTEN/GRAPHITE JOINING ….......................................... 37

4.3 MICROSTRUCTURE EVOLUTION OF TUNGSTEN IRRADIATED IN A MIXED

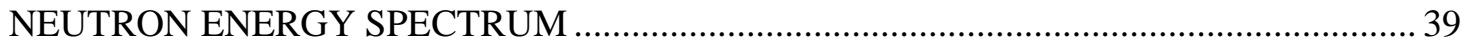

4.4 NEUTRON IRRADIATION EFFECTS IN TUNGSTEN ............................................... 41

4.5 NEUTRON IRRADIATION EFFECTS IN TUNGSTEN-COPPER COMPOSITES .............. 43

4.6 MICROSTRUCTURE AND MECHANICAL PROPERTIES OF TUNGSTEN IN THE



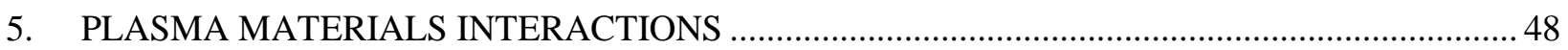

5.1 DAMAGE-MECHANISM INTERACTIONS AT THE PLASMA-MATERIALS



5.2 GAS-DEFECT INTERACTIONS IN FUSION MATERIALS ............................................ 53

5.3 HIGH-HEAT FLUX TESTING OF FUSION MATERIALS …........................................... 56

6. EXPLORATORY, UNIQUE AND INNOVATIVE MATERIALS .................................................. 58

6.1 DESIGN AND DEVELOPMENT OF NOVEL COPPER ALLOYS FOR FUSION

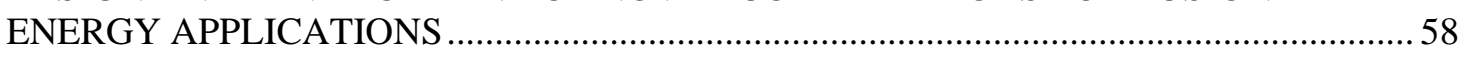



6.3 DISPLACEMENT DAMAGE AND SELF-HEALING IN HIGH-ENTROPY

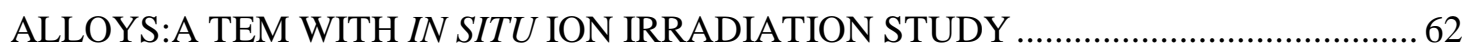

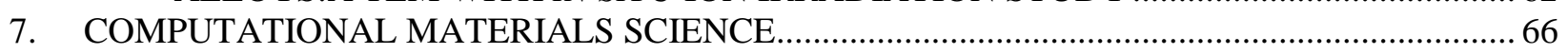

7.1 MECHANICAL PROPERTIES AND RADIATION EFFECTS IN FUSION

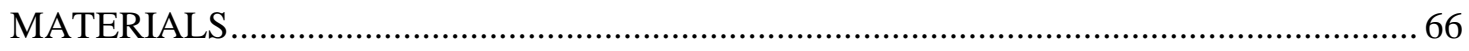

7.2 THEORETICAL ANALYSIS OF PHASE STABILITY AND PRECIPITATION IN W-

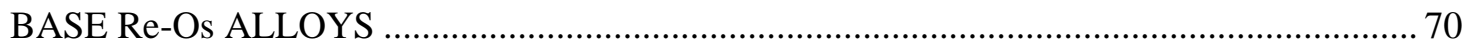

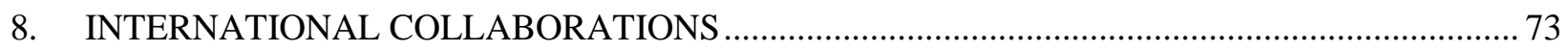

8.1 US-JAPAN COLLABORATIONS ON STRUCTURAL MATERIALS …........................... 73

8.2 US-JAPAN PHENIX PROGRAM …................................................................................ 77 
8.3 US-EUROfusion PROJECT - FATIGUE PRECRACKING M4CVN STEEL



9. MATERIALS ENGINEERING SUPPORTING THE FNSF CONCEPTUAL DESIGN.................. 81

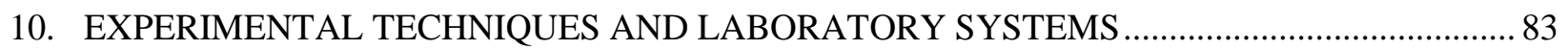

10.1 ORNL PARTICIPATION IN THE IAEA COORDINATED RESEARCH PROJECT TOWARDS THE STANDARDIZATION OF SMALL SPECIMEN TEST

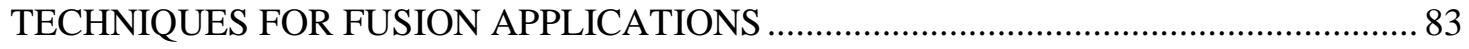

10.2 MINIATURE MECHANICAL TESTS FOR TUNGSTEN BASED MATERIALS ................ 85

10.3 IN-SITU HEATING HOLDER FOR THE TALOS F200X S/TEM ….................................... 87

10.4 ORNL INVENTORY SYSTEM FOR MANAGEMENT OF RADIOACTIVE SPECIMENS

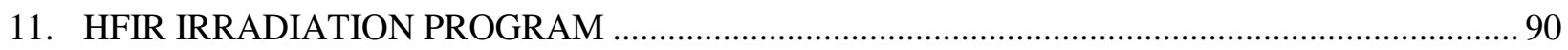

11.1 THE MFE-RB-19J HFIR IRRADIATION EXPERIMENT …........................................... 90

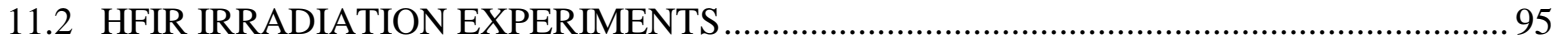

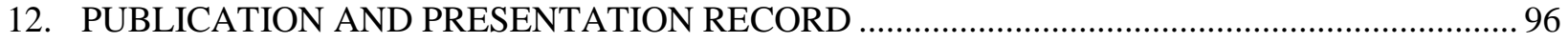

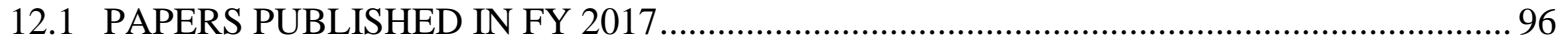

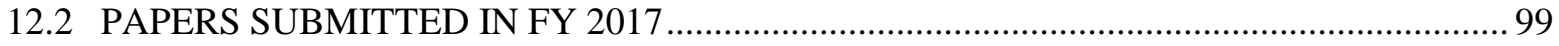

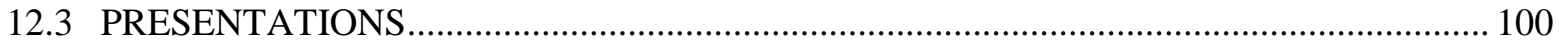




\section{LIST OF FIGURES}

Figure 1. Creep rupture life of CNAs compared to T91 and literature data of F82H, Eurofer97, and ODS-Eurofer97 tested at 600 and $650^{\circ} \mathrm{C}$.

Figure 2. BF-STEM images of alloy CNA4 showing (a) lath structure, dislocations and coarse precipitates and (b) ultrafine precipitates in the matrix.

Figure 3. BSE images showing the ultra-small grains observed in the microstructure of the ODS



Figure 4. Stress-strain curves of the ODS Fe-10Cr M4 and M5 alloys from 22 to $800^{\circ} \mathrm{C}$........................ 7

Figure 5. Reconstructed atom maps and isosurfaces in (a) the as-milled powder, b) powder annealed for $1 \mathrm{~h}$ at $1000^{\circ} \mathrm{C}$, and c) alloy extruded at $1000^{\circ} \mathrm{C}$ showing the presence of larger ( $\mathrm{Zr}, \mathrm{C}, \mathrm{N})$ rich precipitates and smaller (Y,Al,)-rich oxides.

Figure 6. Creep lifetime of ODS FeCrAl alloys, a) $800^{\circ} \mathrm{C}$ results for the first generation ODS

FeCrAl alloys and 106ZY9C alloy, b) Comparison of the 125YZ and 106ZY9C alloys at $700^{\circ} \mathrm{C}$ with ODS Fe-16Cr-4Al-2W(+Zr or Hf) alloys [7]. Note that the 106ZY9C specimen tested at $800^{\circ} \mathrm{C}, 140 \mathrm{MPa}$ was previously tested at $800^{\circ} \mathrm{C}, 100 \mathrm{MPa}$ for $2,000 \mathrm{~h} . \ldots \ldots \ldots . . . .10$

Figure 7. BSE-SEM micrographs of alloy $125 \mathrm{YZ}$ after creep testing, a-b) at $800^{\circ} \mathrm{C}, 100 \mathrm{MPa}$ for

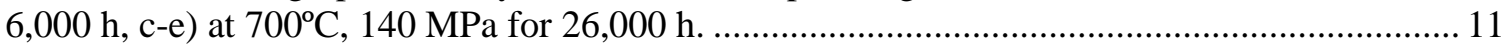

Figure 8. BSE-SEM micrographs of alloy $106 Z$ Y9C after creep testing, a-b) at $800^{\circ} \mathrm{C}, 100 \mathrm{MPa}$ for $6,000 \mathrm{~h}, \mathrm{c}-\mathrm{e}$ ) at $700^{\circ} \mathrm{C}, 140 \mathrm{MPa}$ for $26,000 \mathrm{~h}$.

Figure 9. Comparison of the tensile properties of the two new ODS FeCrAl alloys, 106ZYLN and 126ZTY with the tensile properties of alloy 106ZY9C and 125YZ, a) Yield strength, b) Plastic deformation.

Figure 10. Creep-rupture life of MSLC2-NT plotted on reported creep-rupture lives of 3Cr-3WV and 3Cr-3WVTa steels [1]; (a) tested at $550^{\circ} \mathrm{C}$ and (b) at $600^{\circ} \mathrm{C}$.....

Figure 11. (a) Charpy impact test results of MSLC2 base and weld metals plotted as a function of temperature, and (b) the weld specimen after etching to show the position of the V-notch weld.

Figure 12. Summary of irradiation parameters normalized for alloy F82H for (a) JP28 and (b) JP29 full length targets in the HFIR. Red symbols in temperature plot signify target temperatures.

Figure 13. Tensile curves for ODS steel variants irradiated in JP29(13) [red curves, 43 dpa], JP28(1) [blue curves, $36 \mathrm{dpa}$ ], and JP29(3) [green curves, $48 \mathrm{dpa}$ ] capsules in HFIR. Asreceived curves for PM2000 and 12YWT represented as broken black curves.

Figure 14. SEM fractographs showing transgranular brittle failure in PM2000 irradiated to varying conditions in JP28 and JP29 full length target capsules in HFIR.

Figure 15. Yield and ultimate tensile stress as a function of exposure temperature for the FeCrAlMo (APMT) specimens exposed in the hot and cold legs of the first two flowing $\mathrm{Pb}-\mathrm{Li}$ TCLs operated with maximum temperatures of $550^{\circ}$ and $600^{\circ} \mathrm{C}$. Specimens labeled AR did not receive a pre-oxidation treatment.

Figure 16. Uniform and total elongation as a function of exposure temperature for the FeCrAlMo (APMT) specimens exposed in the hot and cold legs of the first two flowing Pb-Li TCLs operated with maximum temperatures of $550^{\circ}$ and $600^{\circ} \mathrm{C}$. Specimens AR were not preoxidized.

Figure 17. Post-exposure APMT specimens from the cold leg (a) no pre-oxidation specimen exposed at $520^{\circ} \mathrm{C}$ and (b) $1050^{\circ} \mathrm{C}$ pre-oxidation specimen exposed at $527^{\circ} \mathrm{C}$. (c) image analysis was used to quantify the amount of spallation on several specimens.

Figure 18. Light microscopy of polished cross-sections of APMT after exposure for $1000 \mathrm{~h}$ in $\mathrm{Pb}-\mathrm{Li}$ (a) cold leg specimen exposed at $520^{\circ} \mathrm{C}$ with no pre-oxidation and (b) hot leg specimen $\left(579^{\circ} \mathrm{C}\right)$ pre-oxidized at $1100^{\circ} \mathrm{C}$. 
Figure 19. New glove boxes for handling liquid metals in an inert (Ar) environment. Left: large glove box with $\mathrm{O}_{2}, \mathrm{H}_{2} \mathrm{O}$ and $\mathrm{N}_{2}$ control. Right: smaller glove box for cutting Pb-Li.

Figure 20. Typical Kanthal APMT loop assembled for operation. Furnaces are placed over the hot leg for operation and insulation is used as needed.

Figure 21. Schematic of a standard isothermal capsule experiment with an inner Mo capsule and outer stainless steel capsule. The capsule is initially inverted at temperature as shown to submerge the specimen and then flipped over at the end of the experiment to allow the liquid to drain away from the specimen.

Figure 22. Torsion resistance of nonirradiated and irradiated SiC joints......

Figure 23. Flexural behavior of nonirradiated and irradiated CVI SiC/SiC composites. The stressstrain curves are shifted to aid in visibility.

Figure 24. Secondary electron micrographs of cross section of CVI SiC/SiC composites: (a) cross section processed using FIB, (b) non-irradiated condition, (c) irradiated at $319^{\circ} \mathrm{C}$ to 92 $\mathrm{dpa}$, and (d) irradiated at $629^{\circ} \mathrm{C}$ to $99 \mathrm{dpa}$. The observed area in image (b) is indicated in image (a).

Figure 25. High resolution TEM image of neutron irradiated $\mathrm{SiC}$ on the [101] zone. Apparent second-phase precipitate, arrowed, was present. Most or all of these precipitates were located adjacent to a Frank loop (blue $\Rightarrow$ arrows). Scale bar is $10 \mathrm{~nm}$.

Figure 26. Diagram of tungsten and steel foil stacking sequence before processing with corresponding cross section image of composite after processing. In the image on the right, tungsten layers have darker contrast than steel layers.

Figure 27. Stress-strain relationship in the generation 1 tungsten-steel composite. The elastic extension has been removed from the data, so only the plastic strain is shown and the initial part of the curve is represented as a vertical line.

Figure 28. Cross section SEM image of ultrasonically bonded tungsten-steel composite, a) low magnification view showing multiple cracks in the $\mathrm{W}$ foil layer, $\mathrm{b}$ ) example area with a good $\mathrm{W}$ to steel bond, but again with cracking in the $\mathrm{W}$ foil...

Figure 29. EDS result of sample W-steel interface with no interlayer. ................................................. 36

Figure 30. Hot pressed joint between tungsten and silicon carbide........................................................ 37

Figure 31. a) W-SiC joined square after handling. b) two W-SiC joined squares after sectioning. ........... 38

Figure 32. Fracture strength (ultimate tensile strength) for tungsten with crystal orientation $<110>$ and $<100>$ along the tensile axis. All tests were performed at room temperature and each data point represents one test.

Figure 33. Three point bend test data at $22^{\circ} \mathrm{C}$ for selected wrought tungsten foils (OW) and annealed tungsten foils (AW). Data is placed with an arbitrary offset on the x-axis.

Figure 34. TEM microstructure bright field (BF) and high angle annular dark field (HAADF) images of wrought foil and annealed foils after neutron irradiation.

Figure 35. SEM image of the powder sintered tungsten copper composite.

Figure 36. Total elongation comparison for the tungsten-copper particle composite (KW), two orientations of single crystal tungsten, and the tungsten-copper laminate composite (SW), all tensile tested at $22^{\circ} \mathrm{C}$.

Figure 37. Vickers microhardness of single crystal and polycrystalline tungsten samples.

Figure 38. Ultimate tensile strength of tungsten control materials at $22^{\circ} \mathrm{C}$ and a strain rate of $2 \% / \mathrm{min}$

Figure 39. (a) SEM image of a copper-deposited, FIB-prepared thin foil for transmission Kikuchi diffraction. (b) Proper sample mounting for tKD analysis. (c) Improper sample mounting.......... 49

Figure 40. Grain boundary misorientation histograms (a-c) and grain boundary misorientation axis/angle distributions (d-e) for PISCES-grown nanotendril fuzz.

Figure 41. An HRTEM image of neutron irradiated tungsten; many defects, such as precipitates, are visible. Schematically illustrated is a method to create a hyperimage from localized fast Fourier transforms (FFTs) of the HRTEM image. 
Figure 42. HRTEM image of neutron-irradiated tungsten, along with diffractograms extracted by statistical analysis and the spatial scores of the diffractograms.................................................. 51

Figure 43. D desorption spectra from $10 \mathrm{keV} \mathrm{D}$ implanted reference and neutron-irradiated W.............. 54

Figure 44. Thermal helium desorption spectrum from He-implanted tungsten. The dominant He$\mathrm{V}$ clusters contributing to each desorption peaks are labeled.

Figure 45. He desorption spectra from neutron-irradiated and He-implanted SiC.

Figure 46. The main configuration components of the PAL experimental setup (PAL reflector, quartz window, and quartz dome): (a) photo of the setup and (b) schematic of ray tracing toward the specimen.

Figure 47. SSJ3 tensile specimens of the type to be used in HFIR irradiation experiments....................... 59

Figure 48. a) Schematic diagram of the isochronal annealing steps. b) Electrical resistivity measurements recorded during the isochronal annealing, and the associated calculated activation energy of the defects in the $\mathrm{Ti}_{3} \mathrm{AlC}_{2}$ and $\mathrm{Ti}_{3} \mathrm{SiC}_{2} \mathrm{MAX}$ phase materials.

Figure 49. BFTEM images of the FeCrMnNi HEA irradiated with $30 \mathrm{kV}$ Xe ions at $773 \mathrm{~K}$ showing (a) and (b) two adjacent frames and (c) the image computed with MATLAB and representing the difference between (a) and (b): exhibiting the black-dots that appeared between the frames.

Figure 50. BFTEM images showing (a) the final microstructure of the $16^{\text {th }}$ frame and (b) the same microstructure as (a) with the superposed information of the black-dots within the 16 frames analysed. The micrograph (c) is a BFTEM underfocused image with defocus degree of $-1 \mu \mathrm{m}$ of the same region at $2.6 \times 10^{16}$ ions $\cdot \mathrm{cm}^{-2}$ (24 dpa).

Figure 51. Stress-strain curves obtained in MD modeling of an edge dislocation $1 / 2<111>\{110\}$ moving through a periodic array of impenetrable obstacles at different temperatures. The interaction geometry is shown by insets. The strain rate applied was $2 \times 10^{6} \mathrm{~s}^{-1}$ in all cases.

Figure 52. Critical resolved shear stress in reduced units as a function of harmonic mean of an obstacle diameter, $D$, and spacing between them along the dislocation line, $L$. Symbols present current modeling results, lines are dependences obtained in dislocation dynamic modeling for the Orowan mechanism (black line) and voids (red line) using discrete dislocation dynamics.....

Figure 53. Critical resolved shear stress for different obstacles and different sizes compared with the theoretical Orowan mechanism.

Figure 54. Structure of hcp- and $\chi$ - phases with random distribution of atoms for composition $\mathrm{ReOs}_{2} \mathrm{~W}$. The stability of hcp-phase is demonstrated by comparison of the energy per



Figure 55. Vickers hardness test result for F82H irradiated in JP28 and 29........................................ 74

Figure 56. Dose dependence of Vickers hardness for F82H irradiated in JP28 and 29......................... 75

Figure 57. M4CVN specimen dimension in (a) and ID markings in (b) ................................................ 80

Figure 58. Fatigue pre-cracking test fixture for a M4CVN specimen. ..................................................... 80

Figure 59. The phased operations program for FNSF showing blanket peak operating temperatures and radiation damage requirements from nuclear break-in up to DEMOrelevant blanket conditions.

Figure 60. a) PHENIX specimen size (10 mm long) does not span the distance between support radii on a standard fixture. b) The fixture that will be used with the miniature $\mathrm{W}$ samples has a span of $6.1 \mathrm{~mm}$.

Figure 61. The Protochips Fusion heating TEM holder, and a detailed view of the double-tilt tip with a loaded heating chip.

Figure 62. (a) SEM image from the LAMDA Versa3D DualBeam of a sample of ion-irradiated nanostructured ferritic alloy being landed on a heating chip. (b) STEM image $+X$-ray map of a sample in the heating holder. 
Figure 63. The $800^{\circ} \mathrm{C}$ zone analysis model overview: (a) Top view and (b) side view section cut A-A.

Figure 64. Absorption rate to produce ${ }^{185,187}$ Re over time for a representative section of the HFIR RB 19J irradiation capsule.

Figure 65. Capsule RB-19J (a) MIF connection port and (b) capsule storage location while connected to the MIF.

Figure 66. Shipping cask that will be used for RB-19J capsule (a) Handling of the loop cask container and (b) loading of the loop cask container. 


\section{LIST OF TABLES}

Table 1. Tensile properties of the ODS Fe-10Cr M4 and M5 alloys

Table 2. Alloy chemical compositions (mass\% or ppmw for O, C, N and S) determined by inductively coupled plasma analysis and combustion analysis.

Table 3. Nominal compositions of the steels in the present study

Table 4. Test matrix for evaluation of liquid metal compatibility.

Table 5. Processing conditions for fabricating SiC joints

Table 6. The material codes and descriptions for the US materials in the PHENIX RB*19J capsule

Table 7. Cases simulated to obtain heat flux through the containment chamber onto the specimen surface. The thickness of quartz fixtures are given in $\mathrm{mm}$.

Table 8. Compositions of developed $\mathrm{Cu}$ alloys

Table 9. Room temperature properties of $\mathrm{Cu}-\mathrm{Cr}-\mathrm{Nb}-\mathrm{Zr}$ alloys. All alloys were cast, cold-rolled $50 \%$ (70\% for 1CCNZ-T alloy series), then solutionized at $970^{\circ} \mathrm{C}$ for 20 minutes, quenched and aged at $475^{\circ} \mathrm{C}$ for $3 \mathrm{~h}$ (SAA treatment).

Table 10. Dilatometry analysis result of HFIR capsule passive temperature monitors [1]....................... 74

Table 11. Summary of variants of RAFM steels included in this study .................................................. 79

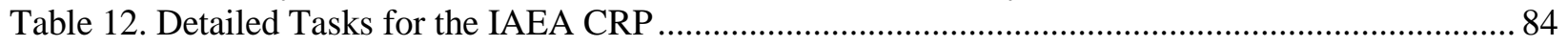

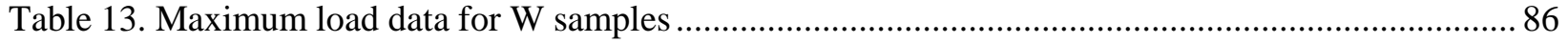

Table 14. Accumulation of Rhenium by HFIR Cycle*.......................................................................... 92

Table 15. Fusion materials program rabbits that completed HFIR irradiation in FY-2017 ...................... 95

Table 16. HFIR fusion materials program rabbit capsules continuing irradiation beyond FY-2017......... 95 


\section{INTRODUCTION}

\section{Yutai Katoh(katohy@ornl.gov) and Bill Wiffen}

Achieving fusion energy presents a formidable challenge to the field of materials science, to provide a suite of suitable materials in close integration to the plasma physics and other applied technologies. The technological challenge presented by the planned fusion power systems is the inability of current materials and components to withstand the harsh fusion nuclear environment. The overarching goal of the ORNL fusion materials program is to provide the applied materials science support and materials understanding to underpin the ongoing DOE Office of Science fusion energy program in parallel with developing materials for fusion power systems. In this effort the program continues to be integrated both with the larger U.S. and international fusion materials communities and with the international fusion design and technology communities.

This long-running ORNL program continues to pursue development of low activation structural materials such as the Reduced Activation Ferritic/Martensitic Steels, higher strength/higher creep resistant/coolant compatible/radiation tolerant advanced steels, and Silicon Carbide Composites. Focus tasks within the steels portfolio are development of Castable Nanostructured Alloys, exploratory work on Bainitic steels and liquid metal compatibility evaluations. Parallel to this is the increased emphasis on radiation effects, high heat flux testing and the development of refractory metals. This includes the use of an ORNL Plasma Arc Lamp facility adapted for the thermal testing of irradiated materials, the development and evaluation of new tungsten materials, and the study and understanding of the irradiation performance of tungsten. In each case the materials are being developed in a design-informed fashion where properties improvements are led by fusion-relevant design studies and directed at advancing the Technology Readiness Level of the material systems.

Work supported by an Early Career Award is looking in depth at the materials side of the Plasma Materials Interactions, characterizing the materials response to plasma impingement and determining the controlling mechanisms of the materials behavior.

A limited effort continues to examine functional and exploratory materials. In the area of diagnostics, ORNL supports basic irradiation materials science of ceramics that could be used in diagnostic systems. For high-temperature superconductors, ORNL has completed a limited program to quantify the irradiation sensitivity of the most recently developed tape materials. Studies of the MAX-phase ceramics, high entropy alloys, and bulk metallic glasses were continued as the materials that potentially possess exceptional or unique radiation tolerance.

This program integrates fundamental modeling into the development efforts as much as practicable.

This fusion materials program makes heavy reliance on neutron irradiation in HFIR, the High Flux Isotope Reactor at ORNL. This is complemented by limited use of the ORNL-University of Tennessee ion irradiation facility and other available accelerator facilities when these are better suited to explore fundamental aspects of materials behavior under irradiation. 
This document summarizes Fiscal Year - 2017 activities supporting the Office of Science, Office of Fusion Energy Sciences Materials Research for Magnetic Fusion Energy carried out by ORNL. The organization of the report is mainly by material type, with sections on specific technical activities.

A continuing activity initiated several years ago, "Materials Engineering in Support of the FNSF Program,” is also reported.

The fusion materials effort consists of a wide array of tasks and collaborations both within the US and with international partners. The major continuing international collaborating partners are the Japan Agency for Quantum and Radiological Science and Technology (QST, reorganized and transferred from Japan Atomic Energy Agency, the US DOE-JAEA collaboration, focused on structural materials), the Japanese National Institute for Fusion Sciences (the PHENIX collaboration, emphasizing plasma facing materials and tritium fuel issues) and the Karlsruhe Institute of Technology in Germany (examining steel materials). 


\section{ADVANCED STEELS}

\subsection{DEVELOPMENT OF ADVANCED RAFM STEELS - CNAS}

\section{L.Tan(tanl@ornl.gov)}

\section{OBJECTIVE}

Castable nanostructured alloys (CNAs) are being developed at Oak Ridge National Laboratory to favor the formation of a larger amount of ultrafine stable precipitates in reduced-activation ferritic-martensitic (RAFM) steels using conventional, affordable steelmaking methods. This high density of fine precipitates is expected to improve high-temperature strength and radiation resistance of the alloys.

\section{SUMMARY}

Two new heats of CNAs, named CNA5 and CNA6, were designed using computational thermodynamics and fabricated by vacuum induction melting. The two alloys were designed to have different amounts of $\mathrm{MX}$ and $\mathrm{M}_{23} \mathrm{C}_{6}$ precipitates to study the effect of the precipitates on mechanical properties. Microstructural characterization of the alloys in the conventional normalized and tempered condition exhibited much finer Ta-rich precipitates with higher densities than literature-reported for alloy F82HBA07. However, clusters of Ta/Ti-rich coarse particles were also observed in the alloys, especially in the CNA6, which is likely to reduce the amount of Ta/Ti-rich fine particles and may consequently diminish the difference in mechanical properties between the alloys. The CNA5 alloy was used to explore the effects of thermomechanical treatment (TMT) on microstructural evolution. Following a warm-rolling (WR) TMT, the CNA5-WR was characterized and found to possess a dual-phase structure, consisting of tempered martensite and a network of fine ferrite grains with size a couple of micrometers. Unlike the tempered martensite which had a high density of lath boundaries and dislocations, the fine ferrite grains had much fewer dislocations. However, some nano-sized Cr-rich carbides, together with many unresolved ultrafine particles $(<10 \mathrm{~nm}$ ), were revealed in the ferrite grains. The TEM sample is being further thinned to better characterize the ultrafine particles, as well as the unresolved rod-shaped carbon-rich particles and possible Laves-structured particles. The progress of creep resistance evaluation is updated in this report.

\section{PROGRESS AND STATUS}

Figure 1 shows the creep rupture test results for the CNAs compared to T91 and literature data for Eurofer97, F82H, and ODS-Eurofer97 (oxide-dispersion-strengthened version of Eurofer97: ODS-E97) tested at 600 and $650^{\circ} \mathrm{C}$. The CNAs and T91 were tested in air using type SS-3 miniature samples. A total of 10 tests of CNAs have been completed, with 5 tested at $600^{\circ} \mathrm{C}$ and 5 at $650^{\circ} \mathrm{C}$. The literature data were primarily obtained from tests in vacuum or flowing argon systems, except for two data on F82H tested in air. The tests in vacuum/argon environment tend to have creep rupture lives superior to the tests in air. Figure 1 indicates that the creep resistance of the CNAs is noticeably greater than F82H, Eurofer97 and T91. The CNAs tested at $650^{\circ} \mathrm{C}$ had creep rupture lives comparable to the ODS-E97 with 0.3 weight percent (wt. \%) $\mathrm{Y}_{2} \mathrm{O}_{3}$. Increasing the $\mathrm{Y}_{2} \mathrm{O}_{3}$ content, e.g., to 0.5 wt. \%, could significantly increase the creep resistance, but in the meantime further reduce the already low impact toughness of that material. The preliminary results for CNAs suggest that the CNAs could have at least $20^{\circ} \mathrm{C}$ enhancement in operation temperature compared to the current RAFM steels, when the air and vacuum test environment is considered. In addition to the significantly greater impact toughness than ODS-E97 [1], the CNAs have creep resistance comparable to the lower-bound ODS-E97. 


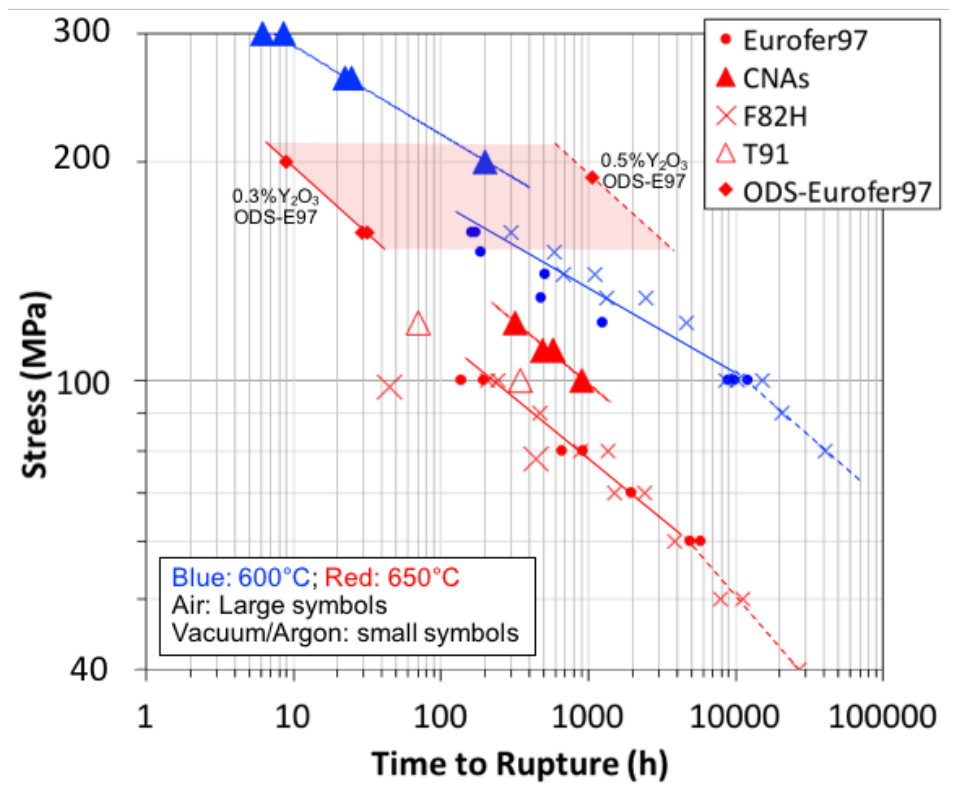

Figure 1. Creep rupture life of CNAs compared to T91 and literature data of F82H, Eurofer97, and ODS-Eurofer 97 tested at 600 and $650^{\circ} \mathrm{C}$.

Figure 2 shows the microstructures of alloy CNA4 in the bright-field scanning transmission electron microscopy (BF STEM) imaging mode, which is one of the CNAs used in the creep tests. The dark domains show a high density of dislocations, which were tilted in the [111] zone axis. The lath width is on the order of $0.3 \mu \mathrm{m}$, which is finer than the general microstructures of F82H and Eurofer97. Unlike the coarse $\mathrm{M}_{23} \mathrm{C}_{6}$ precipitates $(\sim 0.1-0.2 \mu \mathrm{m})$ decorating the lath boundaries in Figure 2a, many ultrafine precipitates, $<10 \mathrm{~nm}$ as shown in the inset of Figure $2 \mathrm{~b}$, are present in the matrix. The finer lath and high densities of dislocations and ultrafine precipitates are responsible for the superior strength of the CNAs as shown in Figure 1.
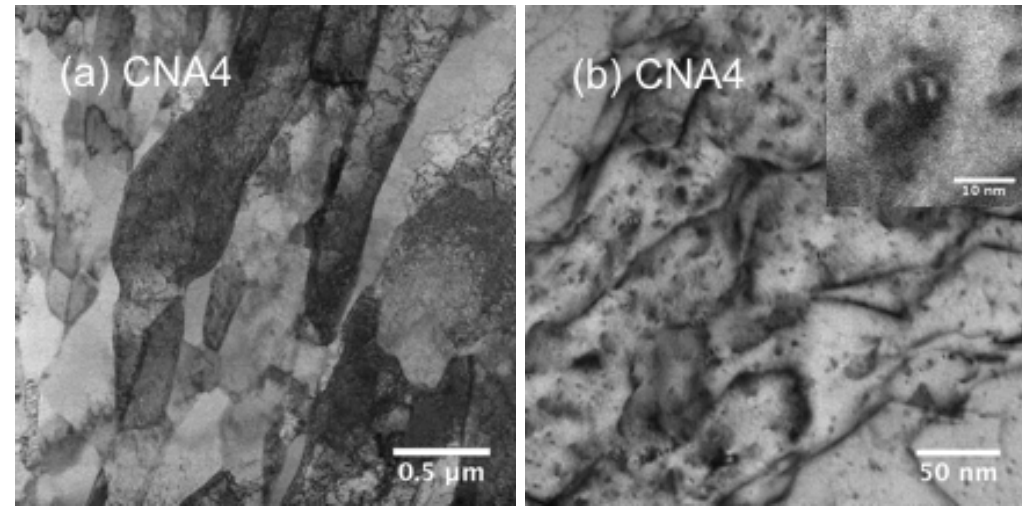

Figure 2. BF-STEM images of alloy CNA4 showing (a) lath structure, dislocations and coarse precipitates and (b) ultrafine precipitates in the matrix. 


\section{FUTURE PLANS}

Microstructures of selective creep-ruptured samples of CNAs will be characterized. Preliminary radiation effects in CNAs will be investigated. Development and optimization of CNAs will continue.

\section{REFERENCES}

[1] L. Tan et al., J. Nucl. Mater. 478 (2016) 42. 


\subsection{DEVELOPMENT OF TRANSFORMATION ENHANCED ODS Fe-Cr ALLOYS}

\section{D.T. Hoelzer (hoelzerd@ornl.gov)}

\section{OBJECTIVE}

The objective of this task is to develop transformation enhanced oxide dispersion strengthened (ODS) Fe$10 \mathrm{Cr}$ alloys for fusion reactor applications requiring high-temperature strength and toughness properties and microstructural stability during exposure to energetic neutrons and transmutated He concentrations.

\section{SUMMARY}

The microstructures and tensile properties of two as-extruded ODS Fe-10Cr alloys, designated M4 and M5, were investigated. Both alloys exhibited microstructures containing ultra-small $(<0.5 \mu \mathrm{m})$ grains and tensile properties showing high-strengths up to $800^{\circ} \mathrm{C}$ and good ductility. However, M4 showed much better ductility than $\mathrm{M} 5$ above $400^{\circ} \mathrm{C}$.

\section{PROGRESS AND STATUS}

Specimens of two ODS Fe-Cr alloys (M4 and M5) were fabricated from as-extruded bars for microstructure analysis and tensile testing. The nominal composition of the two alloys are Fe-10Cr-1W$0.3 \mathrm{Ti}-0.2 \mathrm{~V}$ (M4) and Fe-10Cr-0.3Ti-0.2V (M5), and both contain $0.3 \mathrm{Y}_{2} \mathrm{O}_{3}$ additions (weight \%). The M5 alloy contains no $\mathrm{W}$ to determine if $\mathrm{W}$ provides any benefit to the salient microstructural features and/or the mechanical properties compared to M4.

Figure 3 shows backscattered electron (BSE) images obtained by scanning electron microscopy (SEM) of the two extruded alloys. These images were obtained normal to the extrusion axis to illustrate the ultrasmall grain size, which is $<0.5 \mu \mathrm{m}$. The grains appear with an isotropic shape in this orientation. At this high magnification, very few particles are observed indicating that the extrusion parameters resulted in a very fine scale oxide dispersion that is below the $\sim 13 \mathrm{~nm}$ resolution of the BSE images.

(a)

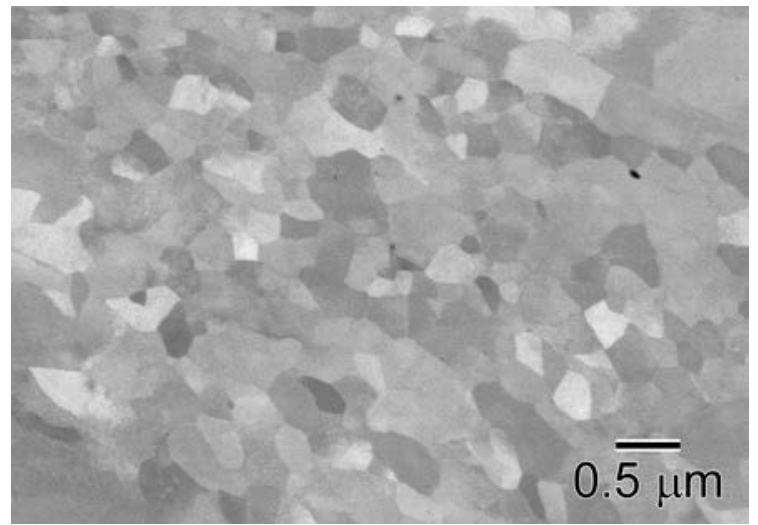

(b)



Figure 3. BSE images showing the ultra-small grains observed in the microstructure of the ODS Fe10Cr M4 and M5 alloys.

Tensile tests were conducted on SS-3 specimens of M4 and M5 from room temperature $\left(22^{\circ} \mathrm{C}\right.$ to $\left.800^{\circ} \mathrm{C}\right)$. The tests were conducted in air using a strain rate of $1 \times 10^{-3} \mathrm{~s}^{-1}$. Figure 4 shows the full set of stress-strain curves for M4 and M5. The tabulated values of yield stress, ultimate tensile strength and uniform and 
total elongations are in Table 1 . Both alloys possess high strengths up to $800^{\circ} \mathrm{C}$. Below $400^{\circ} \mathrm{C}$, M5 (Figure 4b) exhibits higher yield and ultimate tensile strengths, but lower uniform elongation compared to M4 (Figure 4a). However, this trend changes above $400^{\circ} \mathrm{C}$ : M4 has slightly higher strengths and M5 shows much higher total elongations, especially between $400^{\circ} \mathrm{C}$ and $700^{\circ} \mathrm{C}$. These results appear to show that the $1 \% \mathrm{~W}$ addition to $\mathrm{M} 4$ alloy has a substantial effect on the tensile properties and the plastic deformation behavior compared to M5. However, the microstructures observed in M4 and M5 (Figure 3) appear similar in terms of grain size.

(a)

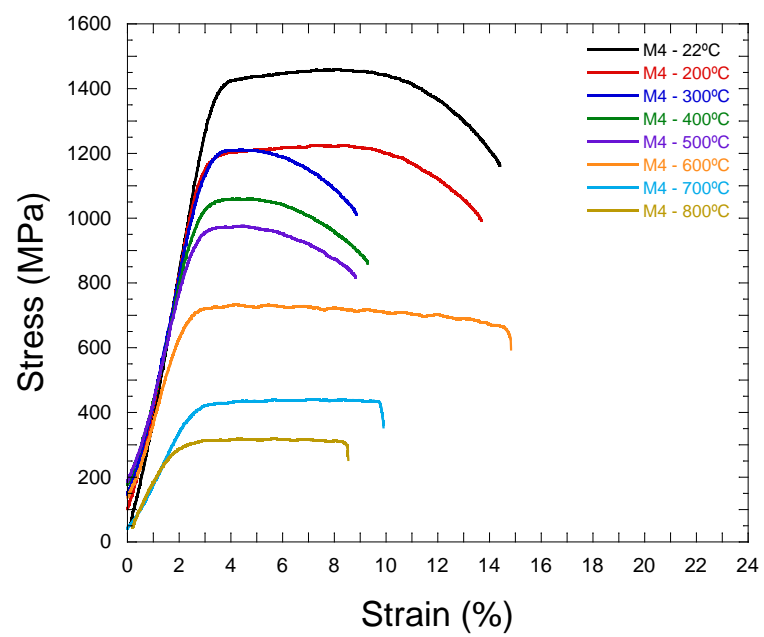

(b)



Figure 4. Stress-strain curves of the ODS Fe-10Cr M4 and M5 alloys from 22 to $800^{\circ} \mathrm{C}$.

Table 1. Tensile properties of the ODS Fe-10Cr M4 and M5 alloys

\begin{tabular}{|c|c|c|c|c|c|c|c|c|}
\hline \multirow{2}{*}{$\begin{array}{c}\text { Test } \\
\text { Temp. }\end{array}$} & \multicolumn{4}{|c|}{ M4 } & \multicolumn{4}{c|}{ M5 } \\
\hline & \multicolumn{2}{|c|}{ Strength } & \multicolumn{2}{c|}{ Elongation } & \multicolumn{2}{c|}{ Strength } & \multicolumn{2}{c|}{ Elongation } \\
\hline$\left({ }^{\circ} \mathrm{C}\right)$ & $\sigma_{\mathrm{ys}}$ & $\sigma_{\text {ust }}$ & $\mathrm{E}_{\mathrm{u}}$ & $\mathrm{E}_{\mathrm{t}}$ & $\sigma_{\mathrm{ys}}$ & $\sigma_{\text {uts }}$ & $\mathrm{E}_{\mathrm{u}}$ & $\mathrm{E}_{\mathrm{t}}$ \\
\hline 22 & 1379 & 1462 & 5.42 & 11.99 & 1458 & 1563 & 1.01 & 7.60 \\
\hline 200 & 1165 & 1227 & 5.44 & 11.61 & 1260 & 1340 & 0.81 & 7.75 \\
\hline 300 & 1158 & 1215 & 1.43 & 6.63 & 1158 & 1226 & 0.88 & 7.75 \\
\hline 400 & 1014 & 1062 & 1.79 & 7.42 & 993 & 1083 & 1.13 & 13.48 \\
\hline 500 & 926 & 978 & 1.96 & 7.01 & 838 & 887 & 2.18 & 18.92 \\
\hline 600 & 674 & 732 & 1.82 & 13.46 & 528 & 570 & 6.05 & 21.44 \\
\hline 700 & 403 & 441 & 6.10 & 7.42 & 372 & 403 & 5.20 & 14.85 \\
\hline 800 & 286 & 318 & 3.51 & 7.16 & 238 & 260 & 1.90 & 7.82 \\
\hline
\end{tabular}

\section{FUTURE PLANS}

Samples of the two ODS Fe-10Cr alloys will be annealed for $8 \mathrm{~h}$ in vacuum at temperatures of $1050^{\circ} \mathrm{C}$ and $1150^{\circ} \mathrm{C}$ to study the thermal stability of the microstructures and to assess the transformation kinetics and volume fractions between the bcc-Fe phase that is stable below $\sim 910^{\circ} \mathrm{C}$ and the fcc-Fe phase that is stable above this temperature. 


\title{
2.3 DEVELOPMENT OF ODS FeCrAl ALLOYS WITH Zr ADDITIONS FOR FUSION REACTOR APPLICATIONS
}

\author{
S. Dryepondt (dryepondtsn@ornl.gov), C. Massey, and Phil Edmondson
}

\section{OBJECTIVE}

The dual coolant lead-lithium (DCLL) blanket concept requires ferritic steels with good Pb-Li compatibility to demonstrate viable blanket operation in a DEMO-type fusion reactor. This project aims at developing low-Cr oxide dispersion strengthened (ODS) FeCrAl alloy with excellent creep resistance up to $800^{\circ} \mathrm{C}$ and great compatibility with $\mathrm{Pb}-\mathrm{Li}$ due to the formation of a protective Al-rich scale.

\section{BACKGROUND}

The first generation of ODS FeCrAl alloys was fabricated by ball milling $\mathrm{Fe}-12 \mathrm{wt}$ \% $\mathrm{Cr}-5 \mathrm{Al}$ powder with $\mathrm{Y}_{2} \mathrm{O}_{3}+\mathrm{ZrO}_{2}, \mathrm{Y}_{2} \mathrm{O}_{3}+\mathrm{HfO}_{2}$ and $\mathrm{Y}_{2} \mathrm{O}_{3}+\mathrm{TiO}_{2}$ powders. These alloys showed good resistance to $\mathrm{Pb}-17 \mathrm{Li}$ at $700^{\circ} \mathrm{C}$, high tensile strength up to $800^{\circ} \mathrm{C}$, but limited ductility [1-4]. The Zr-containing alloy (125YZ alloy) exhibited superior creep resistance at both 700 and $800^{\circ} \mathrm{C}$. Therefore a second generation of ODS FeCrAl alloys was fabricated by ball milling Fe-10-12Cr-6Al-Zr powders with $\mathrm{Y}_{2} \mathrm{O}_{3}$. The goal was to improve $\mathrm{Zr}$ dispersion in the alloy, thus increasing the alloy ductility while maintaining the high temperature creep resistance.

\section{PROGRESS AND STATUS}

\section{ODS FeCrAl Alloy Characterization}

Extensive microstructure characterization of the first generation $125 \mathrm{YZ}$ alloy revealed the presence of fine $\mathrm{Y}_{3} \mathrm{Al}_{5} \mathrm{O}_{12}$ (YAG) oxides, $~ 3 \mathrm{~nm}$ in size with a total number density of $2.5 \times 10^{23} \mathrm{~m}^{-3}$, as well as coarser $\mathrm{Al}_{2} \mathrm{O}_{3}$ and $\mathrm{Zr}(\mathrm{C}, \mathrm{N})$ precipitates [2]. Surprisingly, the $\mathrm{Y}_{4} \mathrm{Zr}_{3} \mathrm{O}_{12}$ oxides observed by Dou et al. in a $\mathrm{Fe}-15 \mathrm{Cr}-2 \mathrm{~W}-0.1 \mathrm{Ti}-4 \mathrm{Al}-0.63 \mathrm{Zr}-0.35 \mathrm{Y}_{2} \mathrm{O}_{3}$ alloy were not found [5]. Atom probe tomography (APT) was used to characterize the size and composition of the nano precipitates in the second generation ODS Fe-10Cr-6Al-0.3Zr- $0.3 \mathrm{Y}_{2} \mathrm{O}_{3}(106 \mathrm{ZY})$ alloys, and Figure 5 compares the reconstructed atom maps and isosurfaces for the as-milled powder, the milled powder annealed for $1 \mathrm{~h}$ at $1000^{\circ} \mathrm{C}$, and a $106 \mathrm{ZY}$ alloy extruded at $1000^{\circ} \mathrm{C}$. No precipitates were detected in the as milled powder but a homogeneous distribution of $\sim 3.5 \mathrm{~nm}$ and $4 \mathrm{~nm}$ (Y,Al)-rich oxides were observed in the annealed 106ZY powder and extruded alloy, respectively. Again, $\mathrm{Zr}$ was tied up with $\mathrm{C}$ and $\mathrm{N}$ and formed larger $\mathrm{Zr}(\mathrm{C}, \mathrm{N})$ precipitates. These results are consistent with the transmission electron microscopy (TEM) work conducted on alloy $125 \mathrm{YZ}$ [2], and demonstrate that adding $\mathrm{Zr}$ in the gas atomized powder or as $\mathrm{ZrO}_{2}$ during ball milling leads to similar nanoprecipitates. Similar APT work will be conducted on a 106ZY alloy extruded at $900^{\circ} \mathrm{C}$ (106ZY9C alloy). Smaller precipitates are expected to be observed due to the lower extrusion temperature [6]. 
a) As-milled powder

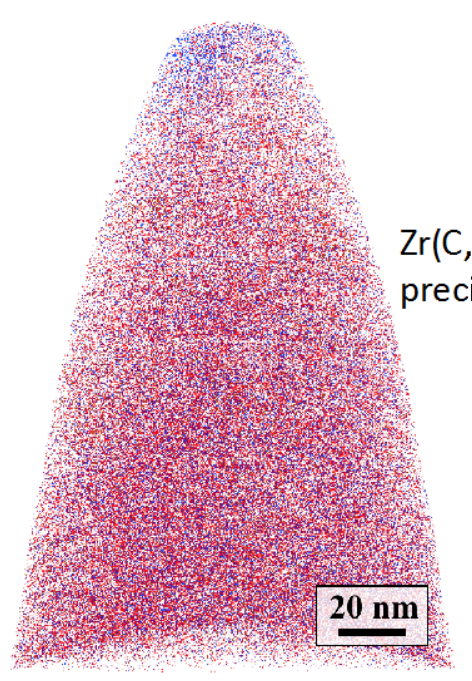

b) $106 Z Y$ powder

1h at $1000^{\circ} \mathrm{C}$ c) $106 Z$ alloy

extruded at $1000^{\circ} \mathrm{C}$

Figure 5. Reconstructed atom maps and isosurfaces in (a) the as-milled powder, b) powder annealed for $1 \mathrm{~h}$ at $1000^{\circ} \mathrm{C}$, and c) alloy extruded at $1000^{\circ} \mathrm{C}$ showing the presence of larger (Zr,C,N) rich precipitates and smaller (Y,Al,)-rich oxides.

\section{ODS FeCrAl creep testing}

Figure 6a shows the results of creep tests conducted at $800^{\circ} \mathrm{C}$ on first generation ODS FeCrAl and second generation 106ZY9C alloy, and the composition of these alloys is given in Table 2. Alloy 106ZY9C was selected among the second generation ODS FeCrAl alloys for creep evaluation due to its superior tensile strength at high temperature. The lifetime for the $125 \mathrm{YT}$ and $125 \mathrm{YH}$ alloys at $800^{\circ} \mathrm{C}, 100 \mathrm{MPa}$ was less than 2,000 h, when the $125 \mathrm{YZ}$ and $106 \mathrm{ZY9C}$ tests were interrupted after $6,000 \mathrm{~h}$ for microstructure characterization. Increasing the stress to $120 \mathrm{MPa}$ led to failure after 2,411 h for the 106ZY9C alloy. For another 106Z9C specimen, stress was increased from 100 to $140 \mathrm{MPa}$ after $2,000 \mathrm{~h}$ of testing at $800^{\circ} \mathrm{C}$, and the specimen ruptured after $40 \mathrm{~h}$ at $140 \mathrm{MPa}$. Two long-term tests were also conducted at $700^{\circ} \mathrm{C}$ and the results are compared in Figure 6b with data for ODS Fe-14Cr-2W-4Al (+Zr or Hf) alloys. The $125 \mathrm{YZ}$ test was stopped after $26,000 \mathrm{~h}$ at $700^{\circ} \mathrm{C}$ with an applied stress of $140 \mathrm{MPa}$, while the estimated lifetime for the best performing Zr-containing Fe-14Cr-4Al-2W alloy was 10,000 h with an applied stress of 120 $\mathrm{MPa}$ [7]. The $106 \mathrm{ZY} 9 \mathrm{C}$ test at $700^{\circ} \mathrm{C}, 140 \mathrm{MPa}$ is still ongoing after $\sim 9,500 \mathrm{~h}$ of exposure.

Table 2. Alloy chemical compositions (mass\% or ppmw for $\mathrm{O}, \mathrm{C}, \mathrm{N}$ and $\mathrm{S}$ ) determined by inductively coupled plasma analysis and combustion analysis

\begin{tabular}{|c|c|c|c|c|c|c|c|c|c|}
\hline Alloy & $\mathbf{F e}$ & $\mathbf{C r}$ & $\mathbf{A}$ & $\mathrm{Zr} / \mathrm{Hf} / \mathrm{Ti}$ & $\mathbf{Y}$ & $C$ (ppm) & N (ppm) & $O$ (ppm) & S (ppm) \\
\hline $125 Y Z$ & 82.8 & 11.51 & 4.86 & $0.3 \mathrm{Zr}$ & 0.18 & 250 & 161 & 1920 & 10 \\
\hline 125YT & 82.4 & 12 & 4.9 & $0.2 T i$ & 0.16 & 350 & 140 & 2220 & 30 \\
\hline 125YH & 82.3 & 11.68 & 4.82 & $0.68 \mathrm{Hf}$ & 0.17 & $\mathbf{2 2 0}$ & 110 & 2280 & 10 \\
\hline 106rY9C & 83.34 & 9.73 & 6.07 & $0.28 \mathrm{Zr}$ & 0.21 & 170 & 919 & 1300 & 30 \\
\hline 106KYLN & 83.67 & 9.65 & 5.91 & 0.27 & 0.21 & 610 & 111 & 1200 & 30 \\
\hline $1262 \pi$ & 82.56 & 11.31 & 5.43 & $0.227 r, 0.11 T i$ & 0.2 & 680 & 89 & 850 & 30 \\
\hline
\end{tabular}



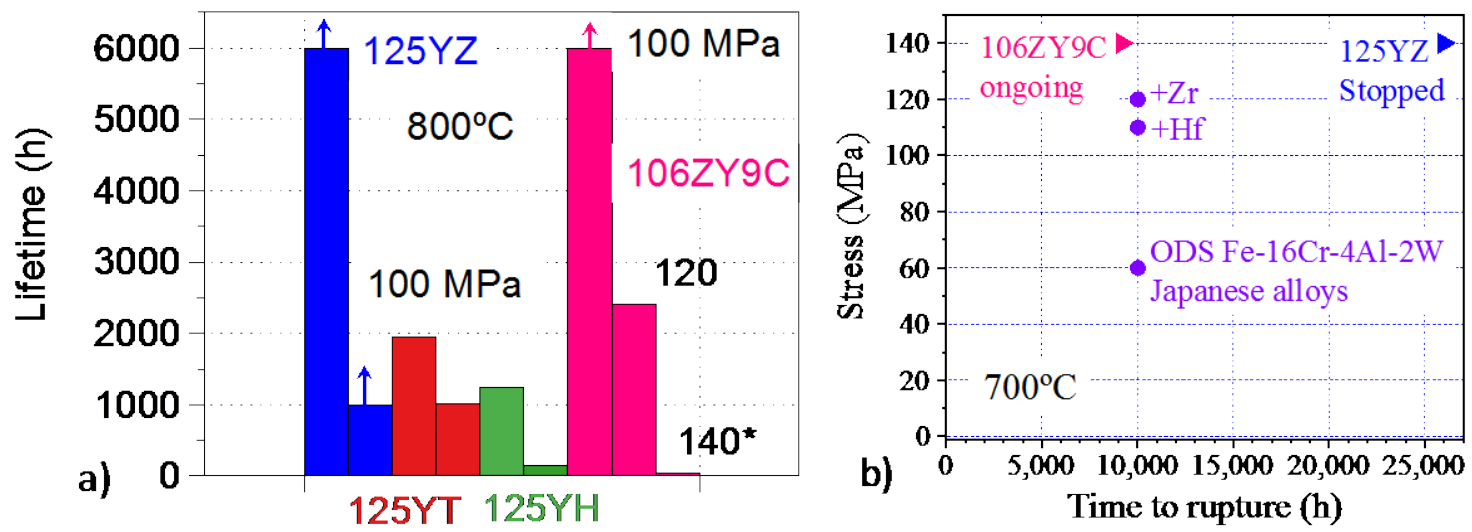

Figure 6. Creep lifetime of ODS FeCrAl alloys, a) $800^{\circ} \mathrm{C}$ results for the first generation ODS FeCrAl alloys and 106ZY9C alloy, b) Comparison of the $125 \mathrm{YZ}$ and $106 Z Y 9 \mathrm{C}$ alloys at $700^{\circ} \mathrm{C}$ with ODS Fe-16Cr-4Al-2W(+Zr or Hf) alloys [7]. Note that the $106 Z Y 9 C$ specimen tested at $800^{\circ} \mathrm{C}$, $140 \mathrm{MPa}$ was previously tested at $800^{\circ} \mathrm{C}, 100 \mathrm{MPa}$ for $2,000 \mathrm{~h}$.

Back scattered scanning electron microscopy (BSE-SEM) pictures of the $125 \mathrm{YZ}$ creep specimens after $6,000 \mathrm{~h}$ at $800^{\circ} \mathrm{C}, 100 \mathrm{MPa}$ or $26,000 \mathrm{~h}$ at $700^{\circ} \mathrm{C}, 140 \mathrm{MPa}$ are shown in Figure 7 . Cavity formation is observed at both temperatures, with a significantly higher void density for the specimen tested for 26,000 $\mathrm{h}$ at $700^{\circ} \mathrm{C}, 140 \mathrm{MPa}$. As can be seen in Figure $7 \mathrm{~d}$, the larger voids were often associated with large grain areas. Further characterization is required to determine if the large grain areas are a consequence or a cause of cavity formation. The higher magnification pictures displayed in Figure $7 \mathrm{~b}$ and Figure 7e highlight the alloy grain structure stability, with $\sim 300 \mathrm{~nm}$ grains slightly elongated along the extrusion direction, as was observed for the $125 \mathrm{YZ}$ alloy just after extrusion.

BSE-SEM micrographs of the 106ZY9C alloy after creep testing for $6,000 \mathrm{~h}$ at $800^{\circ} \mathrm{C}$ with an applied stress of $100 \mathrm{MPa}$ are shown in Figure 8. Large voids were observed in the vicinity of clusters of AlN precipitates. These AlN precipitates were already present in the as extruded 106ZY9C alloy, and are consistent with the high $\mathrm{N}$ concentration in this alloy (Table 2), most likely because of air ingress during the ball milling step. Cavity formation is certainly responsible for the failure after 2,411 $\mathrm{h}$ of the 106ZY9C specimen tested at $800^{\circ} \mathrm{C}$ with an applied stress of $120 \mathrm{MPa}$. 


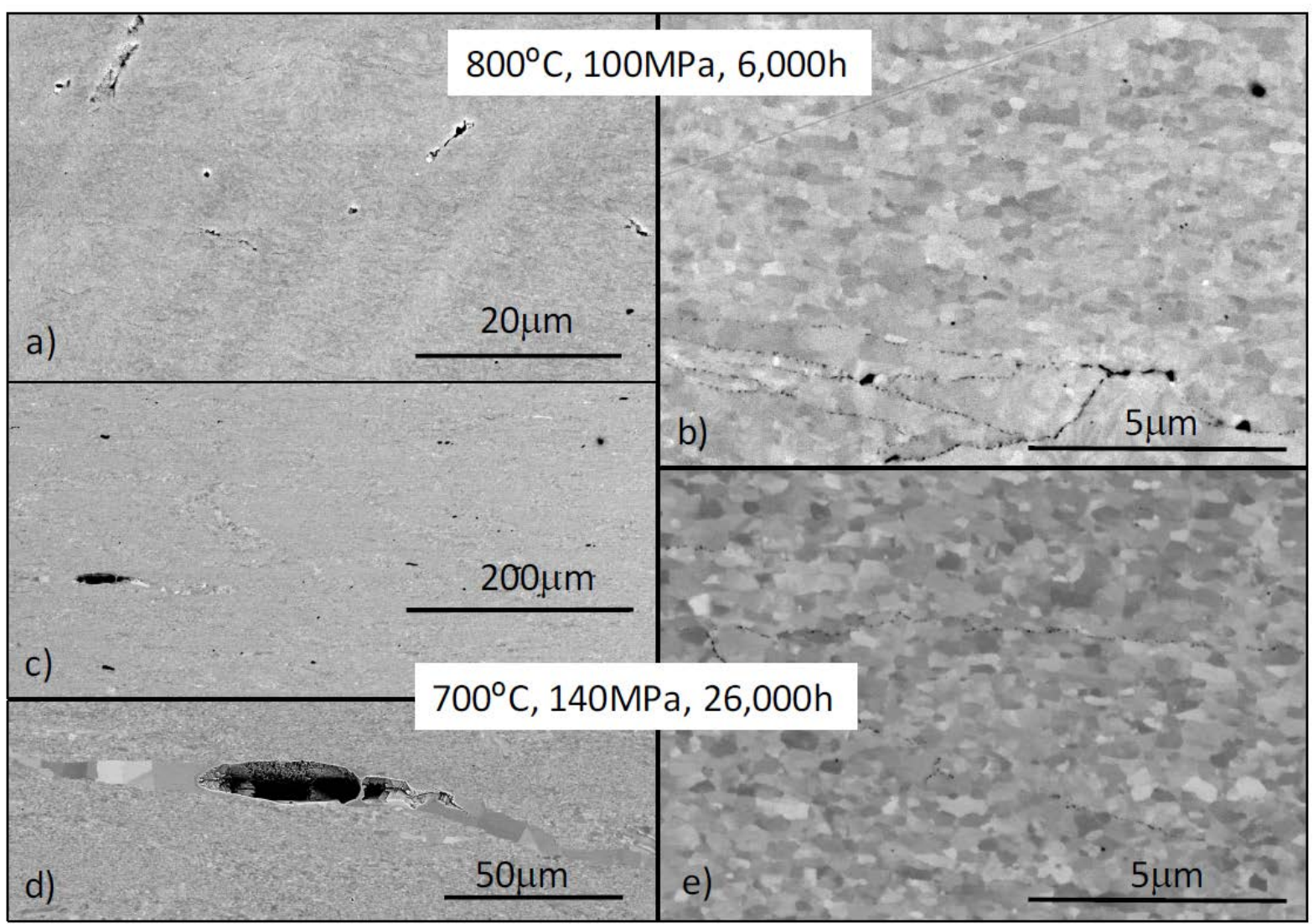

Figure 7. BSE-SEM micrographs of alloy $125 \mathrm{YZ}$ after creep testing, a-b) at $8^{\circ} 0^{\circ} \mathrm{C}, 100 \mathrm{MPa}$ for $6,000 \mathrm{~h}, \mathrm{c}-\mathrm{e})$ at $700^{\circ} \mathrm{C}, 140 \mathrm{MPa}$ for $26,000 \mathrm{~h}$.



Figure 8. BSE-SEM micrographs of alloy $106 \mathrm{ZY9C}$ after creep testing, a-b) at $800^{\circ} \mathrm{C}, 100 \mathrm{MPa}$ for $6,000 \mathrm{~h}, \mathrm{c}-\mathrm{e})$ at $700^{\circ} \mathrm{C}, 140 \mathrm{MPa}$ for $26,000 \mathrm{~h}$. 


\section{Fabrication of two new ODS FeCrAl alloys}

Two new ODS FeCrAl alloys were extruded at $900^{\circ} \mathrm{C}$, one $\mathrm{Fe}-10 \mathrm{Cr}-6 \mathrm{Al}-0.3 \mathrm{Zr}$ alloy (106ZYLN), similar to alloy 106ZY9C but with a lower $\mathrm{N}$ content (see Table 2), and one ODS Fe-12Cr-6Al alloy containing both $\mathrm{Zr}$ and $\mathrm{Ti}$ (126ZTY). The tensile properties of these two alloys are compared in Figure 9 with the tensile properties of the $125 \mathrm{YZ}$ and 106ZY9C alloys. The tensile strengths of the two new alloys at 20$800^{\circ} \mathrm{C}$ are lower than the strength of alloy $106 \mathrm{ZY} 9 \mathrm{C}$, but the ductility of the two alloys at $800^{\circ} \mathrm{C}$ was much higher. Creep testing of alloy 106ZYLN will be initiated to assess the impact of AlN precipitate suppression on the alloy creep properties at $700-800^{\circ} \mathrm{C}$.
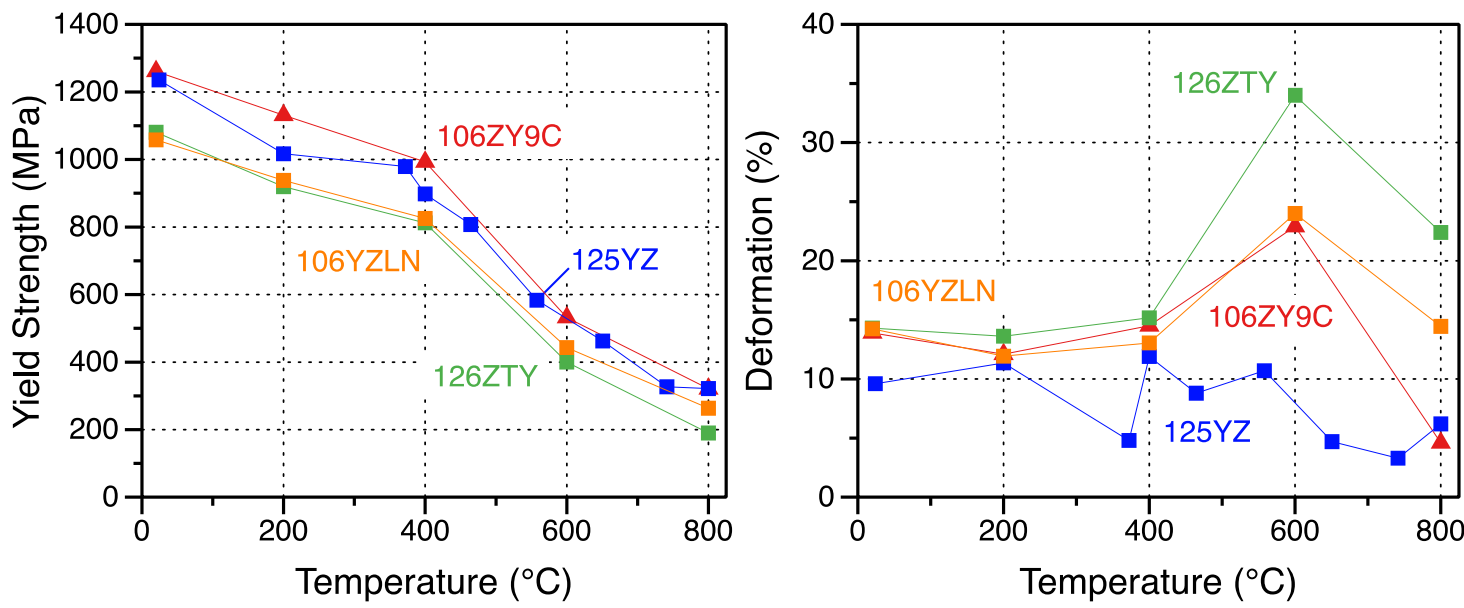

Figure 9. Comparison of the tensile properties of the two new ODS FeCrAl alloys, 106ZYLN and 126ZTY with the tensile properties of alloy 106ZY9C and 125YZ, a) Yield strength, b) Plastic deformation.

\section{FUTURE PLANS}

The microstructure of the 106ZYLN and 126ZTY alloys will be characterized using various advanced microscopy techniques. Nano precipitates at grain boundaries are expected to play a key role in creep strength at temperature above $700^{\circ} \mathrm{C}$ so the nano-oxide distribution will be estimated both in the grain and at grain boundaries. Collaboration with other Fusion projects will also be initiated to perform compatibility experiments on these two alloys and alloy 106ZY9C, and irradiation experiments will be conducted on alloy 106ZY9C. Finally, a new ODS FeCrAlZr alloys will be developed with improved creep strength above $700^{\circ} \mathrm{C}$.

\section{REFERENCES}

[1] B. A. Pint, S. Dryepondt, K. A. Unocic and D. T. Hoelzer, JOM 66, 2458-2466 (2014).

[2] K. A. Unocic, B. A. Pint, and D. T. Hoelzer, J Mater Sci, 51, (2016) 9190.

[3] K. A. Unocic and D. T. Hoelzer, J. Nucl. Mater, 479 (2016) 357.

[4] S. Dryepondt, K.A. Unocic, D.T. Hoelzer, C. P. Massey and B.A. Pint, accepted for publication in J. Nucl. Mater (2017).

[5] P. Dou, A. Kimura, R. Kasada, T. Okuda, M. Inoue, S. Ukai, S. Ohnuki, T. Fujisawa, F. Abe, J. Nucl. Mater, 444, 441-453 (2014).

[6] P. Dou, A. Kimura, T. Okuda, M. Inoue, S. Ukai, S. Ohnuki, T. Fujisawa and F. Abe, J. Nucl. Mater, 417, 166-170 (2011). 
[7] A. Kimura, R. Kasada, N. Iwata, H. Kishimoto, C.H. Zhang, J. Isselin, P. Dou, J.H. Lee, N. Muthukumar, T. Okuda, M. Inoue, S. Ukai, S. Ohnuki, T. Fujisawa, and T.F. Abe, J. Nucl. Mater., 417, 176 (2011). 


\subsection{BAINITIC STEEL DEVELOPMENT FOR FUSION APPLICATIONS}

\section{Y.Yamamoto(yamamotoy@ornl.gov)}

\section{OBJECTIVE}

This work aims to develop a new bainitic steel, based on 3Cr-3WV(Ta) steel originally developed at ORNL, with mechanical properties of both base metal and weldments superior to those of existing commercial bainitic steels or ferritic-martensitic (F-M) steels. Potential uses of the steel are the lifetime components of the conceptual US Fusion Neutron Sciences Facility (FNSF) including the helium-cooled vacuum vessel operating at $400-450^{\circ} \mathrm{C}$ and the helium-cooled structural ring (which supports the blanket modules), operating at $400-550^{\circ} \mathrm{C}$. Improvement of long-term creep properties by introducing fine and stable second-phase dispersions, together with maintaining good weldability and no requirement of postweld heat treatment (PWHT), is targeted via optimization of alloy composition and thermo-mechanical heat treatment.

\section{SUMMARY}

Property evaluation of newly proposed high-Mn, low-C containing 3Cr-3WVTa base steel (ID: MSLC2) with the design strategy for PWHT-free use was initiated. The base metal MSLC2 steel showed creeprupture properties at 550 and $660^{\circ} \mathrm{C}$ comparable to those of the original 3Cr-3WVTa steel. The weld strength reduction factors (WSRF) in as-welded condition were also comparable to those of commercial low alloy steels reported in ASME B31.3. Charpy impact tests indicated that the room-temperature absorbed energy of the weld metal exceeded the original 3Cr-3WVTa steel weld in as-welded condition, suggesting potential use of the steel without post-weld heat treatment (PWHT). However, the ductilebrittle transition temperature (DBTT) of the base metal was increased by tempering, and the absorbed energy of the weld metal lowered by PWHT, indicating the occurrence of temper embrittlement. Detailed characterization is in progress to find the mechanism of the observed temper embrittlement.

\section{PROGRESS AND STATUS}

Table 3 summarizes the nominal composition of the heat of newly proposed steel (heat \#16114943, ORNL ID: MSLC2) together with that of the original 3Cr-3WVTa steel (heat \#: 2751) prepared in the previous effort. The hot-rolled plates were normalized at $1100^{\circ} \mathrm{C}$ for $30 \mathrm{~min}$, and then tempered at $700^{\circ} \mathrm{C}$ for $1 \mathrm{~h}$. For the weld study, the cold rolled plates were sectioned into $1.6 \mathrm{~mm}$ width strips to form compositionally matched filler metal wires. The gas tungsten arc weld (GTAW) was conducted following the weld specification for Gr. 22 in ASME B31.3.

Table 3. Nominal compositions of the steels in the present study

\begin{tabular}{|c|c|c|c|c|c|c|c|c|}
\hline \multirow{2}{*}{ Heat \# } & \multicolumn{7}{|c|}{ Composition, wt\% (balance Fe) } & \multirow{2}{*}{ Remarks } \\
\hline & $\mathrm{C}$ & $\mathrm{Mn}$ & $\mathrm{Si}$ & $\mathrm{Cr}$ & $\mathrm{V}$ & W & $\mathrm{Ta}$ & \\
\hline $\begin{array}{l}16114943 \\
\text { (MSLC2) }\end{array}$ & 0.05 & 2.00 & 0.5 & 3 & 0.2 & 3 & 0.1 & $\begin{array}{l}\text { Modified with high Mn, } \\
\text { low C }\end{array}$ \\
\hline $\begin{array}{c}2751 \\
\text { (Original) }\end{array}$ & 0.10 & 0.4 & 0.14 & 3 & 0.2 & 3 & 0.1 & Original 3Cr-3WVTa \\
\hline
\end{tabular}

Figure 10 shows the creep rupture test results of the MSLC2 base metal and cross-weld specimens. The base metal showed creep-rupture properties comparable to those of the original 3Cr-3WVTa steel at 550 and $600^{\circ} \mathrm{C}$ (reported by Klueh et al. [1]) in the normalized-and-tempered condition (designated "MSLC2- 
NT" in the plots). The cross-weld creep-rupture tests indicated the weld strength reduction factors (WSRF) of $\sim 0.8$ at $550^{\circ} \mathrm{C}$ and $\sim 0.67$ at $600^{\circ} \mathrm{C}$ in as-welded condition, which were also comparable to the WSRF of low alloy steels containing 1-5 wt.\% Cr reported in ASME B31.3. [1].
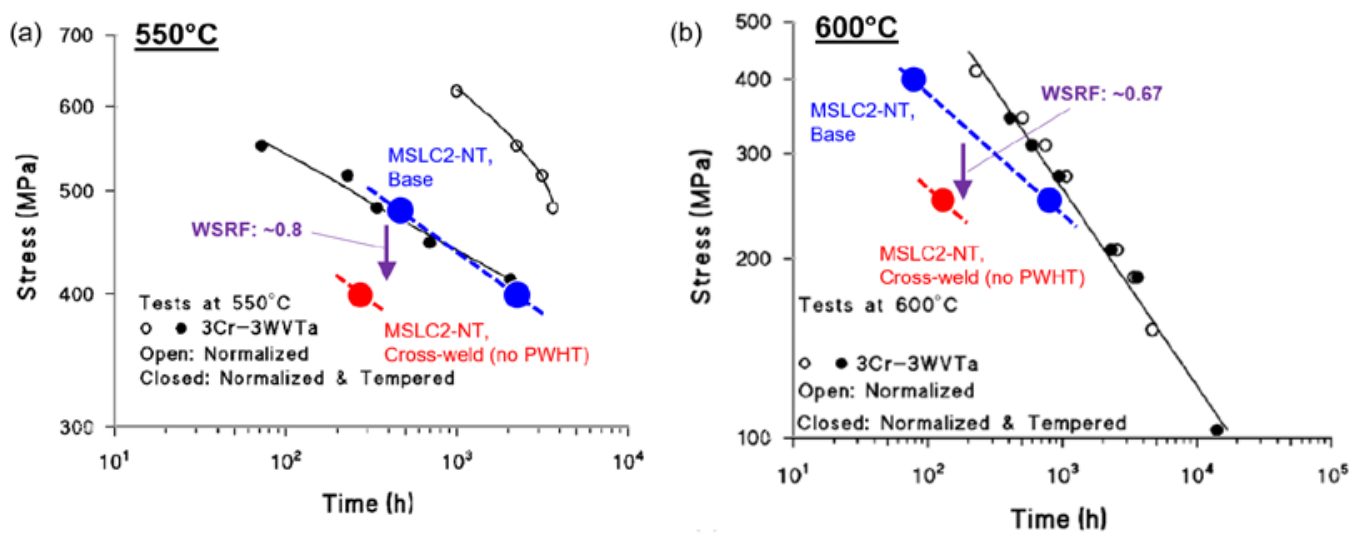

Figure 10. Creep-rupture life of MSLC2-NT plotted on reported creep-rupture lives of 3Cr-3WV and $3 \mathrm{Cr}-3 \mathrm{WVTa}$ steels [1]; (a) tested at $550^{\circ} \mathrm{C}$ and (b) at $600^{\circ} \mathrm{C}$.

Figure 11 summarizes the Charpy impact test results of MSLC2 base metal and weld metal, with or without tempering/PWHT. The room-temperature absorbed energy of the as-welded metal was $277 \mathrm{~J}$, which greatly exceeded the absorbed energy of the original 3Cr-3WVTa steel weld, 39 J, from previous reports, suggesting that the steel could be usable for structural purposes without PWHT. However, the DBTT of the base metal was increased by tempering, from $30^{\circ} \mathrm{C}$ to $76^{\circ} \mathrm{C}$, and the absorbed energy of the weld metal decreased significantly (from $227 \mathrm{~J}$ to $59 \mathrm{~J}$ ) by applying PWHT, indicating the occurrence of the classical "temper embrittlement" which could hypothetically be due to the high Mn contents. Detailed characterization is in progress to find the mechanism of the observed temper embrittlement.
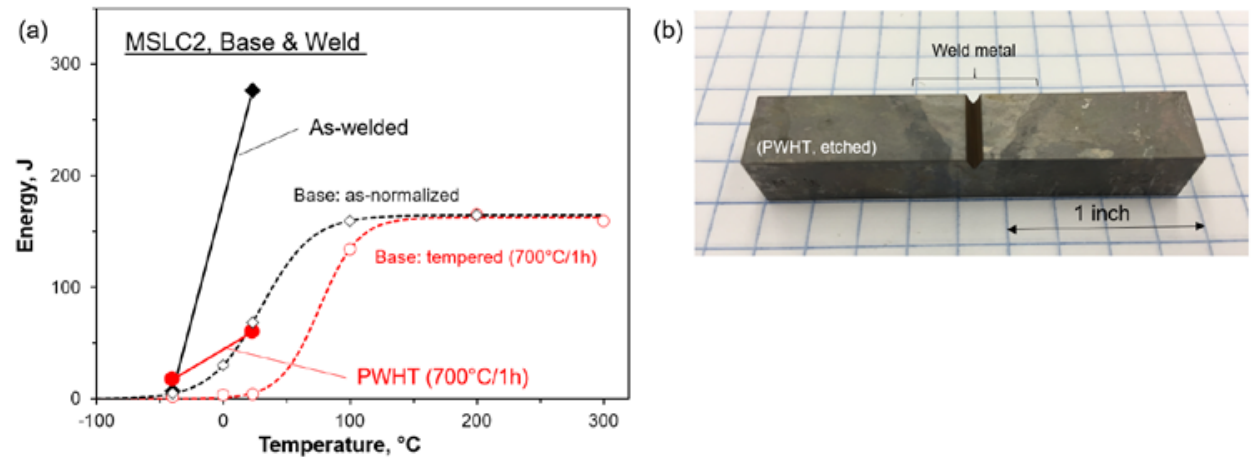

Figure 11. (a) Charpy impact test results of MSLC2 base and weld metals plotted as a function of temperature, and (b) the weld specimen after etching to show the position of the V-notch weld.

\section{FUTURE PLANS}

Property evaluation and detailed characterization of MSLC2 will continue to evaluate the effect of tempering temperature on Charpy absorbed energy, creep properties, and microstructure. Optimization of the heat treatment conditions as well as potential alloy modification will be pursued to balance the desired mechanical properties in the base and the welded materials. 


\section{REFERENCES}

[1] R. Klueh et al., Int. J. PVP. 84 (2007) 29. 


\title{
2.5 MECHANICAL PERFORMANCE OF RAFM AND ODS STEELS IN HFIR JP28 AND JP29 IRRADIATIONS
}

\author{
K.G. Field (fieldkg@ornl.gov), K. Wang, D. Zhang, J.W. Geringer, D.T. Hoelzer
}

\section{OBJECTIVE}

Oxide dispersion strengthened (ODS) and reduced activation ferritic-martensitic steels are currently under consideration for high temperature fusion applications. However, limited data exists on the mechanical performance and correlated microstructure after high dose (damage) neutron irradiations in the temperature regime $300-500^{\circ} \mathrm{C}$. The objective of this work was to perform in-cell mechanical testing including tensile testing and micro hardness measurement of neutron irradiated 12YWT, MA957, PM2000, Eurofer97, and 9Cr-2WVTa alloys irradiated in the High Flux Isotope Reactor irradiation capsules JP28 and JP29. Preliminary scanning electron microscopy (SEM) of the fracture surfaces was also of interest.

\section{SUMMARY}

ODS alloys: 12YWT, MA957, and PM2000, and wrought RAFM alloys: Eurofer97 and 9Cr-2WVTa, were neutron irradiated to nominal damage doses of 36 to $52 \mathrm{dpa}$ at temperatures in the range of $284^{\circ} \mathrm{C}$ to $350^{\circ} \mathrm{C}$ and then tensile tested at room temperature in ambient air to evaluate the post-irradiation mechanical performance of the alloy variants. Irradiation-induced hardening and embrittlement was observed for all alloys with the most severe response observed in PM2000. Fracture in the PM2000 specimens was determined to be brittle-trans-granular based on SEM fractography. Other alloy variants still showed reasonable ductility (as determined by their total elongation) even after irradiation to doses greater than $36 \mathrm{dpa}$. Additional micro hardness testing showed good correlation to the yield strength for the alloys still exhibiting ductility in the tensile tests.

\section{PROGRESS AND STATUS}

The passive SiC thermometry from the sub-capsules in JP28 and JP29 were recovered and tested to determine the actual irradiation temperature of each specimen set prior to mechanical properties evaluation. The completed analysis as well as the irradiation parameters for the full length JP28 and JP29 targets are summarized in Figure 12. Irradiation parameters (neutron fluence, He, and dose) were normalized based on the composition of $\mathrm{F} 82 \mathrm{H}$ and were taken from the Greenwood analysis. Damage dose was estimated to be 36-52 dpa depending on the specimen position within either the JP28 or JP29 capsule. The $\mathrm{SiC}$ thermometry indicated that for capsules with target temperatures of $300^{\circ} \mathrm{C}$, the capsule median temperatures were estimated to be within the expected range. Unfortunately, the capsules targeting irradiation temperatures of $400^{\circ} \mathrm{C}$ and $500^{\circ} \mathrm{C}$ saw significantly lower irradiation temperatures with all median capsule temperatures below $350^{\circ} \mathrm{C}$. SiC thermometry is known to be sensitive to the endof-life irradiation temperature and hence the data provided in Figure 12 only provides a relative estimate of near end-of-life irradiation temperatures.

Figure 13 shows example room temperature tensile curves for the three ODS steels investigated from various irradiation sub-capsules. The PM2000 material, which is a coarse/recrystallized grain material, showed significant embrittlement at all irradiation conditions. Samples all failed within the elastic regime even though ductility was observed in the un-irradiated specimens, Figure 13. Embrittlement could be linked to the formation of the Cr-rich $\alpha^{\prime}$ phase. PM2000 has been shown to be highly susceptible to $\alpha^{\prime}$ embrittlement after thermal aging [1] and $\alpha^{\prime}$ has been shown to embrittle similar wrought and powder metallurgy based alloys at significantly lower damage doses (<13.8 dpa) in similar irradiation temperature 
regimes $\left(320-382^{\circ} \mathrm{C}\right)$ [2]. Figure 14 shows the fracture surfaces of the PM2000 demonstrating that the failure occurred in a trans-granular manner indicative of significant embrittlement.

(a)

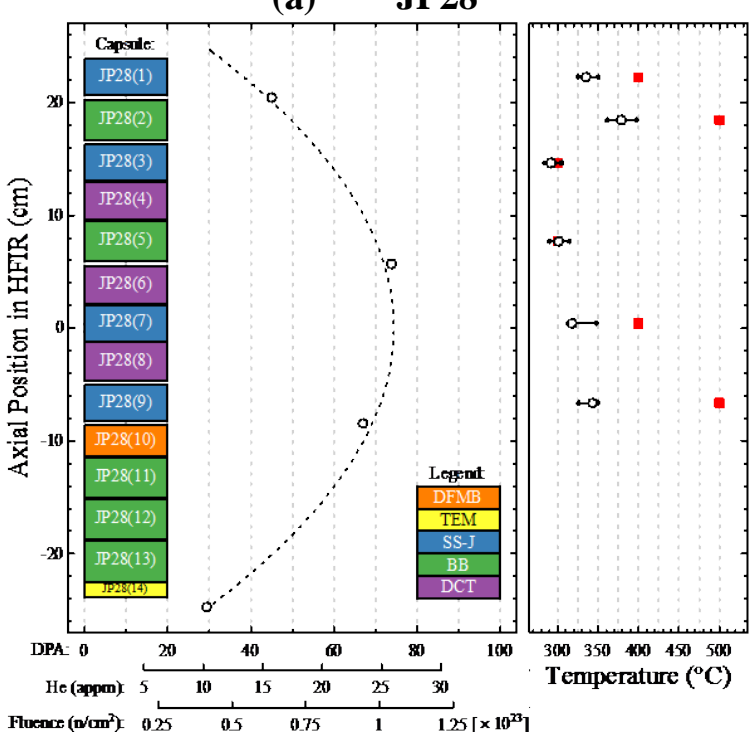

(b) JP29

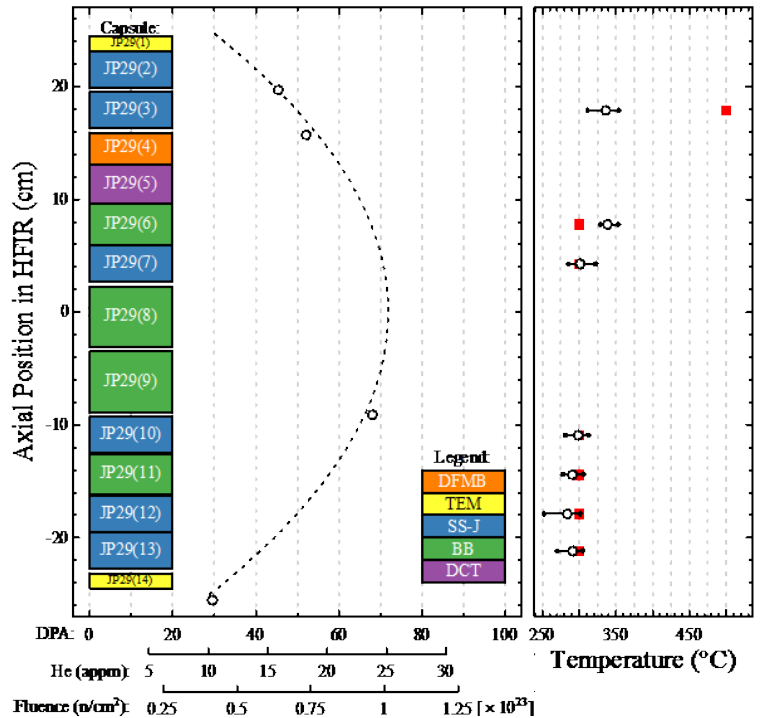

Figure 12. Summary of irradiation parameters normalized for alloy F82H for (a) JP28 and (b) JP29 full length targets in the HFIR. Red symbols in temperature plot signify target temperatures.

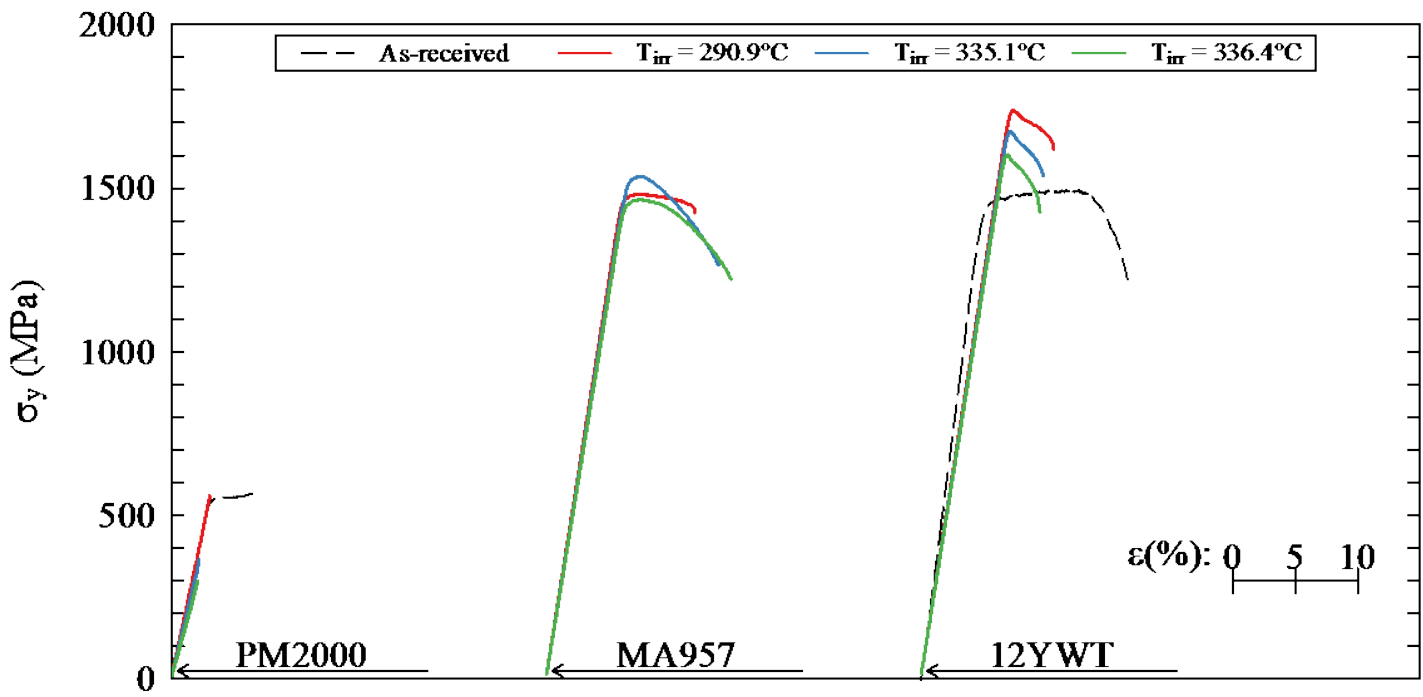

Figure 13. Tensile curves for ODS steel variants irradiated in JP29(13) [red curves, 43 dpa], JP28(1) [blue curves, 36 dpa], and JP29(3) [green curves, 48 dpa] capsules in HFIR. As-received curves for PM2000 and 12YWT represented as broken black curves. 
(a) PM2000 - $291^{\circ} \mathrm{C} \mid 43$ dpa



(b) PM2000 - 335 ${ }^{\circ} \mathrm{C} \mid 36$ dpa

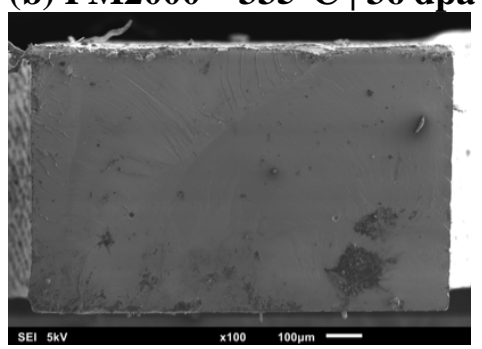

(c) PM2000 - 336 ${ }^{\circ} \mathrm{C} \mid 48$ dpa

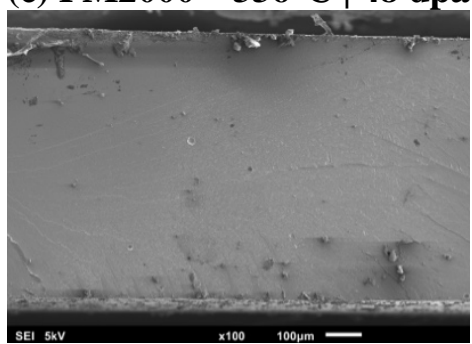

Figure 14. SEM fractographs showing transgranular brittle failure in PM2000 irradiated to varying conditions in JP28 and JP29 full length target capsules in HFIR.

MA957 and 12YWT showed significantly improved mechanical performance over PM2000 after neutron irradiation, with total elongations of $6-9.4 \%$ and 3.3-4\%, respectively regardless of irradiation parameters. Wrought RAFM steels also showed good post-irradiation ductility with total elongations near $10 \%$. Given this, RAFM steels saw limited load carrying capacity after yield resulting in uniform elongations no greater than $3.6 \%$, typically, with only the 9Cr-2WVTa specimen irradiated to $48 \mathrm{dpa}$ at $283.7^{\circ} \mathrm{C}$ showing a uniform elongation greater than $3.6 \%$ at $5 \%$. Vickers micro hardness values were found to scale with yield strength $\left(\sigma_{y} \widetilde{\propto} 3.5 \cdot H v\right)$ for all alloys except the PM2000 and the 12YWT specimen irradiated to 48 $\mathrm{dpa}$ at $336^{\circ} \mathrm{C}$. The current dataset suggests the proportionality between the yield stress and micro hardness presented by Busby et al. [3] remains true even in highly irradiated ODS and RAFM steels.

\section{FUTURE PLANS}

Microstructural characterization including transmission electron microscopy (TEM) will continue on the tensile specimen end sections of select ODS and RAFM steels in Fiscal Year 2018. Data will be complied to develop structure-property relationships on the alloy variants using various models.

\section{REFERENCES}

[1] J. Chao, C. Capdevila, M. Serrano, A. Garcia-Junceda, J.A. Jimenez, M.K. Miller, Effect of $\alpha-\alpha^{\prime}$ phase separation on notch impact behavior of oxide dispersion strengthened (ODS) Fe20Cr5Al alloy, Mater. Des. 53 (2014) 1037-1046. doi:10.1016/j.matdes.2013.08.007.

[2] K.G. Field, S.A. Briggs, K. Sridharan, R.H. Howard, Y. Yamamoto, Mechanical Properties of Neutron-Irradaited Model and Commercial FeCrAl Alloys, J. Nucl. Mater. 489 (2017) 118-128.

[3] J.T. Busby, M.C. Hash, G.S. Was, The relationship between hardness and yield stress in irradiated austenitic and ferritic steels, J. Nucl. Mater. $336 \quad$ (2005) 267-278. doi:10.1016/j.jnucmat.2004.09.024. 


\subsection{LIQUID METAL COMPATIBILITY IN FLOWING SYSTEMS}

\section{B. A. Pint (pintba@ornl.gov) and J. Jun}

\section{OBJECTIVE}

The objective of this task is to identify potential structural materials having sufficient compatibility with flowing $\mathrm{Pb}$-Li eutectic that the maximum metal temperature for operation of the dual coolant $\mathrm{Pb}-\mathrm{Li}$ fusion reactor blanket system can be increased to improve overall system efficiency.

\section{SUMMARY}

A series of monometallic thermal convection loops (TCLs) fabricated using dispersion strengthened FeCrAl (Kanthal APMT, Fe-21Cr-5Al-3Mo) tubing are being operated for $1000 \mathrm{~h}$ with increasing peak temperatures. Further characterization was completed on the APMT specimens exposed to commercial $\mathrm{Pb}-17 \mathrm{Li}$ in the hot and cold legs of the TCL with a peak temperature of $600^{\circ} \pm 1.5^{\circ} \mathrm{C}$. The APMT specimens pre-oxidized to form alumina prior to exposure tended to have low mass changes and the oxide spalled after exposure. The specimens that were exposed without pre-oxidation showed larger mass losses but the oxide was much more adherent. The third TCL with a peak temperature of $650^{\circ} \pm 1.5^{\circ} \mathrm{C}$ was assembled and began operation in September 2017 with completion expected in October 2017. In addition to the experimental work, a major laboratory renovation was completed with all of the liquid metal compatibility equipment relocated to one laboratory.

\section{PROGRESS AND STATUS}

To assess $\mathrm{Pb}-\mathrm{Li}$ compatibility with candidate structural alloys, a series of monometallic thermal convection loops (TCLs) are being operated using dispersion strengthened FeCrAlMo (Kanthal alloy APMT), which is commercially available in tubing form. The first loop operated in 2014 for $1000 \mathrm{~h}$ with a maximum temperature of $550^{\circ} \mathrm{C}$ and the second loop operated for $1000 \mathrm{~h}$ in 2016 with a maximum temperature of $600^{\circ} \mathrm{C}$. The hot and cold legs of the TCL each contained a chain of 20 APMT tensile specimens (25mm long SS-3 type) that were characterized. Initial mass change and characterization of the specimens exposed in the second TCL were presented in last year's report. Additional characterization was completed this year. Figure 15 and Figure 16 show the room temperature tensile properties $\left(10^{-3} \mathrm{~s}^{-1}\right.$ strain rate) of $\sim 50 \%$ of the specimens from the hot and cold legs of the first and second TCLs. The yield stress (YS) and ultimate tensile stress (UTS) results are plotted as a function of the temperatures in the hot and cold legs in Figure 15. These temperatures are interpolated between measured temperatures at several thermocouple wells in each TCL. Figure 16 shows the uniform and total elongation values as a function of temperature in the two TCLs. Unlike the first TCL, there was only a small change in properties in the second TCL $\left(515^{\circ}-600^{\circ} \mathrm{C}\right)$. The range of as-received (AR) APMT properties are shaded in each figure. In the $550^{\circ} \mathrm{C}$ TCL, $\alpha^{\prime}$ precipitates were observed in the alloy after exposures below $500^{\circ} \mathrm{C}$, which explained the observed increase in YS and UTS and decrease in ductility. Figure 15 and Figure 16 also show that the specimens exposed without pre-oxidation (labeled AR) to form a uniform $\alpha-\mathrm{Al}_{2} \mathrm{O}_{3}$ external oxide scale (typically $8 \mathrm{~h}$ at $1050^{\circ} \mathrm{C}$ ), behaved similarly to pre-oxidized specimens despite losing more mass during exposure. 


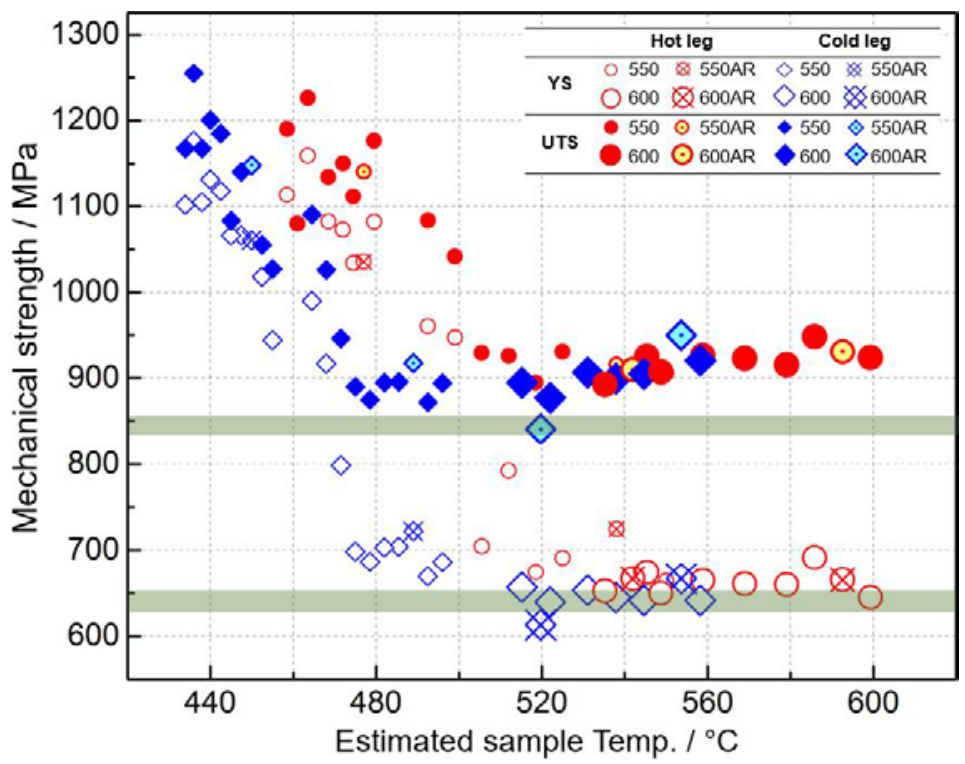

Figure 15. Yield and ultimate tensile stress as a function of exposure temperature for the FeCrAlMo (APMT) specimens exposed in the hot and cold legs of the first two flowing Pb-Li TCLs operated with maximum temperatures of $550^{\circ}$ and $600^{\circ} \mathrm{C}$. Specimens labeled $A R$ did not receive a pre-oxidation treatment.

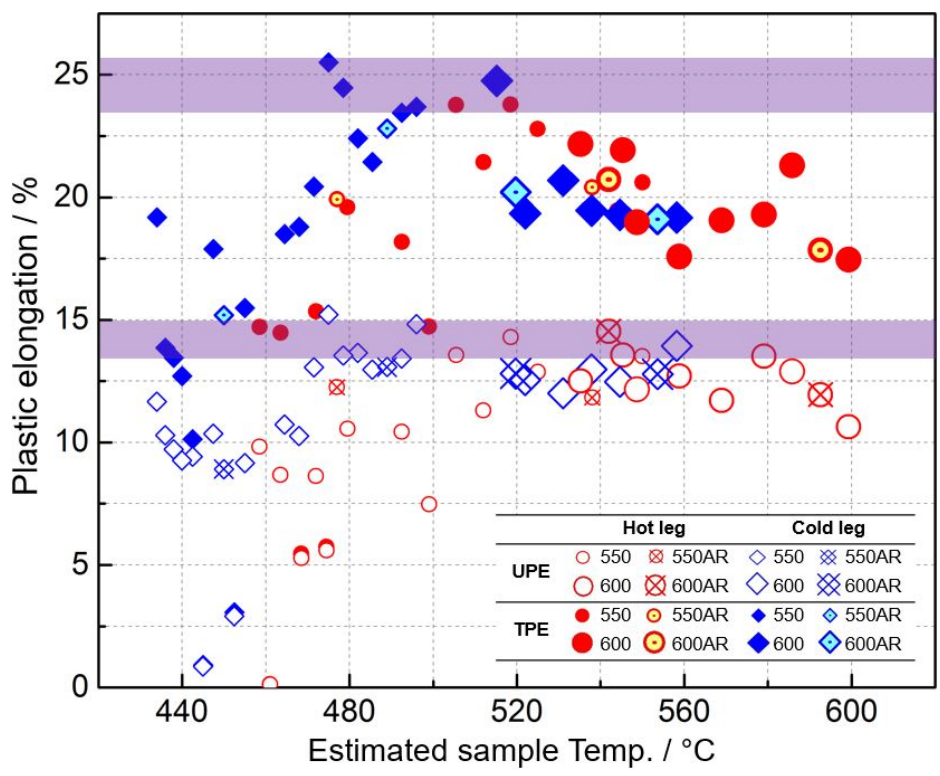

Figure 16. Uniform and total elongation as a function of exposure temperature for the FeCrAlMo (APMT) specimens exposed in the hot and cold legs of the first two flowing Pb-Li TCLs operated with maximum temperatures of $550^{\circ}$ and $600^{\circ} \mathrm{C}$. Specimens $A R$ were not pre-oxidized.

Additional characterization of the exposed specimens also included metallography. One similarity between the two TCL experiments was the spallation of the oxide, particularly on the specimens with a pre-formed oxide. Figure 17 and Figure 18 show two specimens exposed close to each other in the cold leg. The only difference is that the specimen with no pre-oxidation retained its surface oxide (Figure 17a), while the specimen pre-oxidized for $8 \mathrm{~h}$ at $1050^{\circ} \mathrm{C}$ showed significant spallation. While pre- 
oxidation reduced the specimen mass loss, the resulting oxide appeared to be poorly adherent after exposure and cleaning. One explanation for that difference is that the pre-formed external $\alpha-\mathrm{Al}_{2} \mathrm{O}_{3}$ scale transformed to $\mathrm{LiAlO}_{2}$ during exposure, leading to the spallation. The as-received specimens that formed $\mathrm{LiAlO}_{2}$ directly formed a more adherent oxide. The amount of spallation was quantified using image analysis on several specimens. Figure 17 shows that the amount of spallation was not related to mass change or exposure temperature. In general, the variations in the pre-oxidation temperature $\left(1000^{\circ}\right.$ $1100^{\circ} \mathrm{C}$ ) for specimens in the second TCL did not appear to significantly affect the scale adhesion after exposure. Figure 18 shows cross-sections of two specimens showing an adherent oxide and a nonadherent oxide scale.
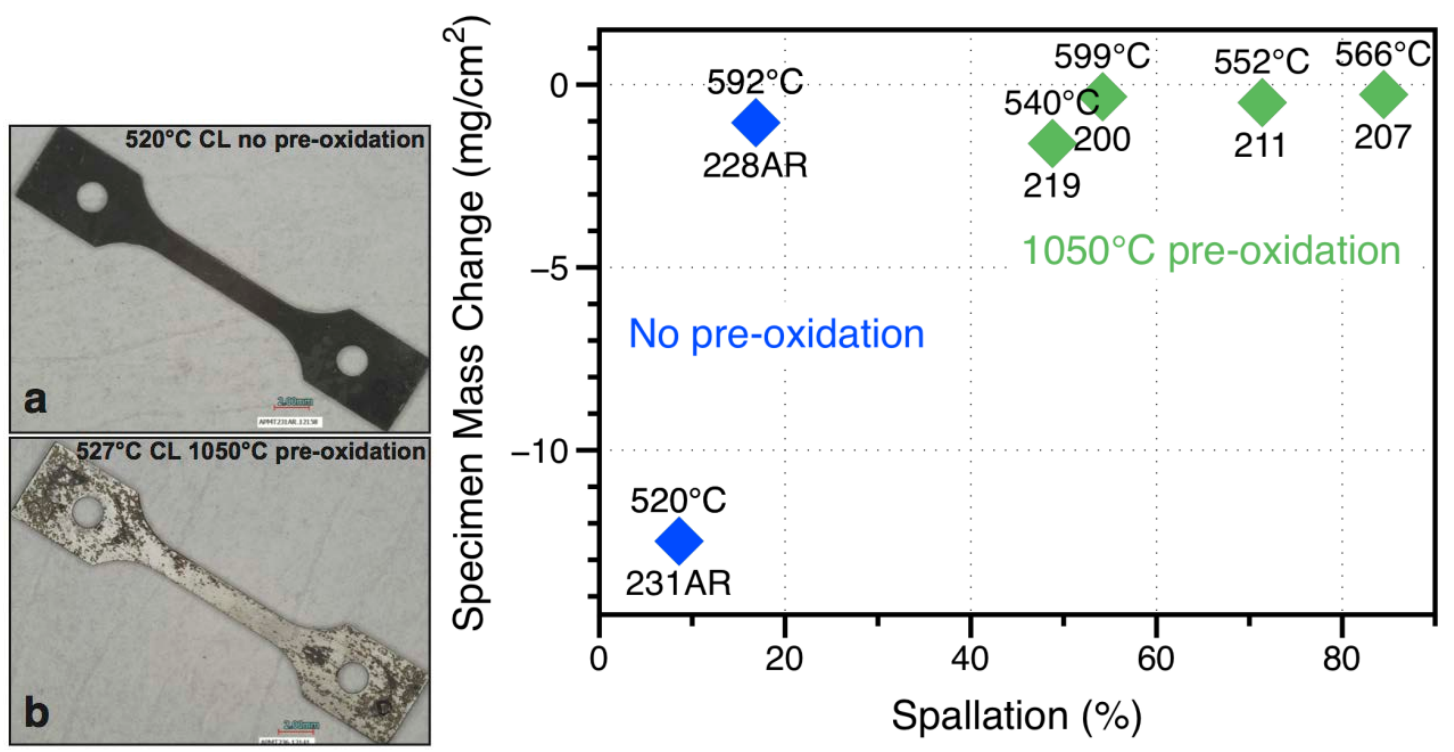

Figure 17. Post-exposure APMT specimens from the cold leg (a) no pre-oxidation specimen exposed at $520^{\circ} \mathrm{C}$ and (b) $1050^{\circ} \mathrm{C}$ pre-oxidation specimen exposed at $527^{\circ} \mathrm{C}$. (c) image analysis was used to quantify the amount of spallation on several specimens.

In addition to the experimental work, a renovation of the ORNL liquid metal and molten salt compatibility laboratory was recently completed with significant support from ORNL for utilities and infrastructure, including a new glove box to replace $40+$ year old equipment. The project paid for an additional nitrogen monitor and purification system on the main glove box and a second, small glove box for cutting Pb-Li for loop and capsule experiments, Figure 19. The loop experiments also are conducted in this laboratory resulting in a more efficient work flow. 




Figure 18. Light microscopy of polished cross-sections of APMT after exposure for $1000 \mathrm{~h}$ in Pb-Li (a) cold leg specimen exposed at $520^{\circ} \mathrm{C}$ with no pre-oxidation and (b) hot leg specimen $\left(579^{\circ} \mathrm{C}\right)$ preoxidized at $1100^{\circ} \mathrm{C}$.



Figure 19. New glove boxes for handling liquid metals in an inert (Ar) environment. Left: large glove box with $\mathrm{O}_{2}, \mathrm{H}_{2} \mathrm{O}$ and $\mathrm{N}_{2}$ control. Right: smaller glove box for cutting Pb-Li.

As no significant degradation was observed in terms of dissolution or degradation in mechanical properties in the second TCL, a third TCL with a maximum operating of $650^{\circ} \mathrm{C}$ was assembled and is currently being operated with completion expected in October 2017. Figure 20 shows a TCL before testing. Both the hot and cold leg contained chains of 20 APMT SS-3 type tensile specimens. The approximate temperature of each specimen location will be estimated by linear extrapolation as a function of position between thermowell locations at the top, middle and bottom of each leg. The loop is running with a $120^{\circ} \mathrm{C}$ temperature gradient, somewhat higher than the $85^{\circ} \mathrm{C}$ gradient in the second loop. Because of the oxide spallation observe after the $1^{\text {st }}$ and $2^{\text {nd }}$ TCLs, the standard pre-oxidation was reduced from $8 \mathrm{~h}$ in air at $1050^{\circ} \mathrm{C}$ to $2 \mathrm{~h}$ at $1000^{\circ} \mathrm{C}$ in air, although four specimens were included with the former preoxidation treatment. In addition, four APMT specimens had no pre-oxidation (i.e. bare metal when inserted) to continue the comparison between pre-oxidized and bare metal specimens. 


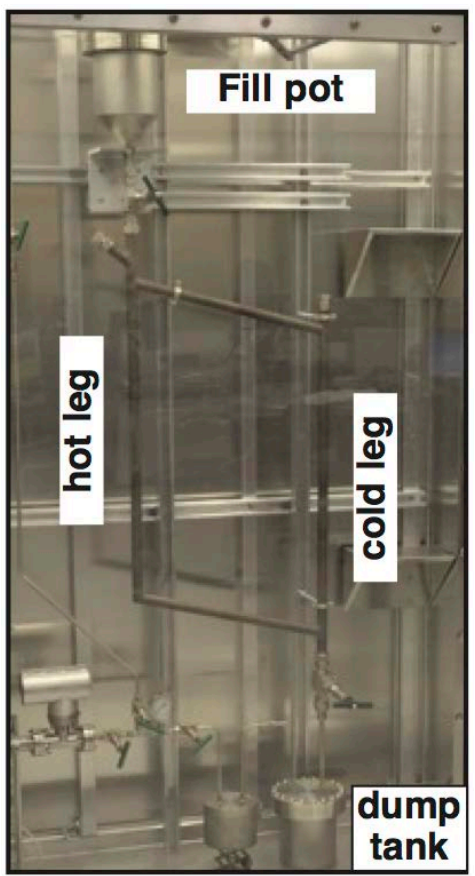

Figure 20. Typical Kanthal APMT loop assembled for operation. Furnaces are placed over the hot leg for operation and insulation is used as needed.

\section{FUTURE PLANS}

The third TCL exposure with a peak temperature of $650^{\circ} \mathrm{C}$ will be completed and the specimen removed for characterization including mass change, room temperature tensile properties and characterization of the reaction products. Once the third TCL reporting is completed, fabrication of the next APMT TCL will begin with operation expected in FY20. 


\subsection{LIQUID METAL COMPATIBILITY IN STATIC Li, Sn AND Sn-Li}

\section{B. A. Pint (pintba@ornl.gov) and J.Jun}

\section{OBJECTIVE}

The objective of this task is an initial evaluation of the maximum use temperature for structural steel compatibility with liquid $\mathrm{Li}, \mathrm{Sn}$ and $\mathrm{Sn}-20 \mathrm{Li}$ and to determine if a thermally grown surface oxide can significantly improve compatibility. For plasma wall applications, Sn and Sn-Li offer much lower vapor pressures than $\mathrm{Li}$ but $\mathrm{Li}$ is known to be compatible at higher temperatures.

\section{SUMMARY}

The compatibility of a reduced activation ferritic-martensitic steel, F82H (Fe-8Cr-2W) with Li, Sn and $\mathrm{Sn}-20 \mathrm{Li}$ is being evaluated in isothermal capsule experiments. For $\mathrm{Pb}-\mathrm{Li}$, compatibility has been significantly improved when an Al-rich oxide was formed on the alloy surface, either by coating or alloying with $\mathrm{Al}$, followed by pre-oxidation to form an external alumina layer. To test this concept for $\mathrm{Li}$, Sn and Sn-20Li, commercial alumina-forming steel, Kanthal APMT (Fe-20Cr-5Al-3Mo), was selected for evaluation with and without pre-oxidation to form $\alpha-\mathrm{Al}_{2} \mathrm{O}_{3}$. The capsules are being assembled with 1000 hour testing to be completed in the first quarter of FY18.

\section{PROGRESS AND STATUS}

The test matrix for alloy exposure to liquid metals in static capsules is shown in Table 4. All of the experiments will be conducted for $1000 \mathrm{~h}$ in sealed Mo capsules contained in type 304 stainless steel (SS) capsules to protect the Mo from degradation during the experiment, Figure 21. The high purity $\mathrm{Sn}$ and Li will be loaded in an Ar-filled glove box to minimize contamination prior to weld closing the Mo and SS capsules. A typical reduced activation ferritic-martensitic structural steel, F82H (Fe-8Cr-2W) was selected for the initial evaluation of compatibility with Li, Sn and Sn-20Li. To avoid the complication of aluminizing F82H, commercial alumina-forming steel, Kanthal APMT (Fe-20Cr-5Al-3Mo), was selected to determine if pre-oxidation to form a stable oxide could inhibit dissolution in Li, Sn and Sn-20Li. Uncoated F82H would form a mixed Fe- and Cr-rich oxide with a complex structure. However, APMT is well-known to form an external alumina layer or scale. A pre-oxidation treatment of $2 \mathrm{~h}$ at $1000^{\circ} \mathrm{C}$ was selected to form a uniform, single-phase, $\alpha-\mathrm{Al}_{2} \mathrm{O}_{3}$ scale, which is much more thermodynamically stable than any Fe- or Cr-rich oxide. Based on a review of the literature, the initial Sn and Sn-20Li experiments will be conducted at $400^{\circ} \mathrm{C}$ as prior work showed significant attack at $500^{\circ} \mathrm{C}$. The Li experiments will be conducted at $600^{\circ} \mathrm{C}$. Table 4 also shows the test matrix with coupons ( 3x10x20 mm) of F82H being exposed in each condition. For APMT, both coupons and $25 \mathrm{~mm}$-long, type SS-3 tensile specimens are exposed. These are similar to the specimens being exposed in the Pb-Li thermal convection loops. Relatively thick coupons are used in these experiments to assure avoiding complete consumption, particularly in the capsules containing Sn.

Table 4. Test matrix for evaluation of liquid metal compatibility

\begin{tabular}{|c|c|c|c|}
\hline Liquid/Temperature & F82H & APMT & $\begin{array}{c}\text { Pre-oxidized APMT } \\
1000^{\circ} \mathrm{C}-2 \mathrm{~h}\end{array}$ \\
\hline Sn at $400^{\circ} \mathrm{C}$ & $\mathrm{X}$ & $\mathrm{XX}$ & $\mathrm{XX}$ \\
\hline $\mathrm{Sn}-20 \mathrm{Li}$ at $400^{\circ} \mathrm{C}$ & $\mathrm{X}$ & $\mathrm{XX}$ & $\mathrm{XX}$ \\
\hline $\mathrm{Li}$ at $600^{\circ} \mathrm{C}$ & $\mathrm{X}$ & $\mathrm{XX}$ & $\mathrm{XX}$ \\
\hline
\end{tabular}

Capsule content $-\mathrm{X}$ : coupon only, $\mathrm{XX}$ : coupon + tensile specimen 




Figure 21. Schematic of a standard isothermal capsule experiment with an inner Mo capsule and outer stainless steel capsule. The capsule is initially inverted at temperature as shown to submerge the specimen and then flipped over at the end of the experiment to allow the liquid to drain away from the specimen.

All nine capsules are assembled and the exposures are expected to be completed by the end of November 2017. After exposure, the capsules will be opened in a glove box. The specimens will be cleaned using ammonia for the Li and sodium hydroxide for the Sn. Specimen mass changes will indicate the extent of reaction, and will be followed by characterization of the surface, including chemistry and morphology. The APMT tensile specimens will be tested at room temperature to determine any change in mechanical properties due to liquid metal exposure.

A second round of capsule tests may be conducted based on the results of these first experiments, perhaps including c-ring specimens to evaluate liquid metal embrittlement. 


\section{CERAMIC AND COMPOSITE MATERIALS}

\subsection{DEVELOPMENT OF SiC JOINING TECHNOLOGIES FOR FUSION}

T. Koyanagi (koyangit@ornl.gov), Y. Katoh, T. Hinoki (Kyoto University, Japan), M. Ferraris (Politecnico di Torino, Italy), C. Henager Jr. (PNNL)

\section{OBJECTIVE}

The objective of this work is to develop irradiation tolerant silicon carbide joining technology for fusion applications. The work in this fiscal year focused on post-irradiation examinations of SiC joints irradiated to high dose of $\sim 20$ dpa.

\section{SUMMARY}

Monolithic silicon carbide (SiC) to $\mathrm{SiC}$ plate joints were fabricated and irradiated with neutrons in HFIR at $530^{\circ} \mathrm{C}$ to $20.2 \mathrm{dpa}$ for $\mathrm{SiC}$. The joining methods included liquid phase sintering (LPS) SiC nanopowder slurry or green sheet, calcia-alumina (CA) glass ceramics joining, and Ti-Si-C MAX-phase joining. All types of joints retained their strength following irradiation. These joining technologies are potentially useful for fusion applications, based on the irradiation resistance.

\section{PROGRESS AND STATUS}

Four types of SiC plate-to-plate joints were fabricated in this study. Table 5 shows the fabrication condition of each joint. Note that these joints have been proven to be irradiation resistant at low neutron dose of 3-5 dpa in our previous studies. Strength of the joint specimens was evaluated by torsional shear test of hourglass-type specimens designed specifically for the rabbit irradiation experiment. Figure 22 summarizes the results of the torsion resistance of the SiC joints. All of the non-irradiated joint types except the LPS SiC slurry sintered joint exhibited torsion resistance of 104-115 MPa, on average. The SiC LPS SiC slurry sintered joints showed relatively high average torsion resistance of $318 \mathrm{MPa}$. Figure 22 also shows the effects of the irradiation on the joint strengths. All types of SiC joints retained their strength (did not show strength degradation) following the irradiation. It is worth noting that this is the first data showing that $\mathrm{SiC}$ joints retain their strength following neutron irradiation to such high dose.

Table 5. Processing conditions for fabricating SiC joints

\begin{tabular}{|l|l|l|l|l|l|}
\hline $\begin{array}{l}\text { Bonding } \\
\text { type }\end{array}$ & Feedstock & $\begin{array}{l}\text { Temperature } \\
{\left[{ }^{\circ} \mathrm{C}\right]}\end{array}$ & $\begin{array}{l}\text { Pressure } \\
{[\mathrm{MPa}]}\end{array}$ & $\begin{array}{l}\text { Time } \\
{[\mathrm{min}]}\end{array}$ & Atmosphere \\
\hline $\begin{array}{l}\mathrm{CA} \\
\text { Glass }\end{array}$ & $\mathrm{CaO}, \mathrm{Al} 2 \mathrm{O} 3$ & 1480 & 0 & 10 & $\mathrm{Ar}$ \\
\hline $\begin{array}{l}\text { LPS SiC } \\
\text { Slurry }\end{array}$ & $\begin{array}{l}\mathrm{SiC}, \mathrm{Al} 2 \mathrm{O} 3, \\
\mathrm{Y} 2 \mathrm{O} 3,(\mathrm{ZrO} 2)\end{array}$ & 1850 & 10 & 60 & $\mathrm{Ar}$ \\
\hline $\begin{array}{l}\text { LPS SiC } \\
\text { Green sheet }\end{array}$ & $\begin{array}{l}\mathrm{SiC}, \mathrm{Al} 2 \mathrm{O} 3, \\
\mathrm{Y} 2 \mathrm{O} 3,(\mathrm{ZrO} 2)\end{array}$ & 1850 & 10 & 60 & $\mathrm{Ar}$ \\
\hline MAX phase & $\mathrm{TiC}, \mathrm{Si}$ & 1425 & $30-40$ & 120 & $\mathrm{Ar}$ \\
\hline
\end{tabular}




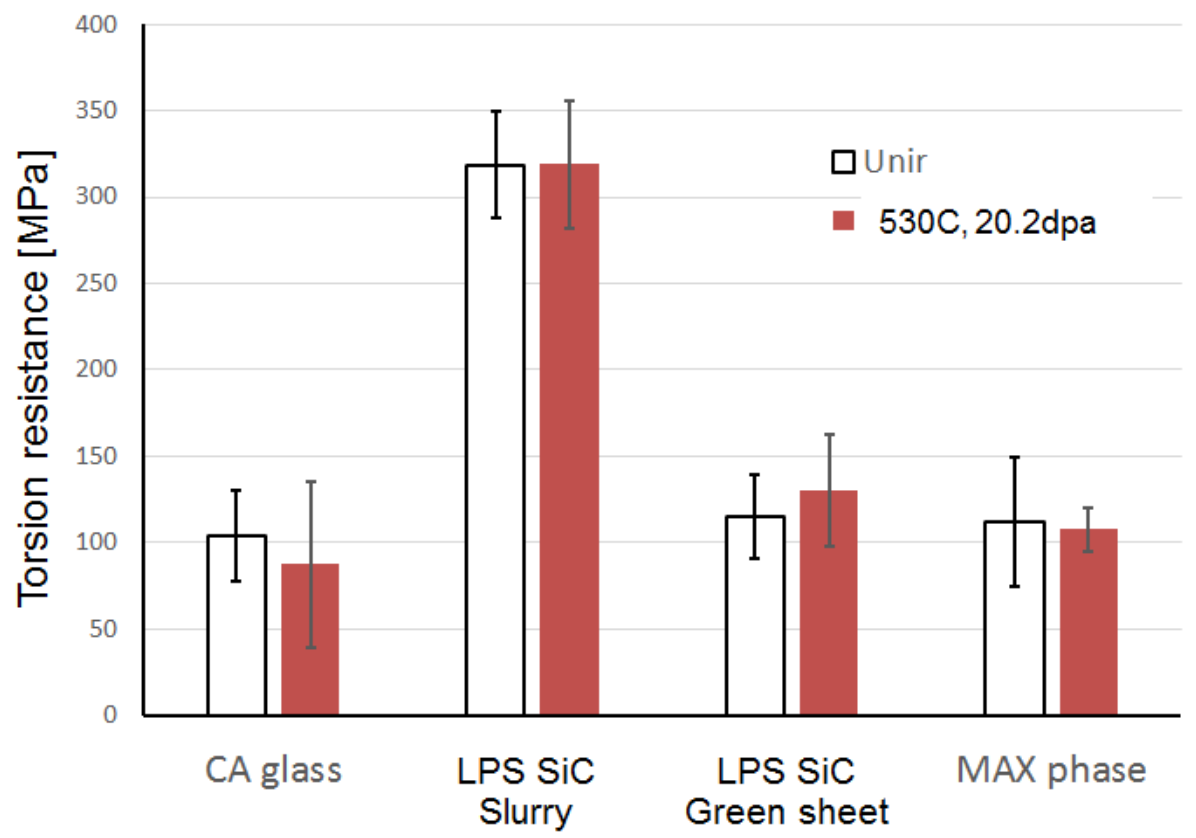

Figure 22. Torsion resistance of nonirradiated and irradiated SiC joints.

\section{FUTURE PLANS}

The work next fiscal year will focus on microstructural evaluation of irradiated SiC joints to understand the irradiation resistance. The experiments will include observation or analysis using scanning electron microscopy, transmission electron microscopy, x-ray diffraction, and electron back scattering diffraction. 


\title{
3.2 HIGH DOSE NEUTRON IRRADIATION EFFECTS ON MECHANICAL PROPERTIES OF SiC MATERIALS AND COMPOSITES
}

\author{
T. Koyanagi (koyangit@ornl.gov), T. Nozawa (QST), Y. Katoh, and L.L Snead (Stony Brook University,)
}

\section{OBJECTIVE}

The objective of this task is to obtain a better understanding of the effects of high neutron fluence irradiation on the mechanical properties and microstructures of silicon carbide ( $\mathrm{SiC}$ ) and $\mathrm{SiC}$ fiber reinforced $\mathrm{SiC}$ matrix (SiC/SiC) composites to be used in fusion structural applications.

\section{SUMMARY}

Post-irradiation examination of early nuclear grade $\mathrm{SiC} / \mathrm{SiC}$ composites irradiated in HFIR to 100 dpa has been completed. Electron microscopy analysis found that the mechanical property degradations at high neutron dose could be explained by loss of functionality of the fiber/matrix interphase. A draft journal paper on this study was prepared in FY17.

\section{PROGRESS AND STATUS}

For development of SiC materials for next generation nuclear structural applications, degradation of material properties due to intense neutron irradiation is a critical feasibility issue. This study evaluated the mechanical properties and microstructure of an early nuclear grade $\mathrm{SiC} / \mathrm{SiC}$ composite following neutron irradiation in HFIR at 319 and $629^{\circ} \mathrm{C}$ to very high dose level of $\sim 100 \mathrm{dpa}$. The test material was a chemical vapor infiltrated $\mathrm{SiC} / \mathrm{SiC}$ composite reinforced with multi-layer $\mathrm{SiC} /$ pyrolytic carbon coated HiNicalon ${ }^{\mathrm{TM}}$ Type S SiC fiber. This study conducted flexural tests (Figure 23) and electron microscopy analysis (Figures 24a-d) to understand such irradiation effects.

Both proportional limit stress and ultimate flexural strength were significantly degraded due to irradiation at both temperatures as show in Figure 23 . In the case of the irradiation at $319^{\circ} \mathrm{C}$, the quasi-ductile fracture behavior of the non-irradiated composite became brittle after irradiation, which was explained by loss of functionality of the fiber/matrix interface associated with disappearance of the interphase during irradiation (Figure 24c). The specimens irradiated at $629^{\circ} \mathrm{C}$ showed increased apparent failure strain because of the fiber/matrix interphase weakened by irradiation-induced partial de-bonding (Figure 24d). This study found stability of the interphase played a critical role in the irradiation resistance of the SiC composites, which shows the need for development of an irradiation tolerant fiber/matrix interphase.

\section{FUTURE PLANS}

To evaluate potentially improved irradiation resistance of $\mathrm{SiC} / \mathrm{SiC}$ composites at high neutron doses, $\mathrm{SiC} / \mathrm{SiC}$ composites with modified interphase and different fibers have been neutron irradiated at $\sim 600^{\circ} \mathrm{C}$ to $44 \mathrm{dpa}$. Post-irradiation examinations of these specimens will be conducted. The experiments will include flexural tests and electron microscopy observations. 


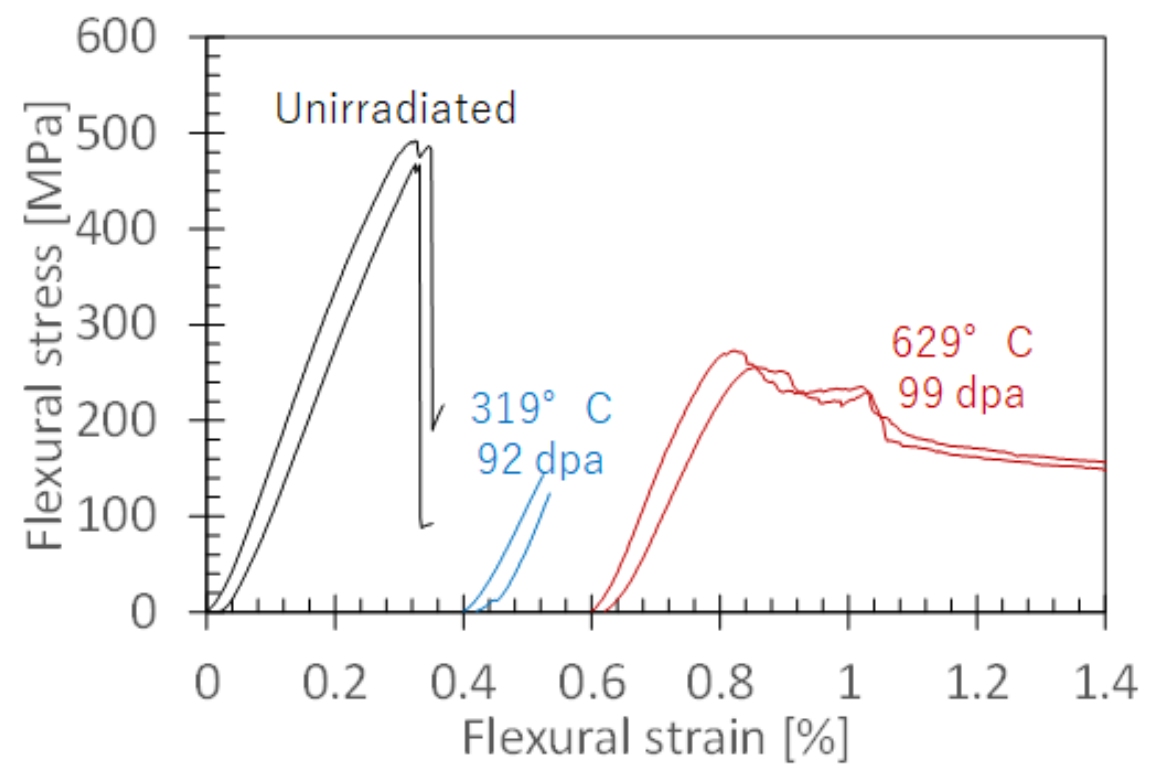

Figure 23. Flexural behavior of nonirradiated and irradiated CVI SiC/SiC composites. The stressstrain curves are shifted to aid in visibility.
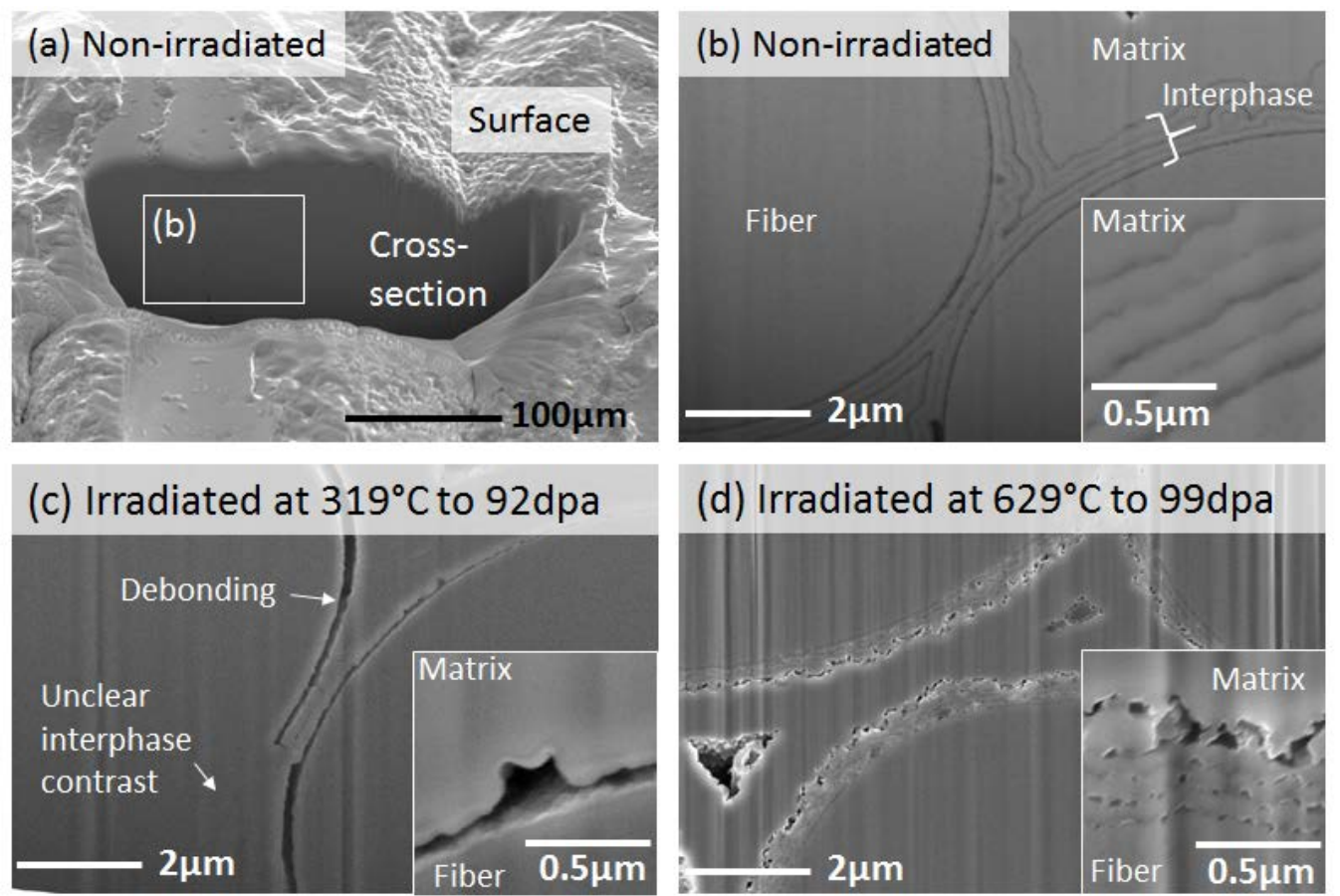

Figure 24. Secondary electron micrographs of cross section of CVI SiC/SiC composites: (a) cross section processed using FIB, (b) non-irradiated condition, (c) irradiated at $319^{\circ} \mathrm{C}$ to 92 dpa, and (d) irradiated at $629^{\circ} \mathrm{C}$ to $99 \mathrm{dpa}$. The observed area in image (b) is indicated in image (a). 


\subsection{ADVANCED CHARACTERIZATION OF IRRADIATION DEFECTS IN SILICON CARBIDE}

T. Koyanagi (koyangit@ornl.gov), C.M. Parish, X. Hu, Y. Katoh, S. Kondo (Kyoto University, Japan), D.J. Sprouster (Brookhaven National Laboratory)

\section{OBJECTIVE}

This project is developing advanced characterization techniques for irradiation defects in SiC, including positron annihilation spectroscopy, high energy x-ray diffraction, and high-resolution transmission electron microscopy. Results from use of these techniques on $\mathrm{SiC}$ and $\mathrm{SiC}$ composites will help in building mechanistic models of the material performance in fusion applications.

\section{SUMMARY}

We have demonstrated that advanced characterization techniques provided new information or better understanding of irradiation effects on SiC materials. Four journal papers regarding this task have been published in FY17, and are listed as references and are included in the PUBLICATIONS section.

\section{PROGRESS AND STATUS}

\section{(1) Positron annihilation spectroscopy[1]}

Positron annihilation spectroscopy characterization results for neutron-irradiated 3C-SiC are described here, with a specific focus on explaining the size and character of vacancy clusters as a complement to the current understanding of the neutron irradiation response of 3C-SiC. Positron annihilation lifetime spectroscopy was used to capture the irradiation temperature and dose dependence of vacancy defects in $3 \mathrm{C}$-SiC following neutron irradiation from 0.01 to $31 \mathrm{dpa}$ in the temperature range from 380 to $790^{\circ} \mathrm{C}$. The neutral and negatively charged vacancy clusters were identified and quantified. The results suggest that the vacancy defects that were measured by positron annihilation spectroscopy technique contribute very little to the transient swelling of SiC. In addition, coincidence Doppler broadening measurement was used to investigate the chemical identity surrounding the positron trapping sites. It was found that silicon vacancy-related defects dominate in the studied materials and the production of the antisite defect $\mathrm{C}_{\mathrm{Si}}$ may result in an increase in the probability of positron annihilation with silicon core electrons.

\section{High-resolution transmission electron microscopy of irradiation induced transformation [2]}

We observed that $\beta$-SiC, neutron irradiated to $9 \mathrm{dpa}$ at $\approx 1440^{\circ} \mathrm{C}$, began transforming to $\alpha$-SiC, with radiation-induced Frank dislocation loops serving as the apparent nucleation sites (Figure 25). $1440^{\circ} \mathrm{C}$ is a far lower temperature than usual for the $\beta \rightarrow \alpha$ phase transformation in SiC. SiC is considered for applications in advanced nuclear systems, as well as for electronic or spintronic applications requiring ion irradiation processing. The $\beta$-SiC preferred for nuclear applications, is metastable and undergoes a phase transformation at high temperatures (typically $2000^{\circ} \mathrm{C}$ and above). Nuclear reactor concepts are not expected to reach the very high temperatures for thermal transformation. However, our results indicate incipient $\beta \rightarrow \alpha$ phase transformation, in the form of small $(\sim 5-10 \mathrm{~nm})$ pockets of $\alpha$-SiC forming in the $\beta$ matrix. In service transformation could degrade structural stability and fuel integrity for SiC-based materials operated in this regime. However, engineering this transformation deliberately using ion irradiation could enable new electronic applications. 


\section{(3) High-resolution transmission electron microscopy on nanostructure of void [3]}

The equilibrium shapes of $6 \mathrm{H}-\mathrm{SiC}$ nanostructures and their surfaces, introduced in monocrystalline $6 \mathrm{H}$ SiC by high temperature neutron irradiation, were studied by analyzing nano-void ( $10 \mathrm{~nm})$ shapes using transmission electron microscopy. The nano-voids were determined to be irregular icosahedrons truncated with six $\{-1100\}$, twelve $\{-1103\}$, one smaller top-basal, and one larger bottom-basal planes, which suggests that $\{-1100\}$ and $\{-1103\}$ are the next stable surface class after the basal planes. The relatively frequent absence of the $\{-1100\}$ surface in the nano-voids indicated that the (-110-3) surface type is energetically rather stable. These non-basal surfaces were found not to be atomically flat due to the creation of nano facets with half unit-cell height in the c-axis. The $\{-1100\}$ and $\{-1103\}$ surfaces were classified as two and four face types according to their possible nano facets and surface termination, respectively. We also discuss the surface energy difference between the (-110-3) and (-1103) face types in relation to the energy balance within the equilibrium, but irregular, polyhedron, in which the $(-1103)$ surface had double the surface energy of the $(-110-3)$ surface $\left(\sim 3900 \mathrm{erg} / \mathrm{cm}^{2}\right)$.

\section{(4) High energy $x$-ray diffraction [4]}

The microstructural response of neutron irradiated 3C-SiC has been investigated over a wide irradiation temperature and fluence range via qualitative and quantitative synchrotron-based X-ray diffraction characterization. We identified several neutron fluence- and irradiation temperature-dependent changes in the microstructure, and directly highlighted the specific defects introduced through the course of irradiation. By quantifying the microstructure, we aim to develop a more detailed understanding of the radiation response of $\mathrm{SiC}$. Such studies are important to building mechanistic models of material performance and to understanding the susceptibility of various microstructures to radiation damage in advanced energy applications.

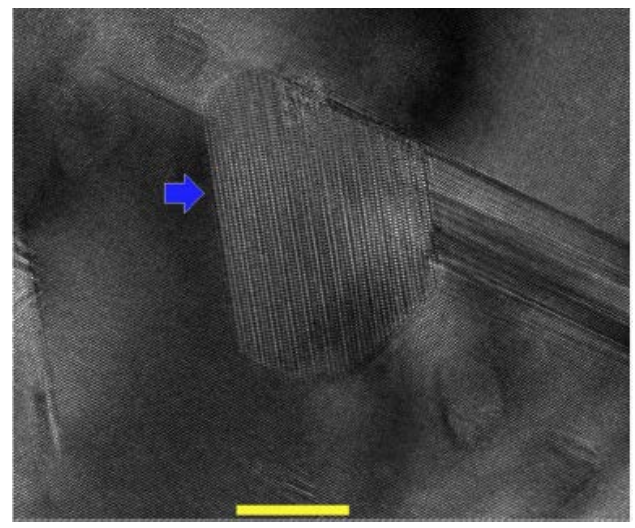

Figure 25. High resolution TEM image of neutron irradiated SiC on the [101] zone. Apparent second-phase precipitate, arrowed, was present. Most or all of these precipitates were located adjacent to a Frank loop (blue $\Rightarrow$ arrows). Scale bar is $10 \mathrm{~nm}$. 


\section{FUTURE PLANS}

More work will be conducted to characterize the atomistic radiation defects, using Raman spectroscopy and high energy x-ray diffraction. The focus will be chemistry (composition) of irradiation defects, which is poorly understood.

\section{REFERENCES}

[1] Xunxiang Hu, Takaaki Koyanagi, Yutai Katoh, Brian D. Wirth, "Positron annihilation spectroscopy investigation of vacancy defects in neutron-irradiated 3C-SiC," Physical Review B, 95 (2017) 104103.

[2] C.M. Parish, T. Koyanagi, S. Kondo, Y. Katoh, Irradiation-induced $\beta$ to $\alpha \mathrm{SiC}$ transformation at low temperature, Scientific Reports 7 (2017) 1198.

[3] S. Kondo, C.M. Parish, T. Koyanagi, Y. Katoh, Equilibrium shapes and surface selection of nanostructures in 6H-SiC, Applied Physics Letters 110 (2017) 142106.

[4] D.J. Sprouster, T. Koyanagi, E. Dooryhee, S.K. Ghose, Y. Katoh, L.E. Ecker, ”Microstructural evolution of neutron irradiated 3C-SiC,” Scripta Materialia 137, (2017) 132-136. 


\section{HIGH HEAT FLUX AND PLASMA FACING MATERIALS}

\subsection{FABRICATION OF FUNCTIONALLY GRADED TUNGSTEN STEEL LAMINATES}

Lauren Garrison (garrisonlm@ornl.gov), Y. Katoh, M. Norfolk (Fabrisonic LLC.), J. Wenning (Fabrisonic LLC.), J. Mettler (University of Illinois)

\section{OBJECTIVE}

The objective of this project is to create functionally graded tungsten to steel laminate composites for use in plasma facing components in fusion reactors.

\section{SUMMARY}

Tensile tests of the generation 1 roll bonded composite were completed and showed increasing strength and decreasing ductility with increased $\mathrm{W}$ content. A feasibility study for ultrasonic welding tungsten to steel was completed. 34 trials were completed that varied the parameters of foil thickness, interlayer material, welding force, vibration amplitude, and other welding parameters. Cross-sections were imaged of the six ultrasonic trials with partial or complete bonding to investigate the interface properties.

\section{PROGRESS AND STATUS}

\section{$\underline{\text { Roll bonded composite }}$}

In the generation 1 roll bonded composite, the thicknesses of $\mathrm{W}$ and steel foils were varied throughout the thickness of the composite to create a functionally graded composition (Figure 26). The bonding of the foils was accomplished by forging and rolling at $1000^{\circ} \mathrm{C}$ to $80 \%$ total thickness reduction. Tensile bars were machined with the tensile direction parallel to the rolling direction of the foils and composite.



Figure 26. Diagram of tungsten and steel foil stacking sequence before processing with corresponding cross section image of composite after processing. In the image on the right, tungsten layers have darker contrast than steel layers. 
The full, graded composite was machined into SSJ2 tensile bars such that each tensile bar primarily contained either 250, 100, or $25 \mu \mathrm{m}$ initial thickness $\mathrm{W}$ foils. These were tensile tested at room temperature with a crosshead speed of $.5 \mathrm{~mm} / \mathrm{sec}$ (Figure 27). The samples are identified according to the thickness of the tungsten foil used to produce the sample, with W250-1, for example, representing the first sample tested which was produced using $250 \mu \mathrm{m}$ thick tungsten foil (the top section in Figure 26). Five samples of each type were tested, and tests which ended in a brittle fracture are excluded from Figure 27. The elastic extension in the data has been removed due to the lack of an extensometer.

Samples consisting of thicker tungsten layers exhibit a greater ultimate tensile strength and higher likelihood of brittle failure than those with a larger fraction of steel, as expected. A much larger variability was observed in the samples consisting of mostly steel. This is likely because the tungsten layers in these samples fragmented during production and no longer formed continuous layers, as seen in the lower region of Figure 26. This resulted in uneven, tearing tensile fractures rather than clean breaks as was observed in other sample types. The two lines depicting "Steel Foil” and "Tungsten Foil” in Figure 27 represent the results of testing the $250 \mu \mathrm{m}$ steel and tungsten foils individually.



Figure 27. Stress-strain relationship in the generation 1 tungsten-steel composite. The elastic extension has been removed from the data, so only the plastic strain is shown and the initial part of the curve is represented as a vertical line.

\section{Ultrasonic welded composite}

An initial investigation of the feasibility of producing composites using ultrasonic bonding was completed with the company Fabrisonic, which specializes in ultrasonic welding of dissimilar materials. Tungsten foils with thickness $250 \mu \mathrm{m}, 100 \mu \mathrm{m}$, and $25 \mu \mathrm{m}$ were used in the trials. Interlayer materials of aluminum and copper were used, and two different baseplates were used in the trials, a C1020 carbon steel baseplate and an aluminum alloy 6061T6 baseplate. The baseplate and interlayer materials were chosen based on Fabrisonics successful bonds in the past. If feasibility of bonding tungsten can be shown, the interlayer and baseplate materials could be expanded to include fusion specific alloys.

Overall, 34 trials were completed that varied the parameters of foil thickness, interlayer material, welding force, vibration amplitude, and other welding parameters. Six of the trials that showed at least partial bonding success were selected for more in depth interface analysis. Small sub-sections of the selected trial joints were machined by electro-discharge machining and then mechanically polished for interface 
analysis. An example interface analysis is shown in Figure 28 and Figure 29 for the W foil directly bonded to the C1020 carbon steel baseplate without an interlayer. Cracks within the $\mathrm{W}$ foil can be seen in Figure 28, and this was a common feature for all of the $\mathrm{W}$ foil layers after ultrasonic bonding. EDS analysis revealed a sharp boundary between the $\mathrm{W}$ and steel layers (Figure 29). This was expected because the ultrasonic bonding is a rapid, low temperature bonding method.
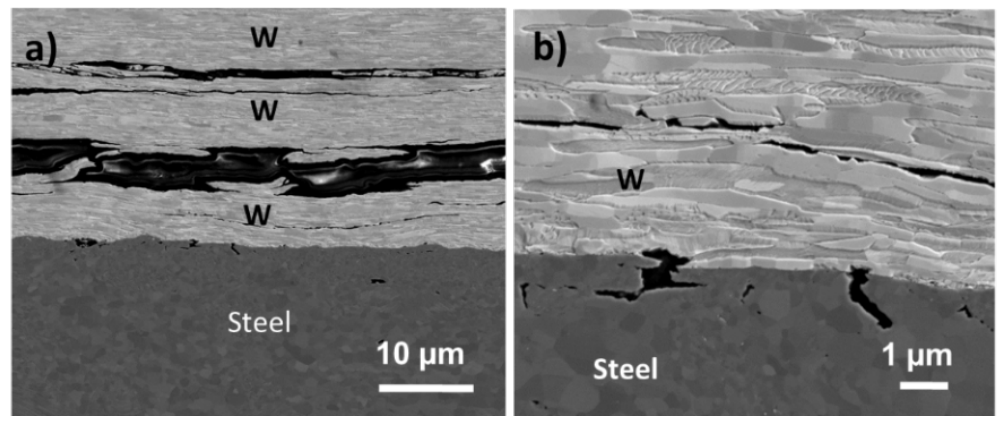

Figure 28. Cross section SEM image of ultrasonically bonded tungsten-steel composite, a) low magnification view showing multiple cracks in the $\mathrm{W}$ foil layer, b) example area with a good $\mathrm{W}$ to steel bond, but again with cracking in the $\mathrm{W}$ foil.


Figure 29. EDS result of sample W-steel interface with no interlayer.

\section{FUTURE PLANS}

Shear punch data collected on the generation $1 \mathrm{~W}$-steel roll bonded composite will be analyzed and compared with the tensile data to generate a correlation between the two. Options to reduce the W foil internal cracking during ultrasonic welding are being investigated. 


\subsection{TUNGSTEN/SiC AND TUNGSTEN/GRAPHITE JOINING}

\section{Lauren Garrison (garrisonlm@ornl.gov), Yutai Katoh, Emily Proehl, Paul Menchhofer}

\section{OBJECTIVE}

The objective of this project is to fabricate thin tungsten layers bonded to graphite and $\mathrm{SiC}$ substrates that will provide a significant reduction in neutron activated volume compared to standard $6 \mathrm{~mm}$ discs, allowing rapid PIE screening tests.

\section{SUMMARY}

Thin tungsten foils, $25 \mu \mathrm{m}$ thick, were joined to graphite and $\mathrm{SiC}$ using hot pressing. Initial results showed that the W-graphite bond was weak but the W-SiC bonding was successful. SEM cross sectional analysis did not show any noticeable reaction layer between the $\mathrm{W}$ and $\mathrm{SiC}$. The $\mathrm{W}$-SiC bond failed when the joined material was sectioned.

\section{PROGRESS AND STATUS}

Tungsten becomes highly activated by neutron irradiation in HFIR and takes an estimated three years cooling time before standard size samples can be accepted in LAMDA for post irradiation examination (PIE). Certain PIE activities such as microstructural analysis and permeation testing only require a small volume of material. By joining a thin layer of tungsten onto a substrate of graphite or SiC, the activated tungsten volume is significantly reduced, and the substrate provides the necessary structural support for handling and clamping the sample while contributing little to the total radioactivity.

Graphite and SiC substrate material $2 \mathrm{~mm}$ thick was machined. Tungsten foils of thicknesses $25 \mu \mathrm{m}$ were purchased from ESPI Metals. In the first joining trial, the foils and substrate materials were joined by hot pressing at $1300^{\circ} \mathrm{C}$ and $10 \mathrm{MPa}$ in a vacuum furnace. Boron nitride was used to prevent bonding between the top of the tungsten foil and the graphite used in the press. The $\mathrm{W}$ foil was only weakly bonded to the graphite substrate, and it de-bonded when the material was sectioned. The $\mathrm{W}$ foil was bonded successfully to a SiC substrate. The cross section image of the $\mathrm{W}$-SiC joined material is shown in Figure 30. The interface between the tungsten and $\mathrm{SiC}$ is relatively smooth with few gaps or pores visible.

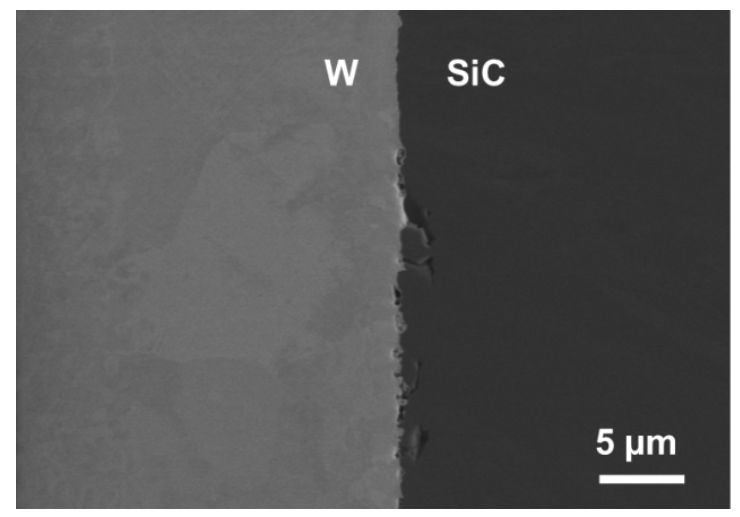

Figure 30. Hot pressed joint between tungsten and silicon carbide. 
For the second joining trial, two additional samples of W-SiC were fabricated. Each joined sample consisted of a square sample of $\mathrm{SiC}$ with a $19 \mathrm{~mm}$ edge length and $5 \mathrm{~mm}$ thickness as the substrate and a $\mathrm{W}$ foil with $25 \mathrm{~mm}$ edge length and $25 \mu \mathrm{m}$ thickness. The joining was accomplished through hot pressing at $10 \mathrm{MPa}$ at $1300^{\circ} \mathrm{C}$ with a 30 minute ramp time and one hour hold time. A graphite foil was used to avoid the tungsten foil sticking to the press ram. Despite the appearance of a successful W-SiC bond, some of the $\mathrm{W}$ de-bonded during handling (Figure 31a) and further de-bonding occurred when the material was sectioned (Figure 31b).

\section{a)}

b)
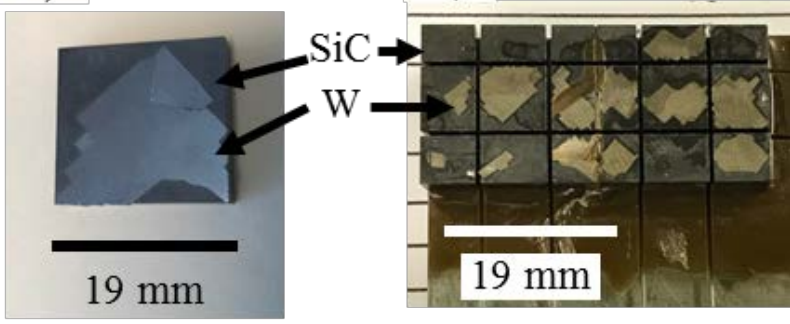

Figure 31. a) W-SiC joined square after handling. b) two W-SiC joined squares after sectioning.

\section{FUTURE PLANS}

Elemental analysis will be completed to determine thickness of the reaction layer. The hot pressing parameters will be varied to attempt to create a stronger bond between the $\mathrm{W}$ and $\mathrm{SiC}$. 


\title{
4.3 MICROSTRUCTURE EVOLUTION OF TUNGSTEN IRRADIATED IN A MIXED NEUTRON ENERGY SPECTRUM
}

\author{
X. Hu (hux1@ornl.gov), T. Koyanagi, C.M. Parish, T. Y. Katoh
}

\section{OBJECTIVE}

This report describes the post irradiation examination activities of pure tungsten subjected to neutron exposure in HFIR. The overarching objective is to capture the irradiation temperature and dose dependence of the microstructure and the resultant mechanical and physical properties of tungsten.

\section{SUMMARY}

Microstructures of single crystal bulk tungsten (W) and polycrystalline W foil with a high degree of crystallographic texture were investigated using transmission electron microscopy, tensile tests, and hardness tests following neutron irradiations at $90-800^{\circ} \mathrm{C}$ to $0.03-4.6 \mathrm{dpa}$ in the HFIR mixed neutron energy spectrum. Dominant irradiation created defects were dislocation loops and small clusters at $90^{\circ} \mathrm{C}$. In addition voids were formed in $\mathrm{W}$ irradiated above $460^{\circ} \mathrm{C}$. Voids and precipitates attributed to transmutation-produced elements Re and Os were dominant defects above $\sim 1$ dpa. Transmutation induced precipitation was investigated in more details by characterizing the crystal structure, chemical composition and phases of the W-Re-Os precipitates in selected polycrystalline tungsten samples.

\section{PROGRESS AND STATUS}

\section{Microstructure of tungsten neutron irradiated in a mixed energy spectru}

Microstructures of single-crystal bulk tungsten (W) and polycrystalline $\mathrm{W}$ foil with a strong grain texture were investigated using transmission electron microscopy following neutron irradiation at $\sim 90 \sim 800^{\circ} \mathrm{C}$ to $0.03 \sim 4.6$ displacements per atom (dpa) in the HFIR mixed neutron energy spectrum. The dominant irradiation defects were dislocation loops and small clusters at $\sim 90^{\circ} \mathrm{C}$. In addition voids were formed in $\mathrm{W}$ irradiated above $460^{\circ} \mathrm{C}$. Voids and precipitates involving transmutation-produced rhenium and osmium were the dominant defects above $\sim 1$ dpa. We found a new phenomenon of microstructural evolution in irradiated polycrystalline W: Re- and Os-rich precipitation along grain boundaries. Comparison of results between this study and previous studies using different irradiation facilities revealed that the microstructural evolution of $\mathrm{W}$ is highly dependent on the neutron energy spectrum in addition to the dependence on irradiation temperature and dose.

\section{Precipitation of transmutant elements in neutron irradiated tungsten}

We have used advanced electron microscopy methods to explore the response of tungsten to high dose neutron irradiation in HFIR, focusing on the detailed characterization of irradiation-induced W-Re-Os precipitates in polycrystalline tungsten through TEM, X-ray mapping in STEM, and multivariate statistical analysis data-mining of the X-ray data. The association of voids and precipitates, the chemical compositions, crystal structures and phases of precipitates along the grain boundary and within the grains were identified. The results showed that the intra-granular precipitates are (Re,Os) ${ }_{2} \mathrm{~W}$ Laves and a strong association of voids and precipitates was observed. More details can be found in the Fusion Materials Semiannual Report, Vol. 62 for the period ending June 30, 2017. 


\section{FUTURE PLANS}

More work will be conducted to characterize the microstructure, physical and mechanical properties of tungsten following neutron irradiation. 


\subsection{NEUTRON IRRADIATION EFFECTS IN TUNGSTEN}

Lauren Garrison (garrisonlm@ornl.gov), Y. Katoh, T. Koyanagi, M. McAlister, T. Hwang (Tohoku University), M. Fukuda (Tohoku U.), L. L. Snead (Stony Brook U.), T. S. Byun (PNNL)

\section{OBJECTIVE}

The objective of this work is to evaluate the effects of neutron irradiation on the mechanical properties and microstructure of tungsten-based materials to aid in developing plasma-facing materials for fusion reactors.

\section{SUMMARY}

Single crystal tungsten irradiated in the TITAN program have been tensile tested and show an initial increase in strength followed by a decrease in strength with increasing dose. Tungsten foils are considered as an option for fabricating tungsten composites, so their mechanical properties were evaluated before and after neutron irradiation with three point bend and shear punch tests.

\section{PROGRESS AND STATUS}

Figure 32 shows the UTS of single crystal tungsten samples tensile tested at room temperature. All tests showed brittle fractures, so the ultimate tensile stress (UTS) is also the fracture stress. Samples that broke in handling are represented on the figure as having zero strength at fracture. This is intended to illustrate the increasing fragility of the material with increasing dose. Both orientations of single crystal tungsten experienced irradiation hardening at the lowest dose tested, $0.004 \mathrm{dpa}$. Both orientations also have a peak UTS at $0.02 \mathrm{dpa}$. Above $0.02 \mathrm{dpa}$, the UTS steadily decreases until at $1.8 \mathrm{dpa}$ all four of the irradiated samples (two each of $\langle 110>$ and $<100>$ ) were broken in handling. TEM and atom probe analysis of these materials showed that the transmutation-produced Re and Os cluster and form precipitates as the dose increases. It is believed that these clusters and precipitates play an important role in the strength increase and loss of toughness of irradiated tungsten.



Figure 32. Fracture strength (ultimate tensile strength) for tungsten with crystal orientation $<110>$ and $<\mathbf{1 0 0}>$ along the tensile axis. All tests were performed at room temperature and each data point represents one test.

Three point bend tests were performed on selected irradiated wrought and annealed tungsten foils (Figure 33). The wrought foil retains bend ductility after irradiation to $0.1 \mathrm{dpa}$ at $90^{\circ} \mathrm{C}$, but the annealed foil irradiated to the same conditions had a brittle failure. Both the wrought foil and annealed foil bend tested after irradiation to $2.9 \mathrm{dpa}$ at $580^{\circ} \mathrm{C}$ had brittle failure. 


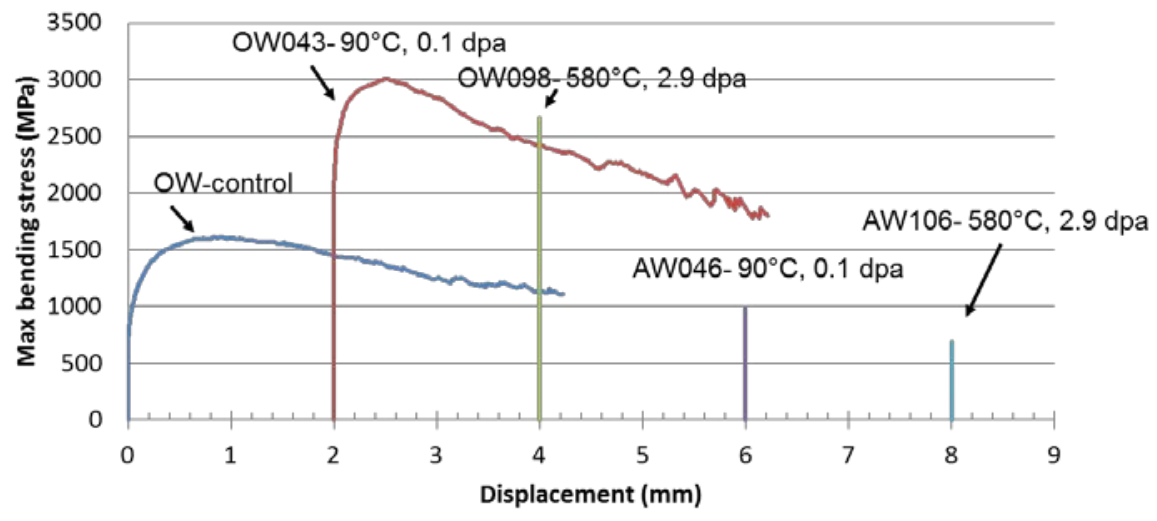

Figure 33. Three point bend test data at $22^{\circ} \mathrm{C}$ for selected wrought tungsten foils (OW) and annealed tungsten foils (AW). Data is placed with an arbitrary offset on the $x$-axis.

The wrought foil has voids and a high density of Re and Os rich precipitates after neutron irradiation at $\sim 800^{\circ} \mathrm{C}$ to $1.5 \mathrm{dpa}$ (Figure 34). Some, but not all, grain boundaries have a narrow, less than $100 \mathrm{~nm}$, zoned denuded of precipitates. The foil that was annealed before neutron irradiation does not show visible voids in the imaged area of Figure 34. The shape and size of precipitates in the annealed foil is approximately the same as in the wrought foil. A denuded zone is not visible near the one grain boundary that was imaged in the annealed foil, but because of the low density of grain boundaries, a representative analysis of many grain boundaries was not done. For both wrought and annealed foils, the precipitates contribute significantly to the hardening and loss of shear and bend ductility after irradiation.

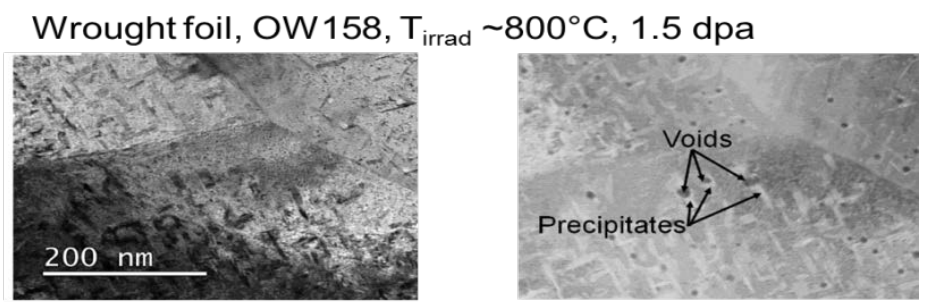

BF image

HAADF image

Annealed foil, AW106, $\mathrm{T}_{\text {irrad }}=580^{\circ} \mathrm{C}, 2.9 \mathrm{dpa}$

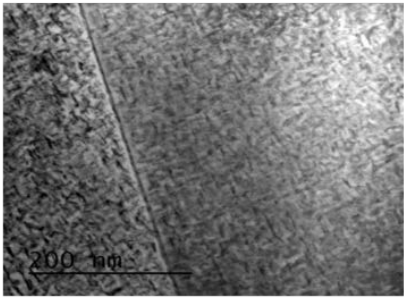

BF image

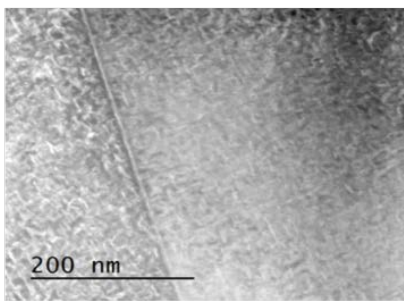

HAADF image

Figure 34. TEM microstructure bright field (BF) and high angle annular dark field (HAADF) images of wrought foil and annealed foils after neutron irradiation.

\section{FUTURE PLANS}

Tungsten foils irradiated to higher doses will be mechanically tested. 


\title{
4.5 NEUTRON IRRADIATION EFFECTS IN TUNGSTEN-COPPER COMPOSITES
}

\author{
Lauren Garrison (garrisonlm@ornl.gov), Yutai Katoh, Lance Snead (Stony Brook University)
}

\section{OBJECTIVE}

The aim of this work is to evaluate tungsten-copper composites for potential use in plasma-facing components for future fusion reactors.

\section{SUMMARY}

As part of the US-Japan TITAN program, a powder sintered tungsten-copper composite was irradiated in HFIR at temperatures from 300 to $900^{\circ} \mathrm{C}$ and fast neutron fluences of 0.01 to $20 \times 10^{25} \mathrm{n} / \mathrm{m}^{2} \quad(\mathrm{E}>0.1$ $\mathrm{MeV}$ ) (0.002 to $4 \mathrm{dpa}$ in tungsten). Tensile tests of the un-irradiated and irradiated tungsten-copper sintered composite have been completed. The powder sintered composite had greater elongation at the highest dose tested than either the tungsten-copper laminated composite or the single crystal tungsten previously tested.

\section{PROGRESS AND STATUS}

As an alternative to the tungsten-copper laminate composite, a powder sintered tungsten copper composite (material irradiation code KW) with 75 wt.\% W and 25 wt.\% Cu was investigated. This material was produced by Mi-Tech Metals Inc. Tungsten, Indianapolis. A polished surface of one of the KW composites is shown in Figure 35. There are sharp boundaries between the rounded W particles and the $\mathrm{Cu}$. As expected, no intermetallic or mixed phase formed between the elements.

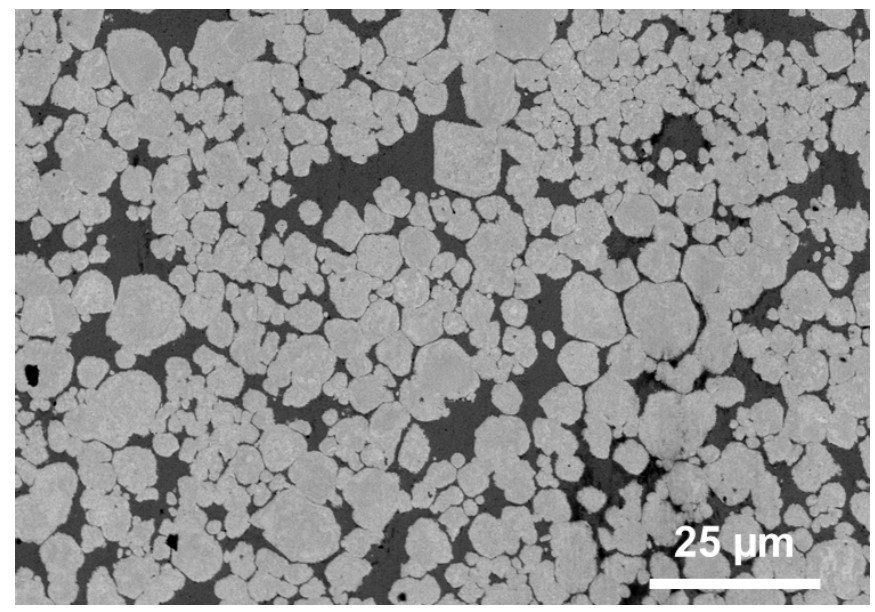

Figure 35. SEM image of the powder sintered tungsten copper composite.

The irradiated powder sintered tungsten-copper composite, single crystal tungsten, and the tungstencopper laminate materials had different trends of total elongation (TE) for $22^{\circ} \mathrm{C}$ tensile tests (Figure 36). Both crystal orientations of single crystal tungsten had brittle failure or very limited plastic deformation for all tested doses. The maximum TE observed for any of the single crystal tungsten was $0.5 \%$. The SW laminate composite initially had a greater TE than the other materials but the TE rapidly decreased with increasing dose. At 0.1 dpa the tungsten-copper laminate had 1\% TE and for doses higher than 0.1 there was no measurable plastic deformation. In contrast, the KW powder sintered composite is more 
consistent and TE remains above 5\% through $0.1 \mathrm{dpa}$. At the highest dose tested of $1.8 \mathrm{dpa}$, the KW composite still retains $1 \%$ TE.

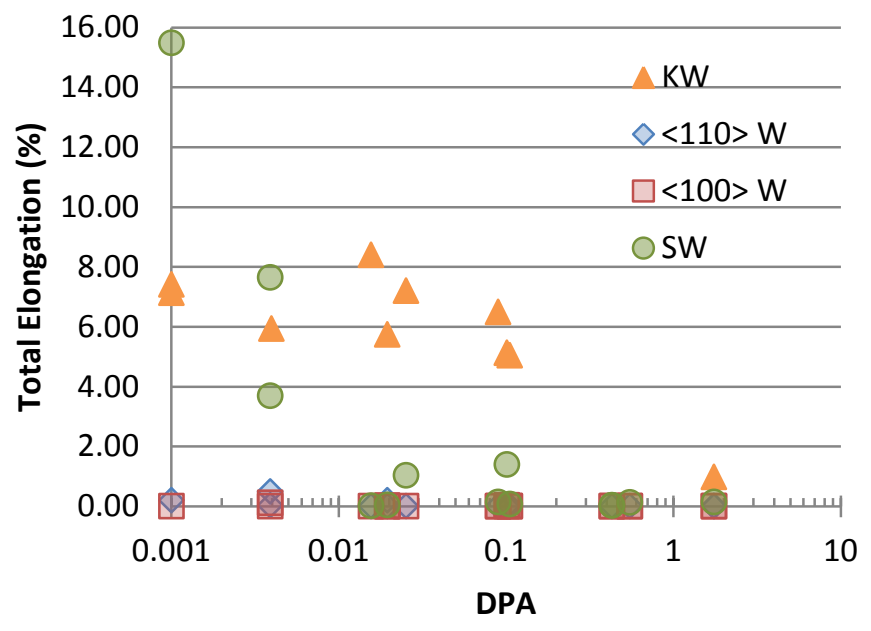

Figure 36. Total elongation comparison for the tungsten-copper particle composite (KW), two orientations of single crystal tungsten, and the tungsten-copper laminate composite (SW), all tensile tested at $22^{\circ} \mathrm{C}$.

\section{FUTURE PLANS}

Elevated temperature tensile tests will be conducted on the powder sintered composite. 


\title{
4.6 MICROSTRUCTURE AND MECHANICAL PROPERTIES OF TUNGSTEN IN THE PHENIX COLLABORATION IRRADIATION
}

\author{
Lauren Garrison (garrisonlm@ornl.gov), Y. Katoh, N. Reid, E. Proehl, M. Fukuda (Tohoku University)
}

\section{OBJECTIVE}

The PHENIX collaboration task on the irradiation of tungsten aims to expand the database on neutron irradiation effects in tungsten materials.

\section{SUMMARY}

Hardness tests, room temperature tensile tests, and microstructural analysis have been completed on the un-irradiated control materials for the PHENIX RB*19J irradiation experiment. Almost all the varieties of polycrystalline tungsten have higher hardness and higher fracture strength than the single crystal tungsten. All tungsten materials had brittle failures in room temperature tensile tests.

\section{PROGRESS AND STATUS}

The PHENIX US-Japan collaboration has a goal of investigating tungsten for use in future fusion reactors. For this potential use, more information is needed on the tungsten response to neutron irradiation at fusion relevant conditions. To investigate this, the PHENIX collaboration prepared over 1500 tungsten samples to go into the RB*19J capsule for HFIR irradiation. Tests are underway to evaluate the control tungsten materials. Many of the room temperature tensile, hardness, and equibiaxial flexure tests have been completed.

For the PHENIX US side materials, several varieties of single and polycrystalline tungsten were selected (Table 6). The materials are identified by a unique two symbol code for the RB*19J irradiation, which is also used here for tracking the many material varieties.

Vickers micro hardness tests were conducted on both single crystal and polycrystalline tungsten samples, using five indents, with each indent at $1000 \mathrm{~g}$ with a dwell time of 10 seconds. The average hardness values are given in Figure 37 with error bars giving the standard deviations. Polycrystalline tungsten (PCW) samples had higher hardness values than single crystal tungsten. The $\mathrm{W}$ foil had the highest micro hardness of all tested materials.

Unirradiated, control tungsten SSJ2 tensile specimens were tested at room temperature on the MTS load frame in LAMDA laboratory with a strain rate of $2 \% \cdot \mathrm{min}^{-1}$ (Figure 38). One sample of each material type was tested. As expected, all fractures were brittle, with single crystal tungsten showing some elongation, but no more than $1 \%$. 
Table 6. The material codes and descriptions for the US materials in the PHENIX RB*19J capsule

\begin{tabular}{|c|c|c|}
\hline $\begin{array}{l}\text { Material } \\
\text { Code }\end{array}$ & Short Name & Description \\
\hline FR & AA plate & Polycrystalline tungsten plate purchased from Alfa Aesar \\
\hline$\overline{\mathrm{GE}}$ & $\begin{array}{l}\text { AA plate } \\
\text { tensile A }\end{array}$ & $\begin{array}{l}\text { Polycrystalline tungsten plate purchased from Alfa Aesar. Tensile bars cut in } \\
\text { direction "A". }\end{array}$ \\
\hline $3 \mathrm{E}$ & $\begin{array}{l}\text { AA plate } \\
\text { tensile B }\end{array}$ & $\begin{array}{l}\text { Polycrystalline tungsten plate purchased from Alfa Aesar. Tensile bars cut in } \\
\text { direction "B". }\end{array}$ \\
\hline EE & $\begin{array}{ll}\text { AA } & 2 \mathrm{~mm} \\
\text { foil } & \\
\end{array}$ & Polycrystalline tungsten purchased from Alfa Aesar as a $2 \mathrm{~mm}$ thick foil \\
\hline TE & SCW-100 & $\begin{array}{l}\text { Single crystal tungsten, produced as a cylinder with }<100>\text { as the direction } \\
\text { along the axis by Goodfellow }\end{array}$ \\
\hline$\overline{\mathrm{UE}}$ & SCW-110 & $\begin{array}{l}\text { Single crystal tungsten, produced as a cylinder with }<110>\text { as the direction } \\
\text { along the axis by Goodfellow }\end{array}$ \\
\hline GW & $\begin{array}{ll}\text { SCW } & 110 \\
\text { GW }\end{array}$ & $\begin{array}{l}\text { Single crystal tungsten produced as a cylinder with }<110>\text { as the direction } \\
\text { along the axis by Goodfellow, different batch than "SCW-110" material }\end{array}$ \\
\hline $\mathrm{RW}$ & $\begin{array}{ll}\text { SCW } & 100 \\
\text { RW } & \\
\end{array}$ & $\begin{array}{l}\text { Single crystal tungsten produced as a cylinder with }<100>\text { as the direction } \\
\text { along the axis by Goodfellow, different batch than "SCW-100" material }\end{array}$ \\
\hline KE & W-0\%Re & $\begin{array}{l}\text { Polycrystalline tungsten reference material with no added Re fabricated by arc } \\
\text { melting at ORNL, measured Re content is approximately } 0.04 \%\end{array}$ \\
\hline $3 \mathrm{R}$ & W-0.4\%Re & $\begin{array}{l}\text { Polycrystalline tungsten with added Re fabricated by arc melting at ORNL, } \\
\text { measured Re content is approximately } 0.4 \%\end{array}$ \\
\hline $5 \mathrm{E}$ & $\mathrm{W}-2.2 \% \operatorname{Re}$ & $\begin{array}{l}\text { Polycrystalline tungsten with added Re fabricated by arc melting at ORNL, } \\
\text { measured Re content is approximately } 2.2 \%\end{array}$ \\
\hline$\overline{\mathrm{RE}}$ & $\begin{array}{ll}\begin{array}{l}\text { Rolled } \\
\text { foil }\end{array} & \text { W } \\
\end{array}$ & The foil was purchased from ESPI metals as a $0.25 \mathrm{~mm}$ thick sheet. \\
\hline$\overline{\mathrm{AT}}$ & $\begin{array}{l}\text { Thick plate } \\
\text { A }\end{array}$ & $\begin{array}{l}\text { Thick plate W, nominally "ITER grade” polycrystalline tungsten. Samples } \\
\text { were machined with various orientations relative to the anisotropic grains }\end{array}$ \\
\hline $\mathrm{BT}$ & $\begin{array}{l}\text { Thick plate } \\
\text { B }\end{array}$ & $\begin{array}{l}\text { Thick plate W, nominally "ITER grade” polycrystalline tungsten. Samples } \\
\text { were machined with various orientations relative to the anisotropic grains }\end{array}$ \\
\hline$\overline{\mathrm{CT}}$ & $\begin{array}{l}\text { Thick plate } \\
\text { C }\end{array}$ & $\begin{array}{l}\text { Thick plate W, nominally "ITER grade" polycrystalline tungsten. Samples } \\
\text { were machined with various orientations relative to the anisotropic grains }\end{array}$ \\
\hline$\overline{\mathrm{ZE}}$ & W PIM & $\begin{array}{l}\text { Tungsten was fabricated at Karlsruhe Institute of Technology by powder } \\
\text { injection molding }\end{array}$ \\
\hline $8 \mathrm{E}$ & W TiC & $\begin{array}{l}\text { Tungsten with TiC particle additions was fabricated at Karlsruhe Institute of } \\
\text { Technology }\end{array}$ \\
\hline
\end{tabular}




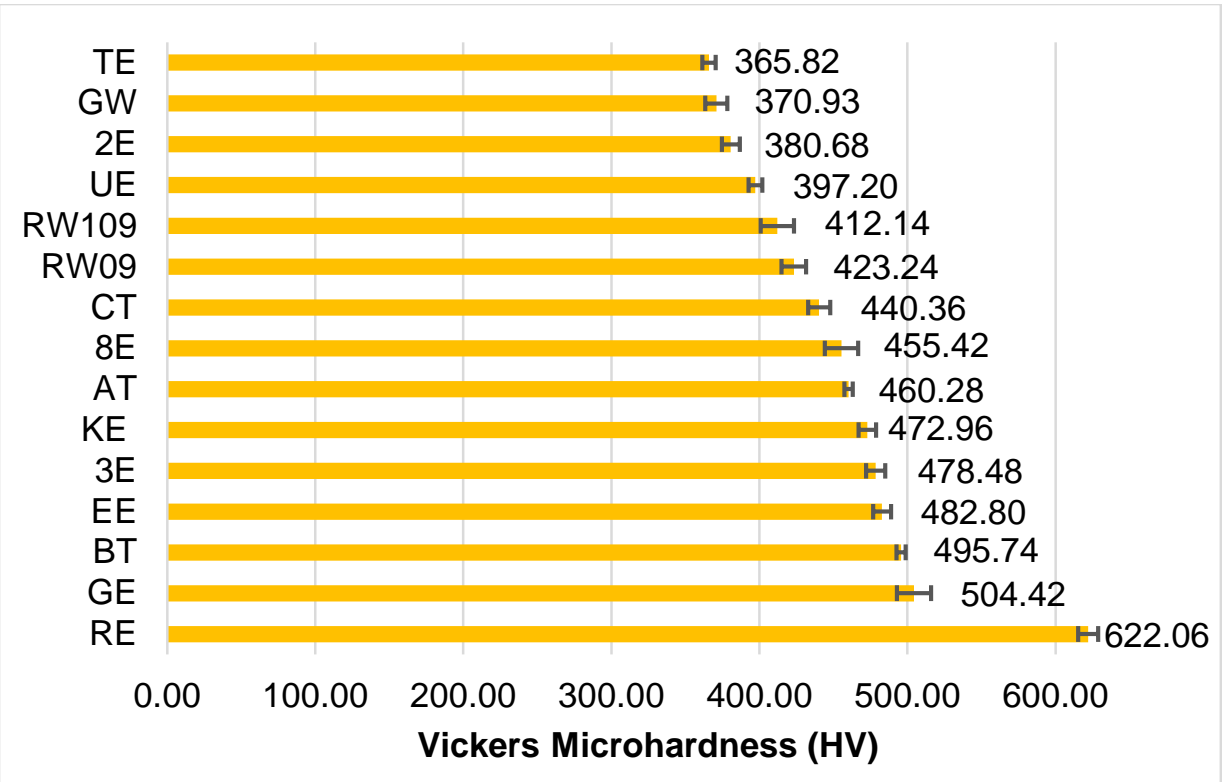

Figure 37. Vickers microhardness of single crystal and polycrystalline tungsten samples.

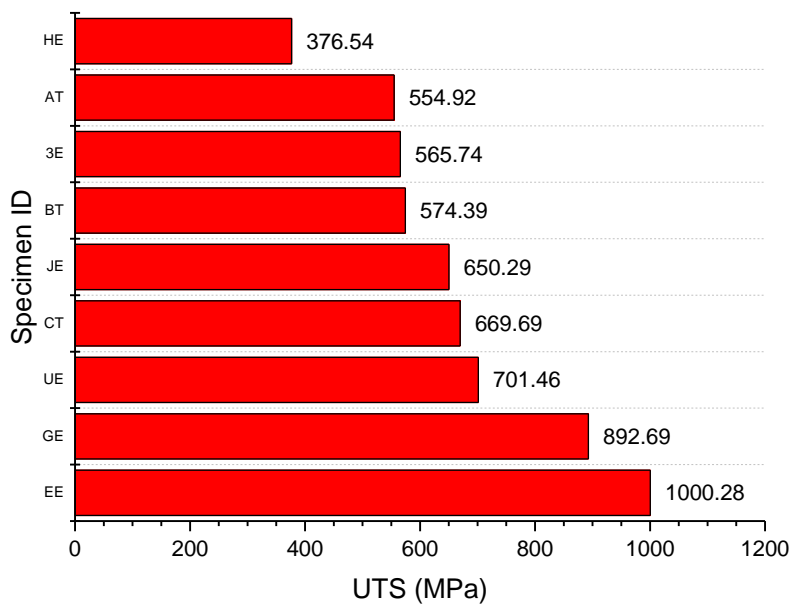

Figure 38. Ultimate tensile strength of tungsten control materials at $22^{\circ} \mathrm{C}$ and a strain rate of $2 \% / \mathrm{min}$.

\section{FUTURE PLANS}

Analysis of the equibiaxial flexure tests is underway. Electron backscatter diffraction analysis will be completed on each of the different microstructures. Elevated tensile tests will be completed. 


\title{
5. PLASMA MATERIALS INTERACTIONS
}

\subsection{DAMAGE-MECHANISM INTERACTIONS AT THE PLASMA-MATERIALS INTERFACE}

\author{
C. M. Parish (parishcm@ornl.gov), K. Wang
}

\section{OBJECTIVE}

The overarching objective of this work is to bridge the gap between the atomistic knowledge and models and the phenomenological materials science underlying the design, fabrication, and service of divertors and other plasma-facing materials for magnetic confinement fusion. Specifically, the influence of intrinsic defects (dislocations, grain boundaries) and extrinsic defects (ion- and neutron-irradiation damage, impurities) interactions with helium and bubbles, in terms of nucleation sites, growth, trapping, and surface degradation, will be measured.

\section{SUMMARY}

This year, three primary thrusts have been underway. First, and necessary to accomplish the other two, we have engaged in electron microscopy technique development in order to improve our abilities to characterize helium-plasma and radiation damage in tungsten. Second, helium plasma and ion beam exposures under different conditions - particularly particle flux - have been performed and examined. Third, tungsten damaged by both neutron and ion irradiation have been examined in order to determine the microstructural details present in the damaged structures. This report will briefly discuss new microscopy technique developments and the fusion-specific experiments enabled thereby.

\section{PROGRESS AND STATUS}

A number of advances in microscopy techniques have been implemented this year. For instance, highresolution analysis of the substrate/tendril interface in tungsten "nanofuzz" is very difficult to perform, due to difficulties in focused ion beam (FIB) fabrication of TEM specimens. We determined that electrodeposition of copper onto the fuzzy mat protects the features of interest during sample preparation, and this has enabled evaluation of the statistical distribution of substrate/tendril grain boundaries, for comparison to the tendril/tendril grain boundary character distributions. Figure 39 illustrates sample preparation considerations for high-resolution analysis, such as by transmission Kikuchi diffraction (tKD) of the substrate/tendril interface, and Figure 40 compares the substrate/tendril, tendril/tendril, and substrate/substrate grain boundary character distributions. Because the substrate/tendril and tendril/tendril grain boundary character distributions are generally similar, we infer it may be possible that the tendril/tendril interfaces were at one point substrate/tendril interfaces, implying that the tendrils are pushed up by the tendril growth (or left behind as the surface recedes), and new substrate/tendril interfaces reform periodically as growth proceeds. This has been in collaboration with UC-San Diego PISCES laboratory, and the sample in Figure 39 and Figure 40 is tungsten, exposed at $900^{\circ} \mathrm{C}$ in PISCESA to a flux of $\sim 10^{23} \mathrm{He} / \mathrm{m}^{2}$ sec and a fluence of $\sim 4 \times 10^{26} \mathrm{He} / \mathrm{m}^{2}$. 



Figure 39. (a) SEM image of a copper-deposited, FIB-prepared thin foil for transmission Kikuchi diffraction. (b) Proper sample mounting for tKD analysis. (c) Improper sample mounting.

Substrate / tendril boundaries
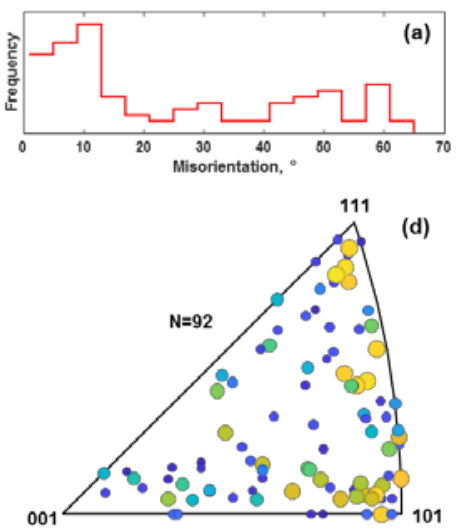

Tendril / tendril boundaries

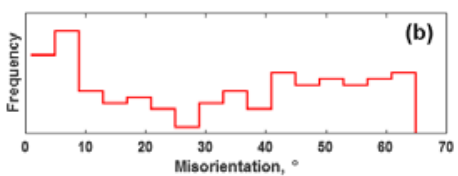

(e)



Substrate/ substrate boundaries

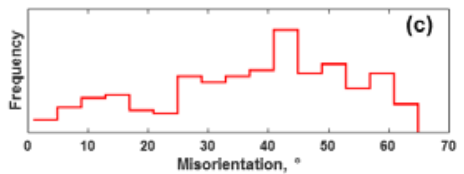

(f)

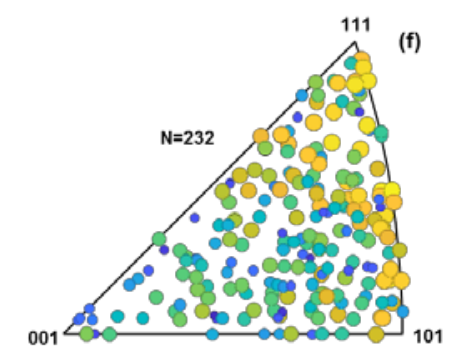

Figure 40. Grain boundary misorientation histograms (a-c) and grain boundary misorientation axis/angle distributions (d-e) for PISCES-grown nanotendril fuzz. 
In addition to the experiments on plasma-surface interactions, we have also investigated radiation damage (both ion and neutron) in tungsten. Due to the rapid transmutation ( $\mathrm{W} \rightarrow \mathrm{Re} \rightarrow \mathrm{Os}$ ) in HFIR-irradiated tungsten, copious precipitation occurs even at modest doses and temperatures. As an example, tungsten specimen 0W158 $\left(\sim 800^{\circ} \mathrm{C}, \sim 2-3 \mathrm{dpa}\right)$ was examined using TEM. Due to the significant radiation damage and complex precipitation structures, analysis of the phases of the precipitates is complex and cannot be performed with high confidence using traditional data analysis methods. We are currently developing computer-assisted data analytics means to extract diffractogram data from the different phases present in a high-resolution TEM. This is illustrated schematically in Figure 41, where local fast Fourier transforms (FFTs) are extracted from a single HREM image and stored similarly to the way an X-ray spectrum image is stored, although in this case, because a 2D dataset (the FFT) is stored at each real-space location, we are creating a hyperimage. Conceptually, this is similar to an electron backscatter diffraction dataset, in that two-dimensional diffraction patterns are present at each spatially resolved point.

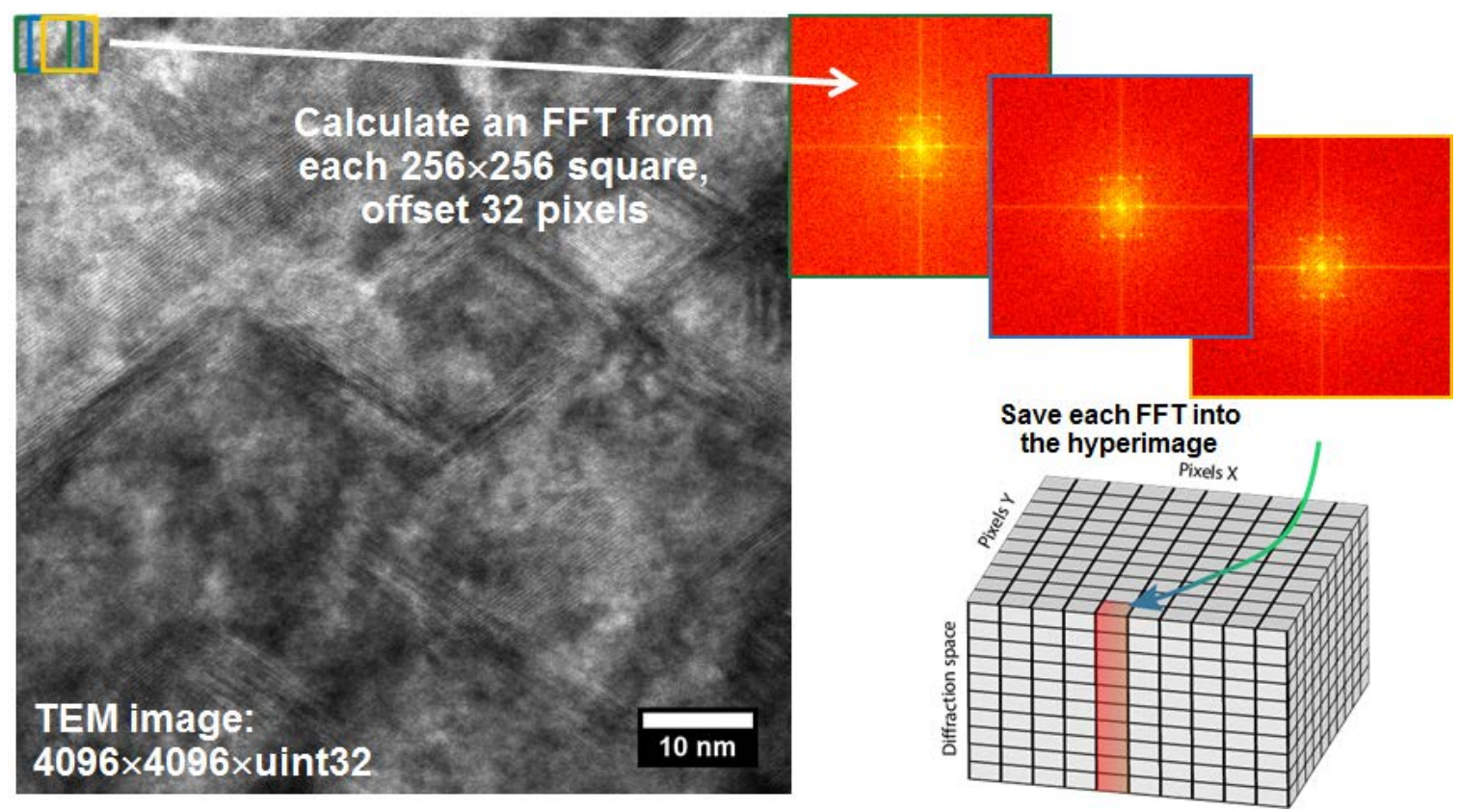

Figure 41. An HRTEM image of neutron irradiated tungsten; many defects, such as precipitates, are visible. Schematically illustrated is a method to create a hyperimage from localized fast Fourier transforms (FFTs) of the HRTEM image.

Attempting to analyze individual local FFT diffractograms by hand is subject to significant errors. First, because features overlap within the thickness of the TEM foil, diffractograms will often be complicated by overlapping patterns. Second, diffuse features (such as weak ordering) may not be visible in a given region, but could become apparent when signal from multiple regions is aggregated. Deconvolution and signal aggregation are the primary reasons to use unsupervised signal unmixing methods, such as singular value decomposition. An early attempt of this analysis (specifically, singular value decomposition of the base-10 logarithm of the hyperimage, followed by Varimax rotation of the basis to maximize spatial contrast and relax orthogonality in diffraction space) is shown in Figure 42. 

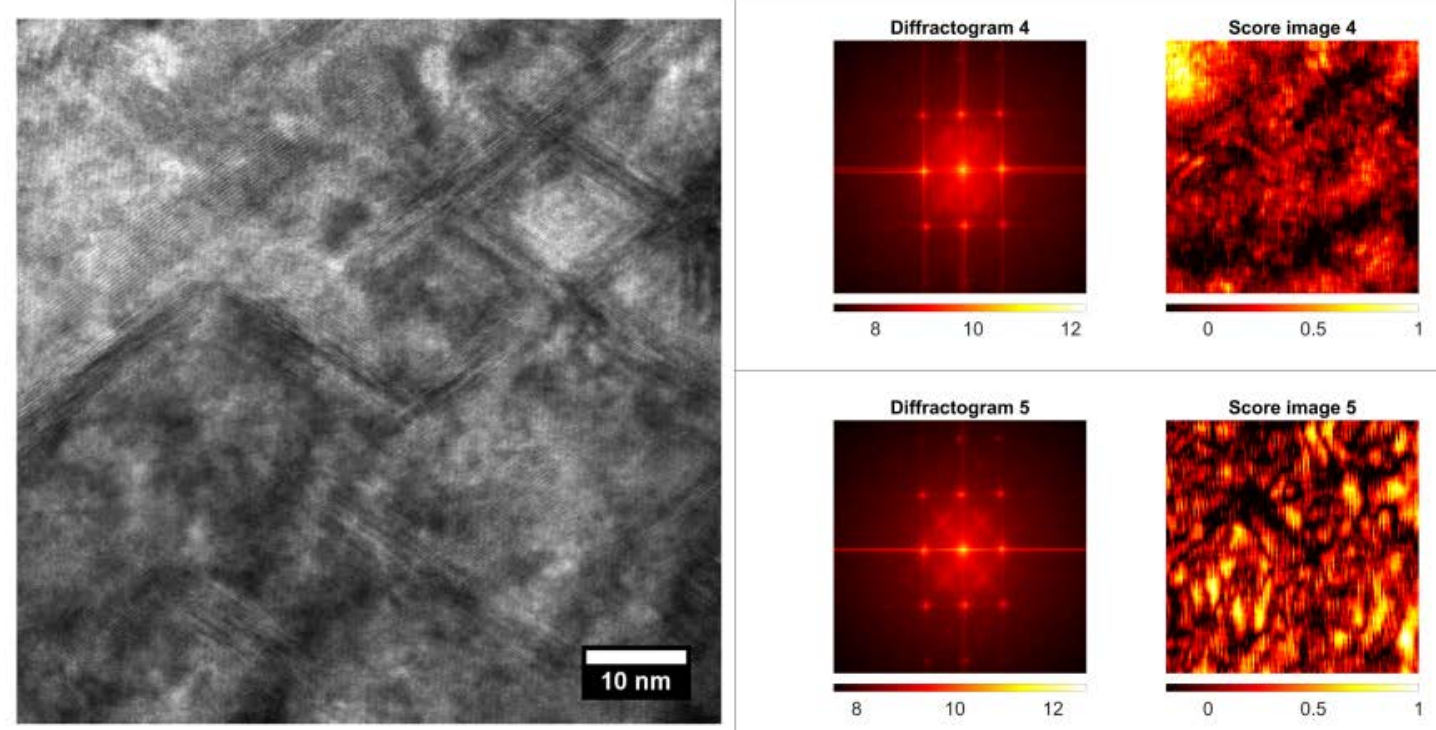

Diffractogram 5

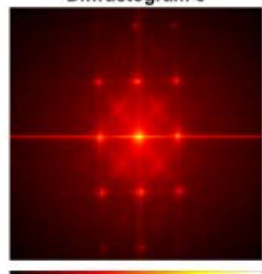

Score image 5


Score image 1

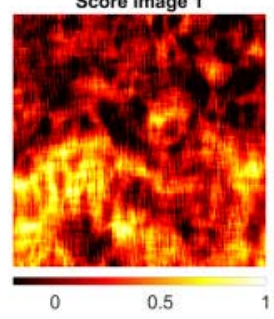

Diffractogram 6

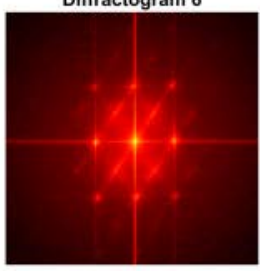

Score image 6
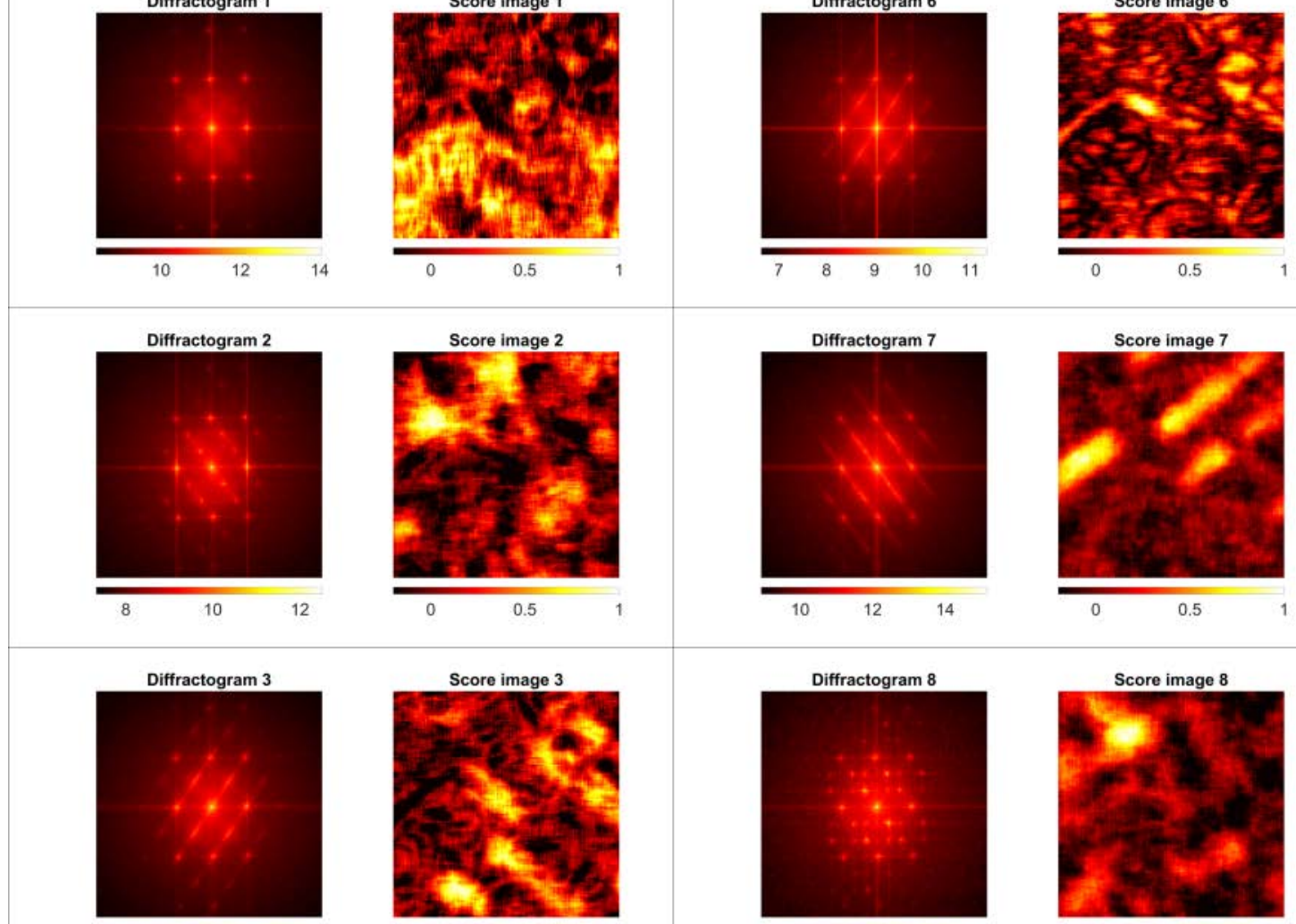

$\begin{array}{lllll}9 & 10 & 11 & 12 & 13\end{array}$

Score image 2

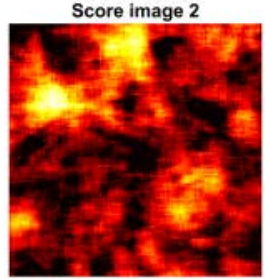

Diffractogram 7
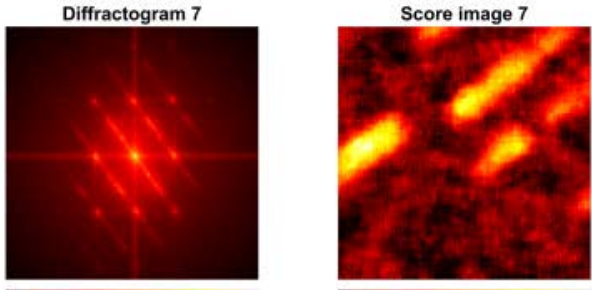

$0.5 \quad 1$

Score image 8
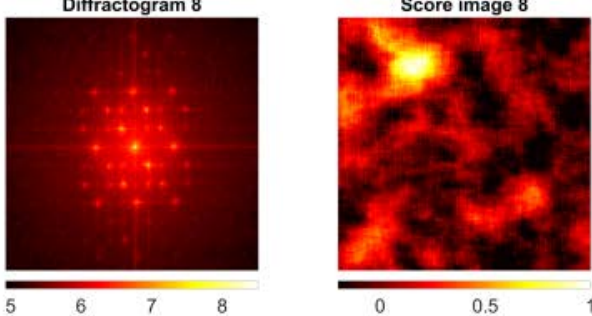

0.5



$\begin{array}{llll}5 & 6 & 7 & 8\end{array}$

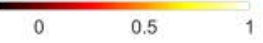

Figure 42. HRTEM image of neutron-irradiated tungsten, along with diffractograms extracted by statistical analysis and the spatial scores of the diffractograms. 
Interpretation is still underway, but several different populations of precipitates (pairs 2, 3, 7, 8) as well as a region of matrix with sharp diffractogram peaks and no noticeable super lattice peaks (pair 4) are found. Interestingly, and invisible using conventional data analysis, X-shaped super lattice peaks are beginning to appear in diffractogram space at this dpa level, and are scattered around the micrograph at random. This could indicate an incipient phase transformation or other degradation mode.

\section{FUTURE PLANS}

We will continue our explorations into plasma-materials interactions and radiation damage effects, and have begun to combine the two thrusts by exploring radiation damage effects on PMI. Emphasis will include different modes of radiation damage and flux and fluence scans in PMI.

To enable these studies, further microscopy technique development will continue, with a particular emphasis on data analytics to maximize the information that can be gleaned from the huge datasets yielded by modern electron microscopes. Data analytics explorations will include parallelizing the current codes and moving amenable algorithms to GPU computations, in order to attack larger datasets. Clustering algorithms (such as k-means and fuzzy c-means) will be explored for both diffraction and Xray data, and we are investigating if deep learning neural networks might be applicable to our problems.

Collaborations this year will continue to include UC-San Diego, the University of Tennessee, and will now include Kyoto University (for ion-beam irradiations). 


\subsection{GAS-DEFECT INTERACTIONS IN FUSION MATERIALS}

\section{X.Hu (hux1@ornl.gov), Jie Qiu (University of Tennessee), T. Koyanagi, Y. Katoh}

\section{OBJECTIVE}

This primary goal of this project is to investigate the gas-defect interactions in iron, tungsten, and SiC, three important fusion materials, through coordinated experiments and modeling.

\section{SUMMARY}

We have studied the neutron irradiation impact on helium desorption behavior in pure iron, the deuterium desorption behavior from neutron irradiated tungsten, helium desorption behavior from helium ionimplanted tungsten, and the helium behavior in SiC. A cluster dynamics model has been employed to investigate the helium-defect interactions in tungsten.

\section{PROGRESS AND STATUS}

\section{Impact of neutron irradiation on thermal helium desorption from iron}

We investigated the impact of neutron irradiation on thermal helium desorption behavior in high purity iron. Single crystal and polycrystalline iron samples were neutron irradiated in HFIR to 5 dpa at $300^{\circ} \mathrm{C}$ and in BOR-60 to $16.6 \mathrm{dpa}$ at $386^{\circ} \mathrm{C}$, respectively. Following neutron irradiation, $10 \mathrm{keV}$ He ions were implanted at room temperature on both samples to a fluence of $7 \times 10^{18} \mathrm{He} / \mathrm{m}^{2}$. Thermal desorption spectrometry (TDS) was conducted to assess the helium diffusion and clustering kinetics by analysis of the desorption spectra. The comparison of He desorption spectra between un-irradiated and neutron irradiated samples showed that the major He desorption peaks shift to higher temperatures for the neutron-irradiated iron samples, implying that strong trapping sites for He were produced during neutron irradiation. These traps appeared to be nm-sized cavities seen in TEM examination. The underlying mechanisms controlling the helium trapping and desorption behavior were deduced by assessing changes in the microstructure, as characterized by TEM, of the neutron irradiated samples before and after TDS measurements. The results and analysis have been published in the Journal of Nuclear Materials 489 (2017) 109-117.

\section{Impact of neutron irradiation on deuterium behavior in tungsten}

W samples irradiated in HFIR to three different conditions were studied, i.e., IW47 $\left(460^{\circ} \mathrm{C}, 0.03 \mathrm{dpa}\right)$, IW17 $\left(710^{\circ} \mathrm{C}, 0.7 \mathrm{dpa}\right)$, and IW19 $\left(770^{\circ} \mathrm{C}, 2.9 \mathrm{dpa}\right)$. TEM characterization of these samples showed that the dominant defect features in IW47 and IW17 were dislocation loops and voids, but a more complex microstructure was observed in IW19, containing dislocation loops, voids, and transmutation-induced precipitates. All the samples were implanted with $10 \mathrm{keV} \mathrm{D}_{2}$ to the same fluence of $1 \times 10^{15} / \mathrm{cm}^{2}$. Subsequent TDS measurements were carried out to determine how these defect features might impact the D desorption behavior. A constant temperature ramp rate of $0.5 \mathrm{~K} / \mathrm{s}$ was used in the ORNL gas implantation and thermal desorption system. Figure 43 shows the D desorption spectra from the neutronirradiated and reference $\mathrm{W}$ samples following $\mathrm{D}_{2}$ implantation. A dominant desorption peak was consistently observed for all samples at $633 \mathrm{~K}$, implying that the majority of the implanted D were captured at weak trapping sites, like dislocation loops and small vacancy clusters. In comparison with the desorption spectrum of the reference sample, one new desorption peak appeared at $\sim 800 \mathrm{~K}$ in the D desorption spectra of IW47 and IW17, although the intensity is not significant. The new peak at higher temperature indicated that part of the implanted D was trapped at stronger trapping sites, which were most likely voids, as shown in TEM observations. An interesting observation of the TDS spectrum from IW19 
was that there were no obvious desorption peaks in the higher temperature regime. Considering its complex microstructure, this observation was not expected. Additional TEM characterization of this sample is being conducted to understand the $\mathrm{D}$ desorption behavior from this high dose sample.



Figure 43. D desorption spectra from $10 \mathrm{keV} \mathrm{D}_{2}$ implanted reference and neutron-irradiated W.



Figure 44. Thermal helium desorption spectrum from He-implanted tungsten. The dominant He-V clusters contributing to each desorption peaks are labeled. 


\section{(3) Helium behavior in tungsten}

We performed spatially-dependent cluster dynamics modeling to simulate the interactions of helium and irradiation-induced defects during He implantation and the subsequent TDS process. The modeling is performed within a multiscale framework to provide input on the energetics and kinetics of small helium and helium-defect clusters, and to predict the evolution of all involved defect clusters. Figure 44 shows the thermal helium desorption spectrum of tungsten He-implanted at room temperature to $5 \times 10^{15} / \mathrm{cm}^{2}$. The cluster dynamics modeling successfully captured the major features of the desorption spectrum. The helium-vacancy cluster sizes contributing to the observed helium desorption peaks were also captured through comparing the cluster distribution before and after the corresponding temperature peaks. This preliminary result will form the basis for our future efforts to improve the self-consistency of the developed cluster dynamics model.

\section{$\underline{\text { He-defect interactions in } \mathrm{SiC}}$}

Thermal desorption measurements have been performed on neutron-irradiated $\mathrm{SiC}$ with in situ He charging (using a coating of a $2 \mu \mathrm{m}$ Ni layer for neutron captures) and He-implanted SiC. Figure 45 shows the He desorption spectra from these samples. It is apparent that the He desorption peaks shifted to higher temperatures in the neutron-irradiated samples, implying the presence of strong He trapping sites produced during neutron irradiation. These are most likely vacancy clusters or voids. A single major He desorption peak was observed at $800^{\circ} \mathrm{C}$ for He-implanted samples, indicating a single type of trapping site is dominant in these two samples, most likely a Si-vacancy due to its larger binding energy with He in comparison with a C-vacancy. Positron annihilation spectroscopy shows the dominant defect is $\left(3 \mathrm{~V}_{\mathrm{Si}}+2 \mathrm{~V}_{\mathrm{C}}\right)$. TEM observation is being performed to characterize the microstructures of the neutronirradiated SiC before and after TDS measurements.

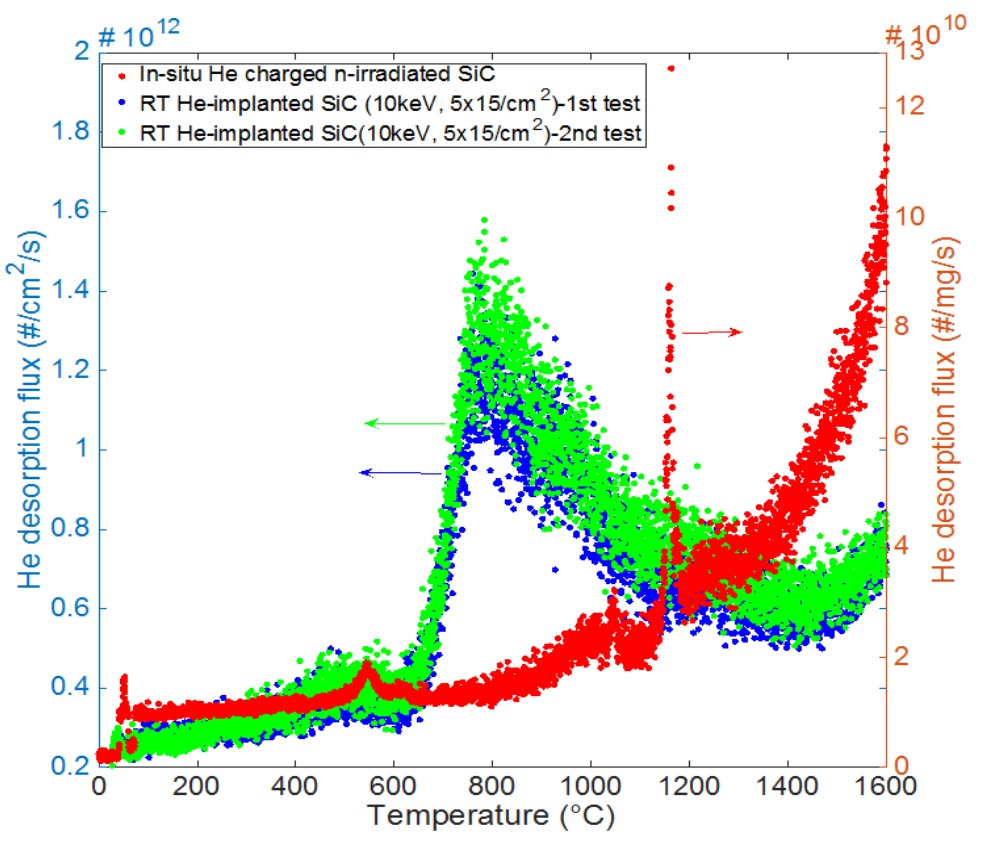

Figure 45. He desorption spectra from neutron-irradiated and He-implanted SiC.

\section{FUTURE PLANS}

More work will be conducted to evaluate the impact of precipitates on helium desorption behavior in CNA steels, and the hydrogen isotopes behavior in these fusion materials. 


\subsection{HIGH-HEAT FLUX TESTING OF FUSION MATERIALS}

\section{A.S. Sabau (sabaua@ornl.gov) and Y. Katoh}

\section{OBJECTIVE}

The objective of this work is high-heat flux testing (HHFT) of irradiated materials for plasma facing components and of mock-up divertor components using Plasma Arc Lamps (PAL). This will provide basic materials property information and constitutive equations for materials behavior in the harsh fusion environment.

\section{SUMMARY}

In this reporting period, effort was mainly focused on design and fabrication of a new reflector to increase the heat flux to the maximum achievable for the maximum arc temperature of the Plasma-arc Lamp. After a significant delay, the fabrication of the new reflector was completed.

\section{PROGRESS AND STATUS}

Effort was conducted in two main areas in order to attain the maximum incident heat flux from PAL of 12 MW/m2 with the new reflector: (a) design and fabrication of a new reflector and (b) instrumenting the test section with a lift mechanism of the dome test section.

The new reflector was designed by Mattson Technologies, Inc. Mattson Technologies conducted simulations for various reflector shapes using a proprietary model of the volumetric distribution of the heat source within the plasma arc, which is confined in a quartz tube. The actual thicknesses of quartz fixtures (windows, dome or cylinder) used for radiological containment were considered in the model simulations, illustrated in Figure 46.

(a)

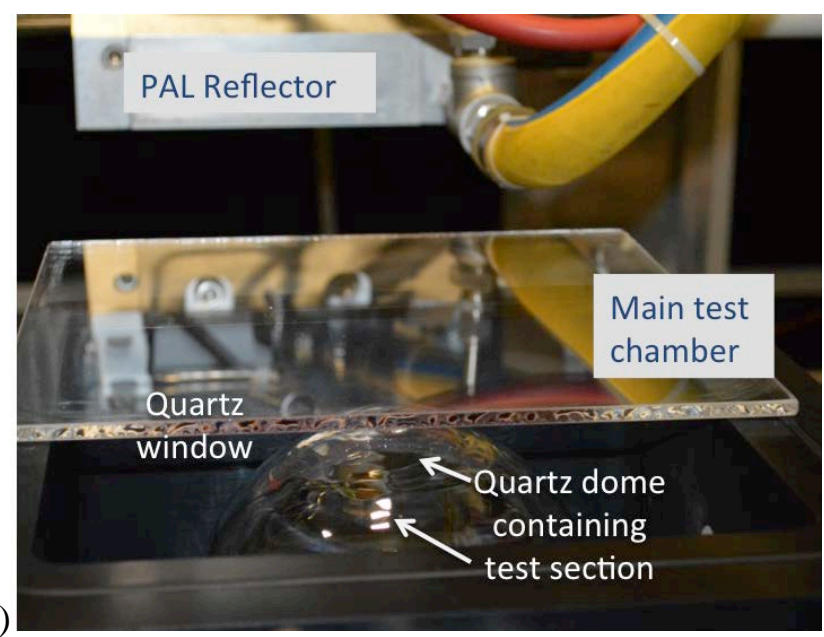

(b)



Figure 46. The main configuration components of the PAL experimental setup (PAL reflector, quartz window, and quartz dome): (a) photo of the setup and (b) schematic of ray tracing toward the specimen. 
Mattson Technologies provided schematics for the various reflector shapes simulated (Table 7). The various thicknesses of quartz fixtures (windows, dome or cylinder) used for radiological containment are given in Table 7. It was found that the best option for the current ORNL program is the case in which the test section is contained in a quartz dome. The maximum heat flux that is estimated to be attained for the dome configuration is $12 \mathrm{MW} / \mathrm{m}^{2}$.

Table 7. Cases simulated to obtain heat flux through the containment chamber onto the specimen surface. The thickness of quartz fixtures are given in $\mathbf{~ m m}$.

\begin{tabular}{|l|l|l|l|}
\hline Test configuration & $\begin{array}{l}\text { Peak Flux } \\
{\left[\mathbf{M W} / \mathrm{m}^{2}\right]}\end{array}$ & $\begin{array}{l}\text { Containment } \\
\text { chambers }\end{array}$ & Applicability \\
\hline Horizontal tube test section & 14 & Tube $(3 \mathrm{~mm})$ & Mockup specimen only \\
\hline Dome test section & 12.3 & Dome $(3 \mathrm{~mm})$ & Best for current setup \\
\hline Thin quartz window & 11.7 & Window $(7 \mathrm{~mm})$ & \\
\hline Thick quartz window & 9.4 & Window $(25 \mathrm{~mm})$ & \\
\hline Thick quartz and dome & 8.3 & $\begin{array}{l}\text { Window }(25 \mathrm{~mm}) \\
\text { Dome }(3 \mathrm{~mm})\end{array}$ & $\begin{array}{l}\text { To be used only when two } \\
\text { containment chambers are } \\
\text { needed }\end{array}$ \\
\hline Baseline (current uniform reflector) & 4 & - & \\
\hline
\end{tabular}

The maximum heat flux from the reflector without containment was estimated to be $21 \mathrm{MW} / \mathrm{m}^{2}$.

\section{ACKNOWLEDGMENTS}

The authors would like to thank Charles (Chuck) R. Schaich for fabricating fixtures for heat-flux measurement and lift mechanism for the dome test section.

\section{FUTURE PLANS}

Efforts are now focused on: (1) installing the new $12 \mathrm{MW} / \mathrm{m}^{2}$ reflector and measuring the heat-flux levels, (2) conducting high-heat flux testing with non-irradiated specimens for the joint US/Japan PHENIX program, and (3) understanding the deformation during HHFT using thermo-mechanical simulation of the high-heat flux testing. 


\section{EXPLORATORY, UNIQUE AND INNOVATIVE MATERIALS}

\subsection{DESIGN AND DEVELOPMENT OF NOVEL COPPER ALLOYS FOR FUSION ENERGY APPLICATIONS}

Ying Yang (yangying@ornl.gov), Ling Wang and Steven J. Zinkle (University of Tennessee and Oak Ridge National Lab), Lance Snead (Stony Brook University)

\section{OBJECTIVE}

This study aims at developing high strength, high conductivity copper alloys with improved thermal creep strength for long pulse fusion high heat flux structures, through an accelerated approach of computational thermodynamics guided alloy design.

\section{SUMMARY}

Novel Cu-Cr-Nb-Zr and Cu-Cr-Ta-Zr alloys have been designed with the aid of computational thermodynamics. Microstructures with bimodal distribution of precipitates have been achieved through the conventional ingot-making fabrication followed by thermomechanical treatment. Optical images and hardness measurements were obtained on all alloys. TEM analysis, tensile tests, and thermal conductivity measurements have been performed on selected $\mathrm{Cu}-\mathrm{Cr}-\mathrm{Nb}-\mathrm{Zr}$ alloys. The results show a good combination of thermal conductivity and mechanical behavior in the alloys for temperature up to $500^{\circ} \mathrm{C}$.

\section{PROGRESS AND STATUS}

We have developed one new Cu-Cr-Nb-Zr alloy and two new Cu-Cr-Ta-Zr alloys in FY 2017: 4CCNZ, 1CCTZ and 2CCTZ. Their compositions and major precipitates are listed in Table 8, together with the other three CCNZ alloys developed in FY2016. The "4CCNZ" alloy differs from the other three CCNZ alloys in the type of matrix precipitates. This alloy utilizes the $\mathrm{Nb}$ as matrix precipitates, where the other three use the $\mathrm{Cr}$ as the matrix precipitate. The 1CCTZ alloy differs from the 2CCTZ alloy in a similar way. These three new alloys were fabricated through traditional (inexpensive) arc melting and drop casting techniques. The $\mathrm{Cr}$ and $\mathrm{Ta}$ (or $\mathrm{Cr}$ and $\mathrm{Nb}$ ) had to be pre-alloyed to avoid vaporization of $\mathrm{Cu}$. The as-cast alloys had dimensions of $0.5 \times 0.5 \times 4$ in. They were then cold rolled to $70 \%$-reduction in thickness. The as-rolled alloys were solutionized at $970^{\circ} \mathrm{C}$ for 20 minutes followed by water quenching and then aging at $475^{\circ} \mathrm{C}$ for 3 hours.

Table 8. Compositions of developed Cu alloys

\begin{tabular}{|l|l|r|r|r|r|l|l|}
\hline & Cu,wt\% & \multicolumn{1}{l}{ Cr,wt\% } & Nb,wt\% & Zr,wt\% & Ta,wt\% & $\begin{array}{l}\text { GB and } \\
\text { Disl. Ppts }\end{array}$ & $\begin{array}{l}\text { Matrix } \\
\text { Ppts }\end{array}$ \\
\hline 1CCNZ & Bal. & 2 & 1.35 & 0.15 & & $\mathrm{Cr}_{2} \mathrm{Nb}$ & $\mathrm{Cr}, \mathrm{Cr}_{5} \mathrm{Zr}$ \\
\hline 2CCNZ & Bal. & 2.25 & 1.35 & 0.3 & & $\mathrm{Cr}_{2} \mathrm{Nb}$ & $\mathrm{Cr}_{2} \mathrm{Cr}_{5} \mathrm{Zr}$ \\
\hline 3CCNZ & Bal. & 2.25 & 1.35 & 0.15 & & $\mathrm{Cr}_{2} \mathrm{Nb}$ & $\mathrm{Cr}, \mathrm{Cr}_{5} \mathrm{Zr}$ \\
\hline 4CCNZ & Bal. & 1.25 & 2 & 0.15 & & $\mathrm{Cr}_{2} \mathrm{Nb}$ & $\mathrm{Nb}$ \\
\hline 1CCTZ & Bal. & 2 & & 0.15 & 2.5 & $\mathrm{Cr}_{2} \mathrm{Ta}_{2}$ & $\mathrm{Cr}_{2} \mathrm{Cr}_{5} \mathrm{Zr}$ \\
\hline 2CCTZ & Bal. & 1.25 & & 0.15 & 4 & $\mathrm{Cr}_{2} \mathrm{Ta}_{1}$ & $\mathrm{Ta}$ \\
\hline
\end{tabular}

In FY2017, in addition to new alloy design and fabrication, a large amount of effort has been devoted to the characterization of the previously developed CCNZ alloys, including electron microscopy of 
microstructures, thermal conductivity measurements, and tensile tests from ambient temperature to $500^{\circ} \mathrm{C}$. For the new alloys, optical images and hardness measurements have been obtained. For alloys listed in Table 8, irradiation experiments have been planned, and a total of fifty-seven samples in the shape of SSJ3 tensile bars, shown in Figure 47, have been machined for the experiments. The results for 1 3CCNZ alloys are summarized in Table 9. These alloys show a good combination of thermal conductivity and mechanical properties.

Table 9. Room temperature properties of $\mathrm{Cu}-\mathrm{Cr}-\mathrm{Nb}-\mathrm{Zr}$ alloys. All alloys were cast, cold-rolled $50 \%$ (70\% for 1CCNZ-T alloy series), then solutionized at $970^{\circ} \mathrm{C}$ for 20 minutes, quenched and aged at $475^{\circ} \mathrm{C}$ for $3 \mathrm{~h}$ (SAA treatment).

\begin{tabular}{|l|c|c|c|c|c|c|}
\hline Alloy and TMT & $\begin{array}{c}\text { Hardness } \\
(\mathrm{VHN})\end{array}$ & $\begin{array}{c}\text { Electrical } \\
\text { conductivity } \\
\text { (\%IACS) }\end{array}$ & $\begin{array}{c}\text { Yield } \\
\text { strength } \\
(\mathrm{MPa})\end{array}$ & $\begin{array}{c}\text { Ultimate } \\
\text { strength } \\
(\mathrm{MPa})\end{array}$ & $\begin{array}{c}\text { Uniform } \\
\text { elongation } \\
(\%)\end{array}$ & $\begin{array}{c}\text { Total } \\
\text { elongation } \\
(\%)\end{array}$ \\
\hline $\begin{array}{l}\text { 1CCNZ-F } \\
(50 \% C W+S A A)\end{array}$ & 124.7 & 55.8 & 230 & 336 & 12.2 & 21 \\
\hline $\begin{array}{l}1 \mathrm{CCNZ}-\mathrm{T} \\
(70 \% \mathrm{CW}+\mathrm{SAA})\end{array}$ & 124.7 & 56.7 & 255 & 385 & 20.2 & 29 \\
\hline $\begin{array}{l}\text { 3CCNZ-X } \\
(50 \% C W+S A A)\end{array}$ & 124.0 & 56.5 & 232 & 302 & 7.2 & 13 \\
\hline $\begin{array}{l}\text { 2CCNZ-Y } \\
(50 \% C W+S A A)\end{array}$ & 106.5 & 57.8 & 239 & 383 & 19 & 28 \\
\hline
\end{tabular}

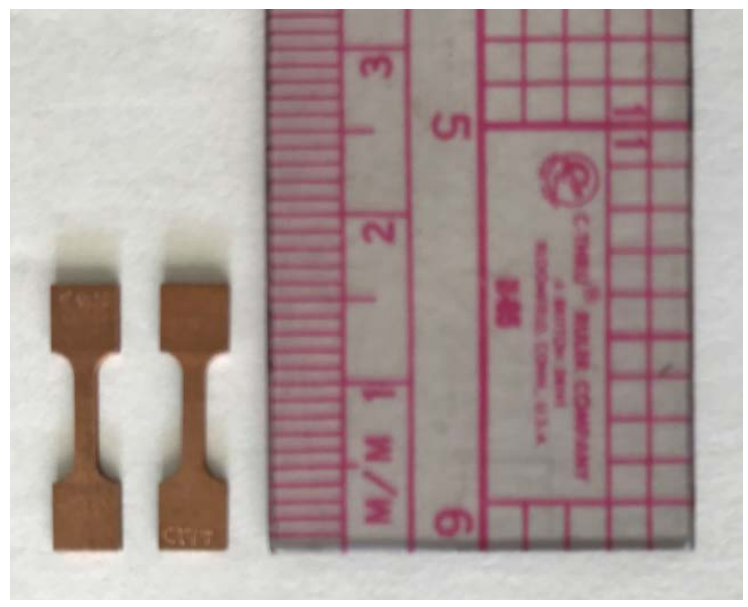

Figure 47. SSJ3 tensile specimens of the type to be used in HFIR irradiation experiments.

\section{FUTURE WORK}

1) Continuing microstructural characterization, mechanical testing and irradiation of the $\mathrm{CuCrNbZr}$ and CrTaZr alloys.

2) Optimize thermomechanical treatment to further improve the properties of these alloy classes. 


\subsection{MAX PHASES UNDER NEUTRON IRRADIATION}

\section{P. D. Edmondson (edmondsonpd@ornl.gov), C. Ang}

\section{OBJECTIVE}

The primary objective of the work is to examine and understand the defect recovery mechanisms in neutron irradiated and thermally annealed Al- and Si-bearing MAX phases.

\section{SUMMARY}

Two MAX phase alloys - $\mathrm{Ti}_{3} \mathrm{AlC}_{2}$ and $\mathrm{Ti}_{3} \mathrm{SiC}_{2}$ - that were irradiated to 2 displacements per atom (dpa) at $400^{\circ} \mathrm{C}$ in the HFIR have undergone isochronal thermal annealing followed by electrical resistivity measurements to enable the determination of the activation energies of the dominant defects formed during the irradiation. To date, the isochronal annealing and electrical resistivity measurements have been successfully conducted, and the microstructural characterization experiments required to complement these data are in progress.

\section{PROGRESS AND STATUS}

A schematic diagram showing the isochronal annealing steps is shown in Figure 48a). The time at which the specimens were at temperature for each isochronal annealing step was $1800 \mathrm{~s}$; the first annealing temperature was $500^{\circ} \mathrm{C}$, and the temperature was increased by $50^{\circ} \mathrm{C}$ at each step up to a final annealing temperature of $900^{\circ} \mathrm{C}$. After each annealing step, the samples were removed and the electrical conductivity measurements were recorded. Furthermore, at periodic intervals, bulk specimens were removed from the annealed sample for post-annealing microstructural characterization to be conducted via XRD and TEM.
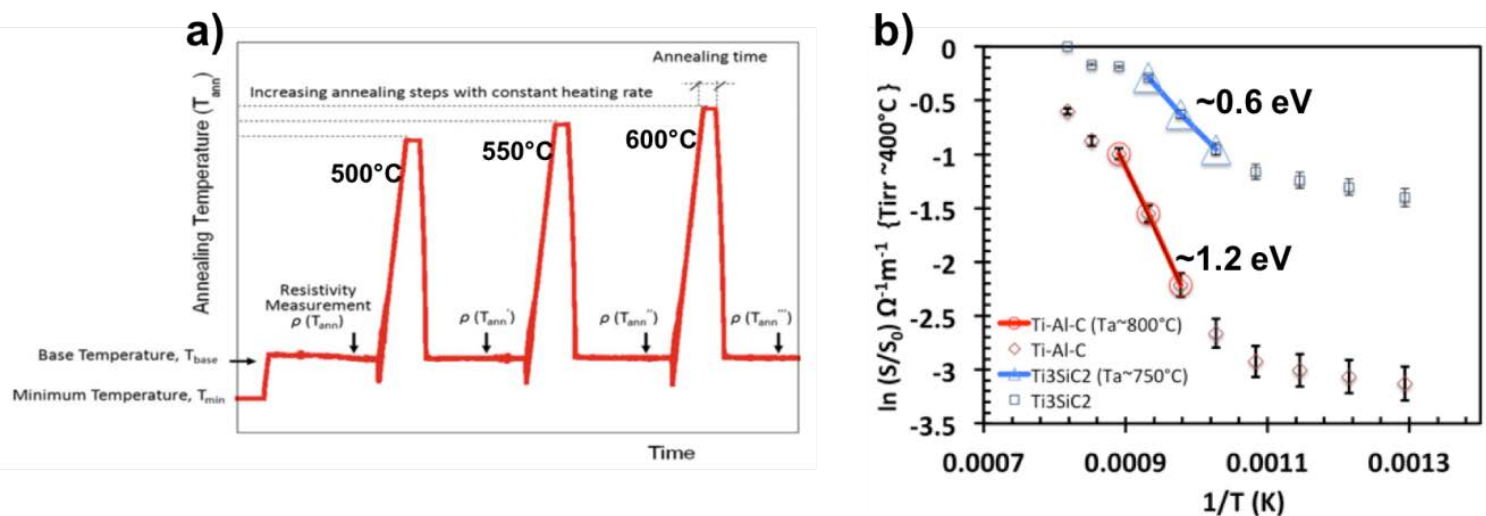

Figure 48. a) Schematic diagram of the isochronal annealing steps. b) Electrical resistivity measurements recorded during the isochronal annealing, and the associated calculated activation energy of the defects in the $\mathrm{Ti}_{3} \mathrm{AlC}_{2}$ and $\mathrm{Ti}_{3} \mathrm{SiC}_{2} \mathrm{MAX}$ phase materials.

The results of the electrical resistivity measurements for the two materials are shown in Figure 48b. In this work, the pre-exponent for the resistivity was extrapolated from the work of Barsoum and Tzenov (using un-irradiated, higher purity materials).

Based on these results, the early indications are that the dominant defects probed during the isochronal annealing and electrical resistivity measurements is likely contained within the M-A layer where $\mathrm{M}$ is the 
metal element, e.g. $\mathrm{Ti}$, and $\mathrm{A}$ is either $\mathrm{Al}$ or $\mathrm{Si}$ in the materials examined. The results also suggest that the defect diffusion/recombination is also vacancy mediated.

In order to fully elucidate the defect structures and microstructural evolution, it is necessary to conduct some additional characterization experiments that include XRD and TEM.

\section{FUTURE PLANS}

Future work will include two activities. First, microstructural characterization of the annealed microstructures will use scanning transmission electron microscopy, combined with energy dispersive spectroscopy. This will help determine the final defect states in the neutron irradiated and thermally annealed materials, thereby assisting in understanding defect formation, recovery, and stability in MAX phases at the near atomic scale. Second, a series of experiments are planned in which ion beams will be used to simulate neutron damage in Al- and Si-bearing MAX phases. Irradiations will be performed on new samples, and on those previously neutron irradiated to $2 \mathrm{dpa}$. The microstructure of the specimens will be compared with the neutron irradiated specimens up to a total of $10 \mathrm{dpa}$, and possible beyond. 


\subsection{DISPLACEMENT DAMAGE AND SELF-HEALING IN HIGH-ENTROPY ALLOYS:A TEM WITH IN SITU ION IRRADIATION STUDY}

Matheus A. Tunes ${ }^{1,2}$ (tunesm@ornl.gov), Philip D. Edmondson ${ }^{2}$, Vladimir M. Vishnyakov ${ }^{1}$ and Stephen E. Donnelly ${ }^{1}\left[{ }^{1}\right.$ University of Huddersfield, ${ }^{2}$ Oak Ridge National Laboratory]

\section{INTRODUCTION}

Recent developments in the field of materials for future nuclear fusion reactors have led to the design of innovative metallic alloys that can sustain their mechanical and structural properties under a wide variety of extreme conditions, such as fast neutrons $(\mathrm{E}<=14 \mathrm{MeV})$ and alpha particle bombardment $\left({ }^{4} \mathrm{He}\right.$ with $\mathrm{E}$ up to $\sim 3.5 \mathrm{MeV}$ ). High-Entropy Alloys (HEAs) are promising candidates for new concepts of nuclear reactors as they have mechanical properties and thermodynamic stability that is believed to be superior to conventional metallic alloys, although their radiation resistance is still a subject of intense research. The efforts to understand the behavior of HEAs under particle irradiation indicated a possible "self-healing" effect of radiation induced defects [1]. In this report, a preliminary study using Transmission Electron Microscopy (TEM) with in situ ion irradiation was performed to investigate the formation and evolution of displacement damage in the microstructure of a FeCrMnNi HEA.

\section{SUMMARY OF EXPERIMENTS}

TEM samples from the FeCrMnNi HEA were produced using the conventional Focused Ion-Beam (FIB) lift-out technique in an FEI Quanta 3D 300i. The alloy was produced in the ORNL Materials Sciences and Technology Division by plasma arc melting and the TEM lamellae were produced from the as-cast alloy. TEM with in situ ion irradiation was performed in the MIAMI-2 facility at University of Huddersfield. MIAMI-2 consists of a $350 \mathrm{keV}$ ion accelerator coupled to a Hitachi H-9500 TEM that allows for the direct imaging and observation of damage as it is formed. Observations of the damaged microstructure were recorded by a Gatan Model 1095 OneView at 8 frames-per-second. SRIM2013 was used to convert MIAMI-2 fluences to displacements-per-ion (dpa) using the methodology of Stoller et al. [2]. The HEA sample was kept at $773 \mathrm{~K}$ in a double-tilt heating holder and irradiated using $30 \mathrm{keV} \mathrm{Xe}^{+}$ions up to a fluence of $2.6 \times 10^{16}$ ions $\mathrm{cm}^{-2}$ (24.8 dpa).

The image frames were extracted from the digital video recordings using the code FFmpeg [3], which preserves the bit depth and high-resolution. The set of 16 frames analyzed in this report correspond to the irradiation between 296.25 and 298.25 seconds (at a fluence of approximately $1.3 \times 10^{16}$ ions $^{\cdot} \mathrm{cm}^{-2}(12.2$ dpa). MATLAB Image Processing Toolbox was used in order to extract the information of black-dots occurrence in a set of frames by taking the difference between two successive frames. The images with the differences are then summed within MATLAB to compose the accumulated damage within the set of frames analyzed.

\section{PROGRESS AND STATUS}

Figure 49 shows the first two image frames (49a-b) within the analyzed temporal interval and the combined MATLAB image (49c) with the computed difference between the two images. The images were taken in the Bright-Field TEM (BFTEM) mode. Throughout the experiment, black-dots were preferentially observed in a grain where the crystallographic direction was indexed with the software Crystalmaker $[4,5]$ and data available in the literature. The highlighted grain is orientated so that the electron beam is approximately aligned along the [100] zone-axis of the face-centred cubic (FCC) structure. 

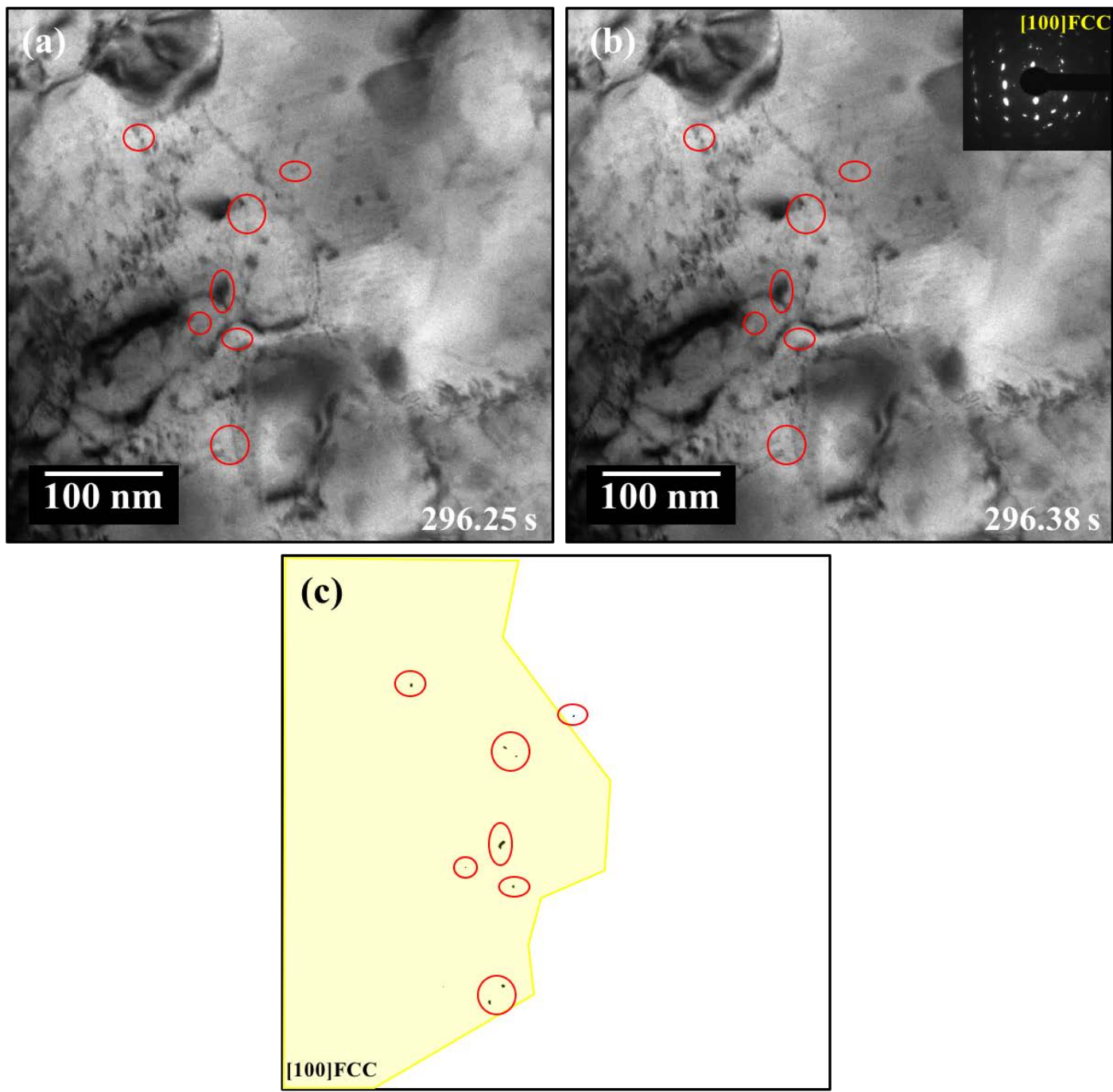

Figure 49. BFTEM images of the FeCrMnNi HEA irradiated with $30 \mathrm{kV}$ Xe ions at $773 \mathrm{~K}$ showing (a) and (b) two adjacent frames and (c) the image computed with MATLAB and representing the difference between (a) and (b): exhibiting the black-dots that appeared between the frames.

Figure 50 exhibits (50a) the final microstructure of the $16^{\text {th }}$ frame and (b) the same final microstructure with the superposed information of all black-dots detected in the 16 frames analyzed. The comparison shows that the majority of the black-dots were annihilated within 2 seconds of irradiation at $773 \mathrm{~K}$. Image (c) is an under focused BFTEM image that was taken at a dose of $2.6 \times 10^{16}$ ions $^{\cdot} \mathrm{cm}^{-2}$ (24 dpa) where Xe bubbles are observable. The area shown in (d) also exhibits a region of a possible secondary phase formed during irradiation. Further investigation is underway. 

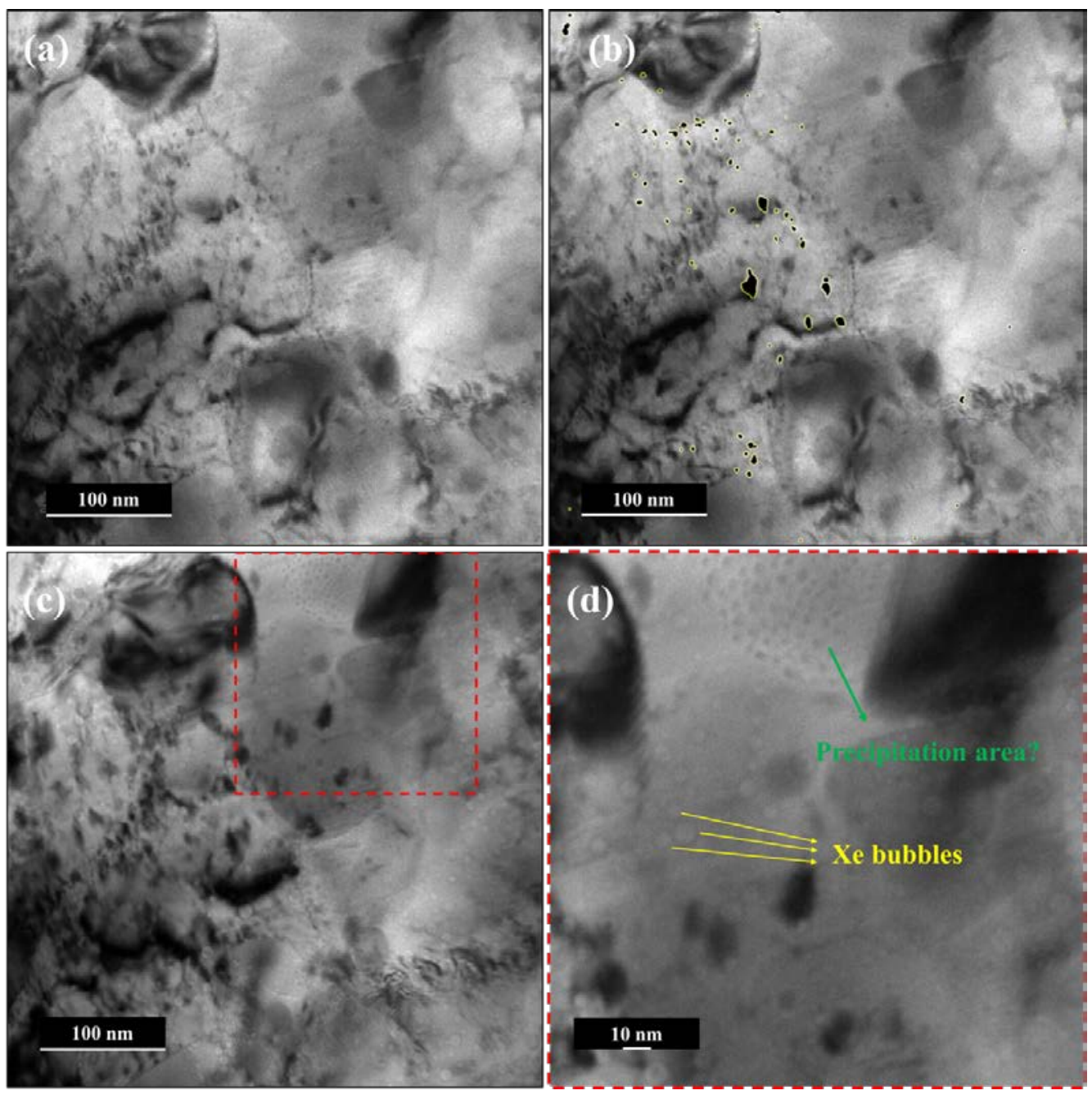

Figure 50. BFTEM images showing (a) the final microstructure of the $16^{\text {th }}$ frame and (b) the same microstructure as (a) with the superposed information of the black-dots within the 16 frames analysed. The micrograph (c) is a BFTEM underfocused image with defocus degree of $-1 \mu \mathrm{m}$ of the same region at $2.6 \times 10^{16}$ ions $\mathrm{cm}^{-2}(24 \mathrm{dpa})$.

\section{FURTHER EXPERIMENTS AND FUTURE PLANS}

The combination of TEM with in situ ion irradiation and image processing using MATLAB described a methodology that may allow further detailed studies of the self-healing of black-dot damage in the microstructure of HEAs under exposure to energetic particles. The MATLAB routine written for this analysis needs implementation for the large data-set produced in each irradiation experiment. The atomistic nature of the black-dots is this HEA is an ongoing subject of research.

\section{REFERENCES}

[1] B. S. Murty, J.-W. Yeh, S. Ranganathan, High-Entropy Alloys, Butterworth-Heinemann, 2014.

[2] R. E. Stoller, M. B. Toloczko, G. S. Was, A. G. Certain, S. Dwaraknath, F. A. Garner, Nucl. Instruments Methods Phys. Res. Sect. B Beam Interact. with Mater. Atoms 2013, 310, 75.

[3] S. Tomar, Linux J. 1994, 2006, 10.

[4] ICDD, Jt. Comm. Powder Diffr. Stand. Cent. Diffr. Data, Swart. USA 1996. 
[5] D. C. Palmer, CrystalMaker Software, Yarnton, UK 2006. 


\title{
7. COMPUTATIONAL MATERIALS SCIENCE
}

\subsection{MECHANICAL PROPERTIES AND RADIATION EFFECTS IN FUSION MATERIALS}

\author{
Y. N. Osetskiy (osetskiyyn@ornl.gov)
}

\section{OBJECTIVE}

The purpose of this research is to understand atomic level strengthening mechanisms in materials with localized radiation induced microstructures such as voids, gas-filled bubbles, secondary phase precipitates and oxide particles. These microstructures serve as obstacles to dislocation motion and cause radiation induced hardening and embrittlement. Currently we are investigating the map of mechanisms depending on the obstacle type, size and temperature.

\section{SUMMARY}

Inclusion-type obstacles to dislocation motion in many cases define material hardness due to either intentional introduction of obstacles, for example secondary phase precipitates and oxide particles, or obstacles formed under working conditions, for example voids and gas-bubbles formed during irradiation. Predicting materials properties, which is the main aim of numerous experimental and theoretical studies, demands understanding of basic mechanisms of dislocation-obstacle interactions responsible for the mechanical response. Inclusion-type obstacles are among the most investigated and usually are described by quite simple models created many decades ago. These models in practice assume the same interaction mechanism for different obstacles and use simplified parameters characterizing their strength. In many cases this consideration is oversimplified and does not give predictive capabilities. The results of extensive atomistic scale modeling of dislocation-obstacle interactions presented here demonstrate that there are low-scale phenomena that affect the interaction mechanisms which depend on the obstacle nature, size, ambient temperature and other parameters such as applied strain rate and interaction geometry. These parameters have mostly not been considered in current models for predicting materials properties.

\section{PROGRESS AND STATUS}

A large database of molecular dynamics (MD) results has been accumulated and is under treatment now using theoretical models of material plasticity. We are investigating a number of effects that include such effects as applied strain rate, ambient temperature and dislocation-obstacle interaction geometry. An example of interaction geometry and temperature effects is presented here for a rigid obstacle $7 \mathrm{~nm}$ in diameter. Figure 51 presents stress-strain curves for three cases of interaction geometry and four temperatures. In these simulations, the edge dislocation extra-half plane is above the slip plane and distance between the obstacle equator and slip plane is $\mathrm{Z}: \mathrm{Z}=0.5 \mathrm{R}$ means that the dislocation slip plane is $0.5 \mathrm{R}(\mathrm{R}=3.5 \mathrm{~nm}$ - radius of the obstacle) above the obstacle equator. Interaction geometries applied are schematically shown in the plots. The maximum stress value on each curve is the critical resolved shear stress (CRSS) which is a measure of the obstacle strength. CRSS values for all the above cases are presented in Figure 51 where we also indicate the standard deviation of the CRSS value obtained as described in [1]. Figure 51 shows that CRSS is temperature dependent: strongly at low temperatures and weakly at high temperatures. The difference in the interaction geometry is important at low $\mathrm{T}$ for $\mathrm{Z}=0.5 \mathrm{R}$ but not for the case with $\mathrm{Z}=-0.5 \mathrm{R}$. The latter case results in practically the same CRSS as an interaction along the obstacle equator, $\mathrm{Z}=0$. Such an asymmetry in the CRSS values indicates that the usual assumption that CRSS is proportional to the radius of the obstacle area intersected by the slip plane is not 
valid in general. This means that the obstacle strength parameter used in dispersed barrier hardening models (see e.g. [2,3]) should be corrected towards higher values.



Figure 51. Stress-strain curves obtained in MD modeling of an edge dislocation $1 / 2<111>\{110\}$ moving through a periodic array of impenetrable obstacles at different temperatures. The interaction geometry is shown by insets. The strain rate applied was $2 \times 10^{6} \mathrm{~s}^{-1}$ in all cases.

Figure 52 shows the example of how critical resolved shear stress (CRSS) for different obstacles in bcc Fe depends on the obstacle size. These interactions were modeled at $300 \mathrm{~K}$ with the constant strain rate $5 \times 10^{6} \mathrm{~s}^{-1}$ which corresponds to a dislocation velocity equal to $12 \mathrm{~m} / \mathrm{s}$ in the modeled system.

It is clearly seen that there are at least three different mechanisms that describe interactions with:

1. $\quad$ Rigid (modeling oxide) particles;

2. $\quad$ Voids and near-equilibrium bubbles; and

3. $\quad$ Coherent Cu-precipitates.

Atomic-scale analysis revealed the detailed phenomena responsible for the above mechanisms. For example, rigid obstacles repel the interacting dislocation thus increasing the effective obstacle size. To overcome a rigid obstacle the edge dislocation may create a long dipole of screw dislocations that then unzips by cross-slip and thus create an Orowan shear loop. This process is energy demanding and therefore the CRSS increases significantly at large obstacles.

Strengthening mechanisms due to coherent Cu-precipitates depend on the precipitate size in a specific way due to a dislocation induced structural phase transformation inside the precipitates. Small Cuprecipitates are weak obstacles and a gliding edge dislocation cuts and shears them at a low applied stress. However, when they are above $4 \mathrm{~nm}$ in diameter the non-coherent fcc-like structures induced by the cutting dislocation becomes a stronger obstacles significantly increasing the CRSS. 


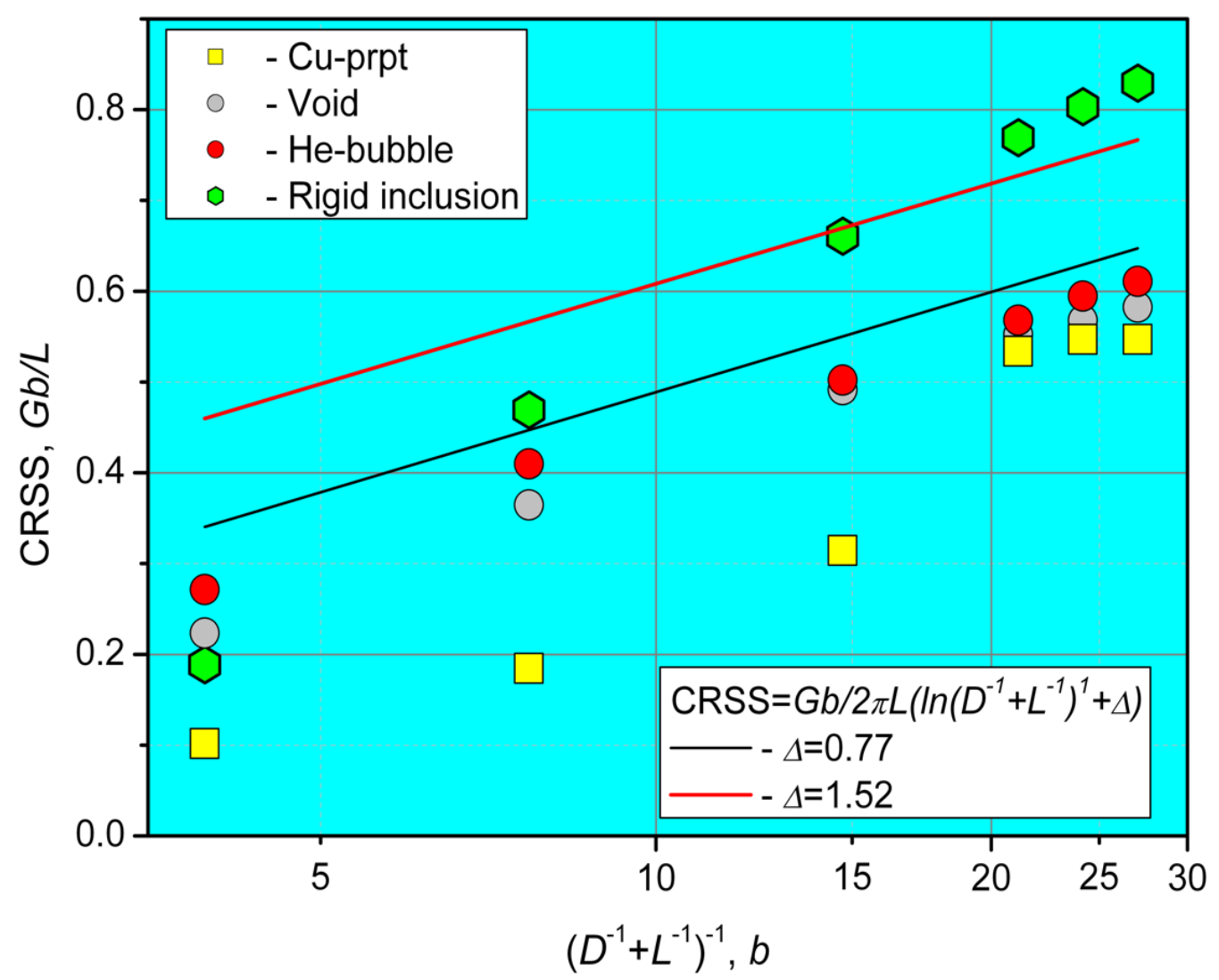

Figure 52. Critical resolved shear stress in reduced units as a function of harmonic mean of an obstacle diameter, $D$, and spacing between them along the dislocation line, $L$. Symbols present current modeling results, lines are dependences obtained in dislocation dynamic modeling for the Orowan mechanism (black line) and voids (red line) using discrete dislocation dynamics.

In contrast to the above mechanisms, interaction mechanisms with voids and near-equilibrium bubbles are very simple and qualitatively follow the predictions observed by earlier discrete dislocation modeling. The only difference from the previous continuum models is a significant dislocation climb observed by atomistic modeling. Such phenomena cannot be predicted in continuum models.

Treatment of other details of interaction mechanisms is currently in progress. The preliminary results reveal significant temperature and interaction geometry effects.

CRSS of different obstacles, the size dependence and a comparison with the strongest possible Orowan mechanism are presented in Figure 53 . It can be seen that small obstacles, $\leq 4 \mathrm{~nm}$, demonstrate quite different behavior. On the other side, larger obstacles, $\geq 5 \mathrm{~nm}$, can be separated into the two groups: strong rigid inclusions in one group and all other obstacles studied in another group. A detailed atomic-scale description of these features is now in progress. 


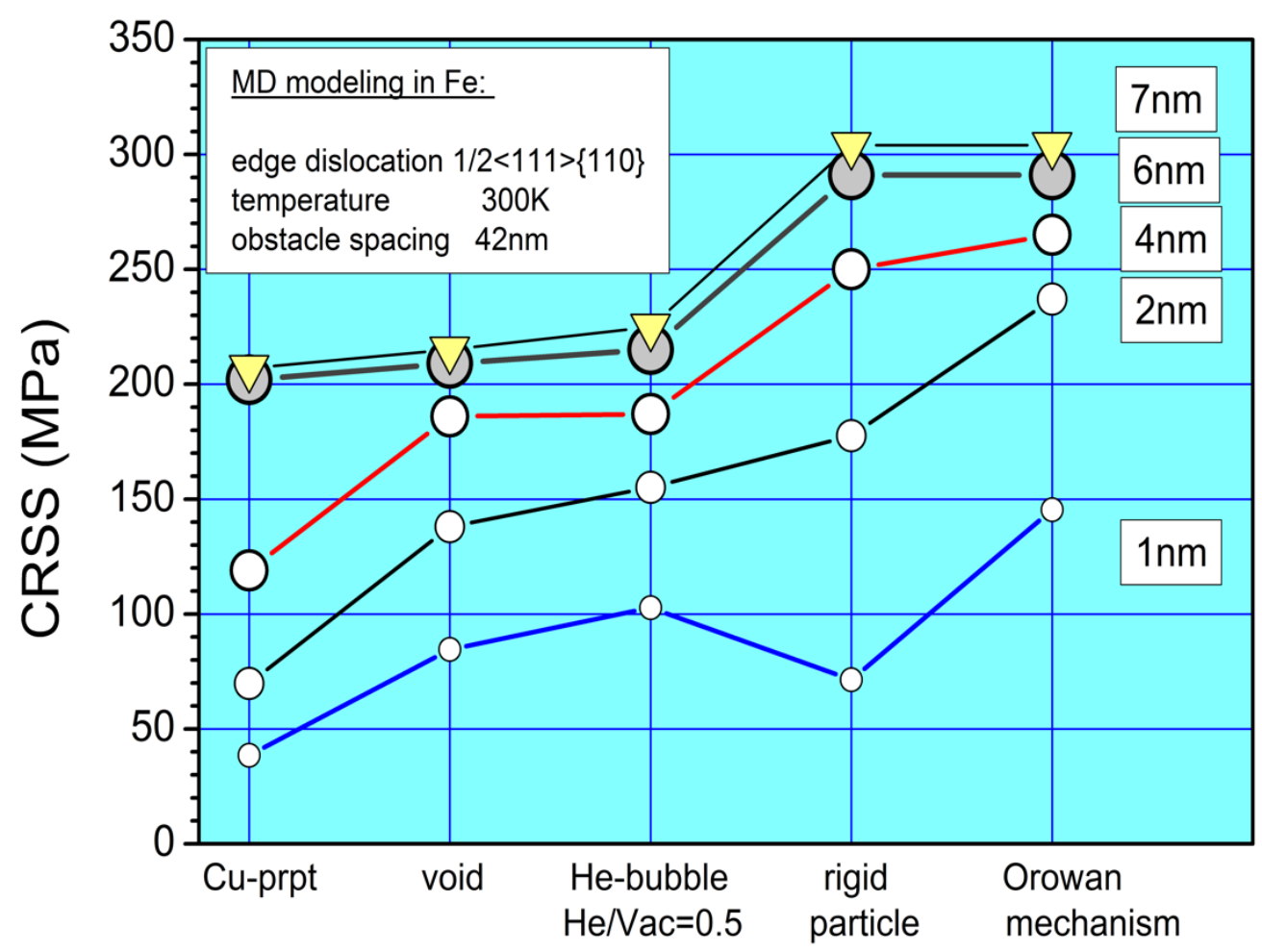

Figure 53. Critical resolved shear stress for different obstacles and different sizes compared with the theoretical Orowan mechanism.

The comprehensive treatment of all these results will be completed in about two months. A manuscript will be drafted focused on the description of interaction mechanisms for different obstacles and how these mechanisms can be used in predicting mechanical responses.

\section{FUTURE STUDY}

1. This treatment will be extended to screw dislocations and multicomponent materials such as Fe-CrNi stainless steels.

2. A similar simulation program on atomic-scale dislocation dynamics in W-based alloys will be initiated.

\section{REFERENCES}

[1] Y.N. Osetsky and R.E. Stoller, Atomic-scale Mechanisms of Helium Bubble Hardening in Iron, J. of Nucl. Mater., 465 (2015) 448-454.

[2] A. J. E. Foreman, The bowing of a dislocation segment, Phil. Mag., 15, 1011 (1967). 79.

[3] D. J. Bacon, U. F. Kocks and R. 0. Scattergood, The effect of dislocation self-interaction on the Orowan stress, Phil. Mag., 1241 (1973). 


\title{
7.2 THEORETICAL ANALYSIS OF PHASE STABILITY AND PRECIPITATION IN W-BASE Re-Os ALLOYS
}

\author{
G. D. Samolyuk (samolyukgd@ornl.gov) and Y. N. Osetskiy
}

\section{OBJECTIVE}

The purpose of this research is to understand the electronic/atomic level properties of defects. Microstructure features and phenomena such as precipitates, interfaces and their properties and effects on mechanical properties are the primary targets. The main methods applied are density functional (DFT) base modeling of microstructures and low-scale properties combined with atomistic modeling, depending on the available interatomic potentials. Another objective is phase stability in complex oxide-metal system. Such as ODS steels.

\section{SUMMARY}

We have finished developing a thermodynamic model for multi-phase multi-component systems to study defects equilibrium in complex oxide-metal systems. The new approach allows investigation of defect concentration as a function of both precipitate volume fraction and size distribution. It also includes consideration of the specific orientation of the precipitate-matrix interface.

The research is in its initial stage. We applied first principles methods to study the energy of hcp and $\chi$, optimized structures with composition $\mathrm{ReOs}_{2} \mathrm{~W}$. It was found that the hcp structure has lower energy than $\chi$. This result agrees with experimental observation. It was illustrated that this result could be understood within a simple virtual crystal approximation (VCA).

\section{PROGRESS AND STATUS}

Enhancing the preferential adsorption of radiation produced defects on interfaces is one of the most promising approaches to the development of radiation resistant materials. A practical realization of this idea is represented by oxide-metal systems (OMSs), such as ODS steels. OMSs materials demonstrate both radiation tolerance and improved mechanical properties. We recently proposed a thermodynamic approach to study equilibrium in these multiphase systems. We estimate the thermodynamic equilibrium by minimizing the free energy of the whole multiphase system using a limited set of defects and microstructural features for which the properties are calculated by DFT. The initial approach has now been extended and directly includes defects on the interface. The new approach allows investigation of defect concentration as a function of both precipitate volume fraction and size distribution; it also includes specific orientation of the precipitate-matrix interface. As an example, we considered $\mathrm{Y}_{2} \mathrm{O}_{3}+$ bcc Fe with vacancies in both the $\mathrm{Y}_{2} \mathrm{O}_{3}$ and bcc Fe phases, $\mathrm{Y}$ substitutions and $\mathrm{O}$ interstitials in Fe, Fe impurities and antisite defects in $\mathrm{Y}_{2} \mathrm{O}_{3}$. Special attention is devoted to the role of vacancies in the stability of $\mathrm{Y}_{2} \mathrm{O}_{3}$ precipitates. At the current stage the formalism part has been developed and the project is at the stage of code testing.

Tungsten and its alloys are the primary candidate materials for plasma facing components in fusion reactors where they are exposed to high-energy neutrons. Previous reports have shown that neutron irradiation of tungsten results in transmutation reactions following the sequence $W \rightarrow \operatorname{Re} \rightarrow$ Os and include other products in lesser amounts such as Ta, He, etc. It is therefore important to determine the stability of different phases in $\mathrm{W}$ alloys with such a complex composition. 
We have launched an extended program of DFT-based calculations to estimate solubility of different phases in W-Re-Os alloys. This activity is correlated with the ongoing experimental program on tungsten.

Initially we studied the basic properties of structures relevant to the problem. Thus, we optimized the crystal structure of both bcc $\mathrm{W}$ and $\mathrm{Re}_{2} \mathrm{~W}$. The calculation has been executed using the electronic structure calculation package, VASP, with $5 \times 5 \times 2 \mathrm{k}$-points in the irreducible part of the Brillouin zone, with $230 \mathrm{eV}$ plane wave energy cut-off. The lattice parameters obtained are $\mathrm{a}=3.1863 \AA$, and $\mathrm{a}=5.13232$ $\AA, c=8.3773 \AA$ for bcc $\mathrm{W}$ and $\mathrm{Re}_{2} \mathrm{~W}$ Laves phase, respectively. The calculated parameters deviate from experiment by $0.7 \%$ for the case of pure $\mathrm{W}$ and by $-5 \%$ for both a and c for $\operatorname{Re}_{2} \mathrm{~W}$.

At the next stage, we compared the energies of hcp and $\chi$ optimized structures with composition $\mathrm{ReOs}_{2} \mathrm{~W}$. According to the experiment, the precipitates correspond to solid solution (ss). In order to imitate the ss W, Re and Os atoms were randomly distributed between 96 or 232 possible lattice sites of hcp or $\chi$ structure supercells, respectively. The calculation has been executed using electronic structure calculation package, VASP, with $4 \times 4 \times 4$ and $2 \times 2 \times 2 \mathrm{k}$-points in the irreducible part of the Brillouin zone of hcp or $\chi$ structures, respectively, with $300 \mathrm{eV}$ plane wave energy cut-off. The hcp structure has lower energy by $0.11 \mathrm{eV}$ per atom compared to the $\chi$ structure. This result is in agreement with a virtual crystal approximation (VCA) estimation. According to VCA, the average number of valence electrons per atom, 7.25, is close to the Re case, thus the structure should order in the same ground state as Re, i.e. hcp. The results are summarized in Figure 54 where hcp- and $\chi$ - phase structure are shown.

\section{$\mathrm{ReOs}_{2} \mathrm{~W}$ ground state structure}

hcp structure supercell with 96 atoms

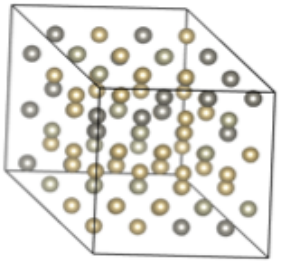

Atoms in supercell are randomly distributed and number of atoms $\chi$-structure supercell with 232 atoms of each type preserves concentration

VASP calculations result

(the atomic position, volume and c/a ratio were optimized)

$$
\mathrm{E}_{\text {hex }}-\mathrm{E}_{\chi}=-0.11 \mathrm{eV} \text { per atom }
$$

In agreement with virtual crystal approximation, the averaged number of valence electrons per atom, 7.25, is close to the Re one, this the structure should order in the same with $\mathrm{Re}$ ground state, i.e. hcp

Figure 54. Structure of hcp- and $\mathcal{x}$ - phases with random distribution of atoms for composition $\mathrm{ReOs}_{2} W$. The stability of hcp-phase is demonstrated by comparison of the energy per atom. 


\section{FUTURE STUDY}

1. The existing thermodynamic model will be extended to include precipitate-matrix interfaces as an additional region with specific defect properties calculated in the corresponding DFT studies. This allows consideration of the specific orientation of the oxide-matrix interface

2. The general aim in studying $\mathrm{W}$-alloy phase stability is to increase model size which demands significant computational resources. However, large simulated crystal will allow:

- $\quad$ investigation of the stability of Laves vs sigma phase;

- $\quad$ more precise treatment of composition effects, especially lower concentration of Re and Os;

- consideration of statistics of the components distribution; and

- inclusion of point defects such as vacancies and interstitial atoms in phase stability calculations. 


\section{INTERNATIONAL COLLABORATIONS}

\subsection{US-JAPAN COLLABORATIONS ON STRUCTURAL MATERIALS}

H. Sakasegawa (sakasagawah@ornl.gov), H. Tanigawa, M. Ando, D. Hamaguchi, T. Nozawa, T. Hirose (National Institutes for Quantum and Radiological Science and Technology, Japan), X. Cheng, Y. Katoh and J.W. Geringer (Oak Ridge National Laboratory)

\section{OBJECTIVE}

This collaboration between the Department of Energy (DOE) and the National Institutes for Quantum and Radiological Science and Technology (QST), Japan jointly pursues activities using the advanced capabilities for materials irradiation and post-irradiated examination at Oak Ridge National Laboratory, especially the High Flux Isotope Reactor (HFIR). The focus is on ferritic steels and other advanced materials, especially the development of the materials database for the design of facilities beyond ITER. The goals include achieving DEMO-relevant performance data on structural materials neutron irradiated in HFIR to high levels of displacement damage.

\section{SUMMARY}

The DOE-QST collaboration continues to make steady progress in building the materials data bases for the reduced activation ferritic martensitic (RAFM) F82H steel and SiC/SiC composites. In particular, high temperature tensile properties of heavily irradiated $\mathrm{F} 82 \mathrm{H}$, up to $87 \mathrm{dpa}$, were obtained in 2016 after the irradiation campaign of HFIR capsules JP28 and 29. However, the thermometry analysis demonstrated that irradiation was possibly conducted at lower temperatures than designed for the specimen holders at 673 and $773 \mathrm{~K}$. We then focused on measuring irradiation hardening behavior to verify this thermometry analysis result and obtained comparable hardness between the specimen holders at designed temperatures of 673 and $773 \mathrm{~K}$. Though this supports the result of thermometry analysis, it can be assumed that the decrease in actual irradiation temperature did not largely affect the irradiation behavior for the specimen holder at $673 \mathrm{~K}$. This follows from the summary of dose dependence of irradiation hardening including the results of past irradiation campaigns in JP26 and 27. This is because irradiation hardening saturated after about 9 dpa and no increase in hardness was observed at $~ 87$ dpa at $673 \mathrm{~K}$.

\section{PROGRESS AND STATUS}

Irradiation of the high-dose JP28 and 29 capsules was completed in 2013 and PIE has been mainly conducted on these heavily irradiated specimens since then. Table 10 shows the results of thermometry analysis for the tested specimen holders. It shows lower irradiation temperatures than designed for the specimen holders at 673 and $773 \mathrm{~K}$ [1]. These specimen holders were located on and around the horizontal mid-plane of the irradiation capsule to receive equivalent dose. 
Table 10. Dilatometry analysis result of HFIR capsule passive temperature monitors [1]

\begin{tabular}{llll}
\hline $\begin{array}{l}\text { Designed temperature } \\
(\mathrm{K})\end{array}$ & Specimen ID & $\begin{array}{l}\text { Analyzed median temperature } \\
(\mathrm{K})\end{array}$ & $\begin{array}{l}\text { Difference } \\
(\mathrm{K})\end{array}$ \\
\hline \hline \multirow{2}{*}{573} & JP29TM0704 & 591.6 & 18.6 \\
& JP29TM0708 & 557.3 & -15.7 \\
\hline \multirow{2}{*}{673} & JP28TM0702 & 593.5 & -79.5 \\
& JP28TM0704 & 587.7 & -85.3 \\
\hline \multirow{2}{*}{773} & JP28TM0902 & 620.2 & -152.8 \\
& JP28TM0904 & 612.3 & -160.7 \\
\hline \hline
\end{tabular}

This result was verified through Vickers hardness test and Figure 55 shows the results for F82H IEA and mod3 heats. In the figure, the temperatures shown are the design temperatures. For the IEA heat, hardness decreased with increasing irradiation temperature, but mod3 heat showed no significant difference in hardness between 673 and $773 \mathrm{~K}$. This unexpected irradiation hardening behavior of mod3 supports the possible lower irradiation temperatures for the 673 and $773 \mathrm{~K}$ specimen holders.

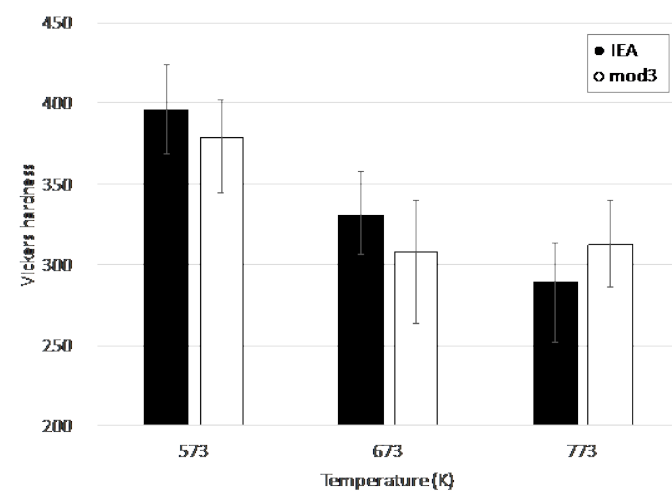

Figure 55. Vickers hardness test result for F82H irradiated in JP28 and 29.

Figure 56 shows the dose dependence of Vickers hardness summarized from the results of HFIR capsules JP26, 27, 28 and 29. As reported in the previous work [2], designed temperatures had been successfully achieved in JP26 and 27. 


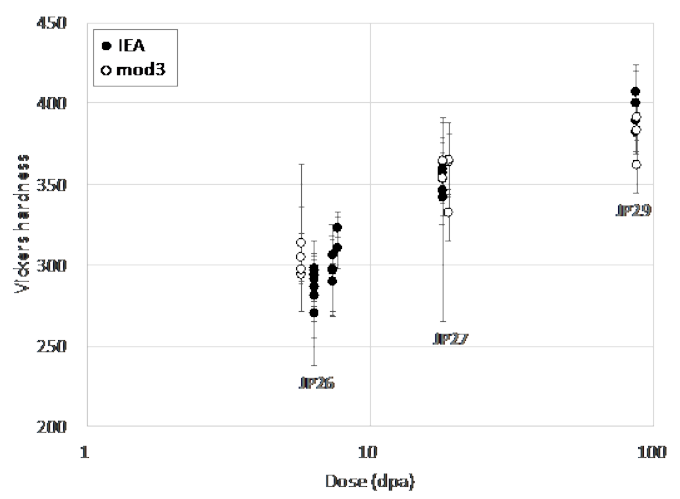

(a) $573 \mathrm{~K}$

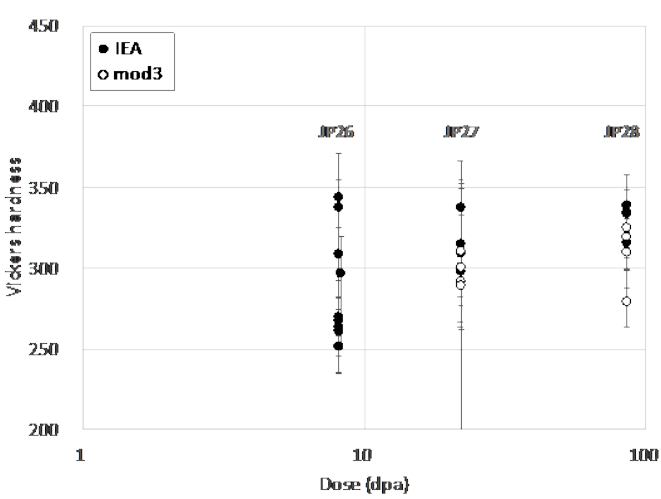

(b) $673 \mathrm{~K}$

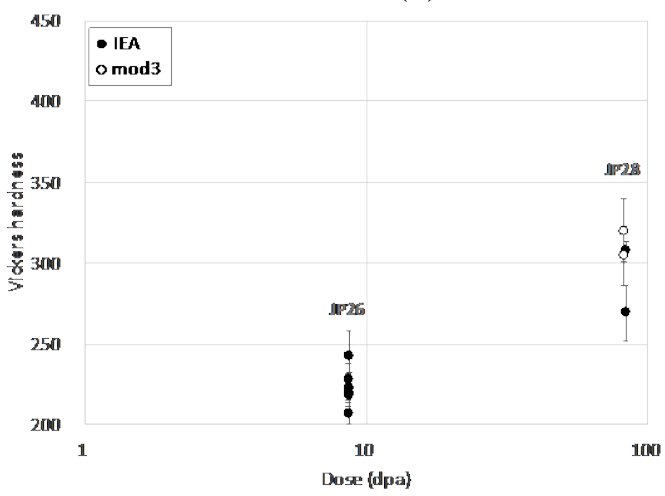

(c) $873 \mathrm{~K}$

Figure 56. Dose dependence of Vickers hardness for F82H irradiated in JP28 and 29.

For the result of $573 \mathrm{~K}$ irradiation in Figure 56 (a), hardness increased with increasing dose, though postirradiation tensile and hardness test results in the past report indicated that irradiation hardening was saturated by 9 dpa [3]. For the result at $673 \mathrm{~K}$ in Figure 56 (b), no significant change was found from $\sim 22$ dpa (JP27) to 86 dpa (JP28). The thermometry analysis of JP28 indicated that the actual irradiation temperature was lower than the designed temperature by about $80 \mathrm{~K}$, as given in Table 10 . In general, a decrease in irradiation temperature tends to enhance irradiation hardening and to increase hardness. No significant change in hardness means that the decrease in actual irradiation temperature did not largely affect the irradiation behavior of F82H in the $673 \mathrm{~K}$ specimen holder. However, attention needs to be paid to the possibility of softening during irradiation, since such softening can compensate for the hardening due to a temperature decrease. However, in the case of aged IEA heat, no significant softening was reported for up to $100 \mathrm{kh}$ at temperatures lower than $823 \mathrm{~K} \mathrm{[4]} \mathrm{and} \mathrm{FFTF} \mathrm{irradiation} \mathrm{at} 673 \mathrm{~K}$ with better controlled temperature operation showed irradiation hardening rather than softening from 40 to 60 dpa [5]. For the result of $773 \mathrm{~K}$ irradiation in Figure 56(c), hardness showed no significant change up to 8.6 dpa, but increased after $\sim 86$ dpa irradiation. As given in Table 10, the thermometry analysis indicated that the actual irradiation temperature was lower than the designed temperature by about $155 \mathrm{~K}$. Irradiation hardening was possibly promoted due to the decrease in irradiation temperature and this can be supported by the result of mod3 heat given in Figure 55.

\section{FUTURE PLANS}

Microstructural observation will be performed and dimensional changes in specimen holders will be additionally investigated for PIE on JP28 and 29. This will evaluate one of the possible reasons for temperature changes, that is if creep deformation of specimen holders during irradiation gives 
simultaneous improved cooling condition and decrease irradiation temperature. It will also be helpful to perform thermometry analyses for other specimen holders which have not yet been performed. Other PIE will be performed on JP30 and 31 target capsules containing TIG and EB weldments and HIP joints of F82H, complementary rabbit capsules of the F8 and F13 series irradiated up to $50 \mathrm{dpa}$, and RB-19J companion rabbit capsule irradiated at a low temperature.

In addition, new irradiation campaigns have started, including irradiation of F82H pressurized creep tube at lower temperatures and lower doses related to ITER-TBM operating conditions and irradiation of $\mathrm{Cu}$ alloys to provide information supporting an ITER tungsten diverter prototype design.

\section{REFERENCES}

[1] H. Sakasegawa, H. Tanigawa, T. Hirose, M. Ando, Y. Katoh, C.O. Stevens, M.R. McAlister, “TENSILE FRACTURE MECHANISM OF HFIR-HEAVILY-IRRADIATED F82Hs”, DOE/ER0313 Semi-Annual Progress Reports, 59 (2015) 22-25.

[2] T. Hirose, N. Okubo, H. Tanigawa, Y. Katoh, A.M. Clark, J.L. McDuffee, D.W. Heatherly, R.E. Stoller, "IRRADIATION TEMPERATURE DETERMINATION OF HFIR TARGET CAPSULES USING DILATOMETRIC ANALYSIS OF SILICON CARBIDE MONITORS”, DOE/ER-0313 Semi-Annual Progress Reports, 49 (2010) 94-99.

[3] T. Hirose, N. Okubo, H. Tanigawa, M. Ando, M.A. Sokolov, R.E. Stoller, G.R. Odette, “IRRADIATION HARDENING IN F82H IRRADIATED AT 573 K IN THE HFIR”, Journal of Nuclear Materials, 417 (2011) 108-111.

[4] Takuya Nagasaka, Yoshimitsu Hishinuma, Takeo Muroga, Yanfen Li, Hideo Watanabe, Hiroyasu Tanigawa, Hideo Sakasegawa, Masami Ando, "EXTRACTION RESIDUE ANALYSIS ON F82HBA07 HEAT AND OTHER REDUCED ACTIVATION FERRITIC/MARTENSITIC STEELS”, Fusion Engineering and Design, 86 (2011) 2581-2584.

[5] T. Hirose et al., Effects of high dose neutron irradiation on reduced-activation ferritic/martensitic steels, ICFRM-17, Aachen, Germany, 11-16 October (2015). 


\subsection{US-JAPAN PHENIX PROGRAM}

\section{J.W. Geringer (geringerjw@ornl.gov), L.M. Garrison, A.S. Sabau, Y. Katoh}

\section{OBJECTIVE}

The PHENIX Project on Technological Assessment of Plasma Facing Components for DEMO Reactors is the current US/Japan Fusion Research Collaboration Project that started in April 2013. The goal of the project is to evaluate the following critical issues on plasma-facing components (PFCs) under divertor conditions of fusion reactors: (1) heat transfer, (2) mechanical properties, (3) neutron irradiation effects, and (4) tritium retention and permeation. The project participants are ORNL, Idaho National Laboratory, Sandia National Laboratory, Georgia Institute of Technology, National Institute for Fusion Science of Japan, and various Japanese universities. The roles of ORNL are to participate in Task 1 on high heat flux testing, Task 2 on neutron irradiation effects, and provide neutron irradiation in HFIR in support of all research tasks.

\section{SUMMARY}

In FY17, the HFIR-RB-19J instrumented capsule finished its fourth and final irradiation cycle, cycle 469, December 2016. It houses 1100 tungsten specimens. There are four different temperature zones of which the $800^{\circ} \mathrm{C}$ zone operated most consistent at design temperature. The reported operating temperatures for the three temperature zones relevant to the PHENIX collaboration were on average $550^{\circ} \mathrm{C}, 800^{\circ} \mathrm{C}$ and $1100^{\circ} \mathrm{C}$. Two companion rabbit capsules, PXW2 and PXW5, which were irradiated for one HFIR cycle, 458 , at designed temperature of $800^{\circ} \mathrm{C}$ and $1100^{\circ} \mathrm{C}$ respectively, were disassembled and shipped to the various end destinations.

Testing capabilities for miniature irradiated $\mathrm{W}$ specimens have been developed while pre-irradiation test results on the companion un-irradiated materials are being analyzed.

The plasma arc lamp facility is in the process of being upgraded. A new reflector was fabricated that will maximize the heat flux for the existent facility to achieve a target heat flux of $12 \mathrm{MW} / \mathrm{m}^{2}$ (incident) or 6 $\mathrm{MW} / \mathrm{m}^{2}$ (absorbed in $\mathrm{W}$ ) over a $2 \times 15 \mathrm{~cm}^{2}$ area.

\section{PHENIX Task 1. High heat flux testing of W-based specimens}

For the heat load test group, the new test stand and the installation of the new reflector for the ORNL PAL facility was the main objective for this annual period. The main effort will be directed towards extensive HHFT after the installation of the new reflector. The new reflector was received and is pending installation. After preliminary test, such as direct temperature measurement and characterization of test material, the heat load test for RB-19J irradiated materials will be started under heat flux levels expected to reach $12 \mathrm{MW} / \mathrm{m}^{2}$.

\section{PHENIX Task 2. Effects of neutron irradiation}

During May 2017 a workshop on the pre- and post-irradiation examination (PIE) was held in Oak Ridge. During FY17 focus was on efforts to ship and disassemble the two irradiation experiments, the rabbit capsules PXW2 and PXW5, consisting of disc specimens and the RB-19J capsule consisting of disc, tensile, fracture toughness, and torsion specimens.

In parallel, new test capabilities are being developed and testing of the companion un-irradiated materials is underway. Hardness testing has been completed on all the US materials. Room temperature 
tensile tests have been completed and elevated tensile tests are underway. Initial trials of equibiaxial flexure tests on selected materials were completed successfully and will be followed with additional measurements. Scanning electron microscopy of most of the RB-19J materials was used to analyze the pre-irradiation grain structures. This will be followed by electron backscatter diffraction analysis.

The two rabbit capsules were successfully disassembled and a portion of the specimens were shipped to Idaho National Laboratory while the remaining irradiated specimens were transferred to LAMDA. The RB-19J experiment, categorized as a shipping Hazard Category 3, required a more rigorous shipping approval process. The transfer from HFIR to the building 3525 hot cell facility was approved in September 2017, and it is expected that shipping and disassembly will occur during the first months of 2018.

New test techniques under development for the specimens from RB-19J include fiber tests, miniature fracture toughness, miniature electrical resistivity and miniature thermal diffusivity. For tungsten fibers with lengths between 36-40 mm and $150 \mu \mathrm{m}$ diameters, a new tensile test method is being developed with ASTM C1557 as a guide. A three-point bend fixture has been designed for the tungsten bend bars with dimensions $4 \times 2 \times 10 \mathrm{~mm}$. New procedures are being adapted for these small specimens. To evaluate the thermal properties changes of tungsten after irradiation, using samples $6 \mathrm{~mm}$ in diameter and $1 \mathrm{~mm}$ thick, a Netzsch LFA 467 HT HyperFlash instrument has been purchased for thermal diffusivity measurements. As the instrument suffered some shipping and installation damage, it is being repaired by the Manufacturer and should be available late in 2017.

\section{FUTURE PLANS}

PIE will begin on the rabbit specimens late in 2017. After disassembly of the RB-19J capsule, estimated to be completed in calendar year 2018, mechanical tests of the RB-19J materials will begin with tensile tests and micro hardness tests in the hot cells. HHFT will commence once the new reflector has been installed in the PAL facility.

All technical tasks will continue through FY-19. ORNL will contribute to the project by providing project management, participating in personnel exchanges and workshops, and publishing and presenting the results, in addition to the continuing research in the areas planned for FY18. 


\title{
8.3 US-EUROfusion PROJECT - FATIGUE PRECRACKING M4CVN STEEL SPECIMENS
}

\author{
X. Chen (chenx2@ornl.gov), R.L. Swain, E.T. Manneschmidt, K.D. Linton, Y. Katoh
}

\section{OBJECTIVE}

The aim of this task is to perform fatigue pre-cracking of multi-notch bend type specimens (referred to as M4CVN specimens) for the EUROfusion project. Fatigue pre-cracking results in a sharp initial crack in the specimen, necessary for fracture toughness testing.

\section{SUMMARY}

We performed fatigue pre-cracking of M4CVN specimens for the EUROfusion project. The test materials include variants of reduced activation ferritic - martensitic (RAFM) steels from both Europe and US for the EUROfusion project. A total of 153 M4CVN specimens have been successfully fatigue pre-cracked.

\section{PROGRESS AND STATUS}

In the EUROfusion project, the irradiation effects on transition fracture toughness of Eurofer 97 RAFM steel is one of the core required properties. To fully utilize limited irradiation volume in HFIR, a M4CVN specimen is used, which enables four fracture toughness tests in one single specimen. The prerequisite of transition fracture toughness testing is to create a sharp starting crack in the specimen which is realized by high frequency fatigue pre-cracking. This task performed fatigue pre-cracking on M4CVN specimens for the project.

A wide variety of RAFM steels from both Europe and US were included for machining M4CVN specimens. Table 11 summarizes different material variants and number of specimens machined.

Table 11. Summary of variants of RAFM steels included in this study

\begin{tabular}{|c|c|}
\hline Material & Number of M4CVN specimens \\
\hline Eurofer 97 baseline & 37 \\
\hline EUROFusion task \#7 (10 material variants) & 72 \\
\hline US augment (CNA-54, E97-23, E97-54) & 44 \\
\hline
\end{tabular}

The M4CVN specimen dimensions as well as ID markings for the specimen are shown in Figure 57. The specimen has a thickness B of $1.65 \mathrm{~mm}$, width $\mathrm{W}$ of $3.3 \mathrm{~mm}$, and four machined notches with $0.51 \mathrm{~mm}$ depth, $30^{\circ}$ angle, and $0.08 \mathrm{~mm}$ root radius. Each individual notch of the specimen is uniquely marked from left to right as L, LM, RM, and R.

Fatigue pre-cracking of M4CVN specimens used a 3-point bend type test fixture mounted on a $44.5 \mathrm{kN}$ capacity servo-hydraulic frame as shown in Figure 58. The detailed fatigue pre-cracking methods, procedures, and results have been reported previously [1]. For the majority of tests, the final fatigue precrack length for each notch was approximately 1.452-1.485 mm corresponding to a crack length to specimen width ratio $(\mathrm{a} / \mathrm{W})$ of $0.44-0.45$. 


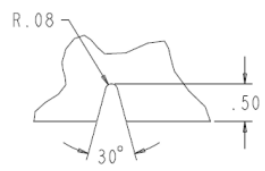

$\underset{\text { SCALE }}{\text { DET }}$ A 000
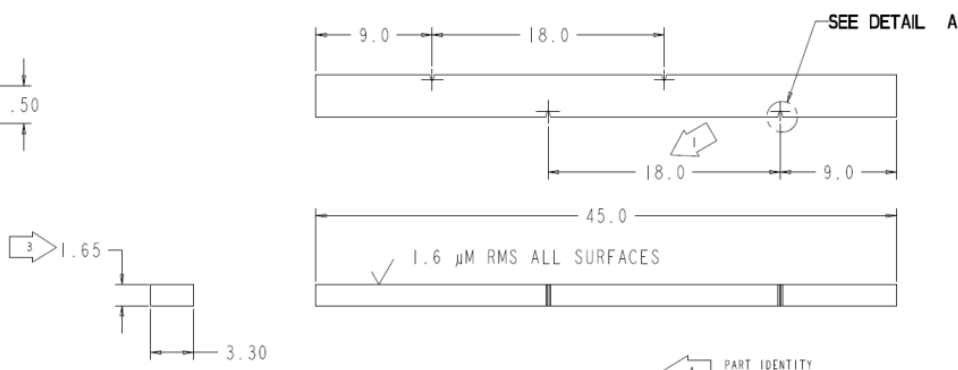

47 PART LEENITY

(a)



(b)

Figure 57. M4CVN specimen dimension in (a) and ID markings in (b).

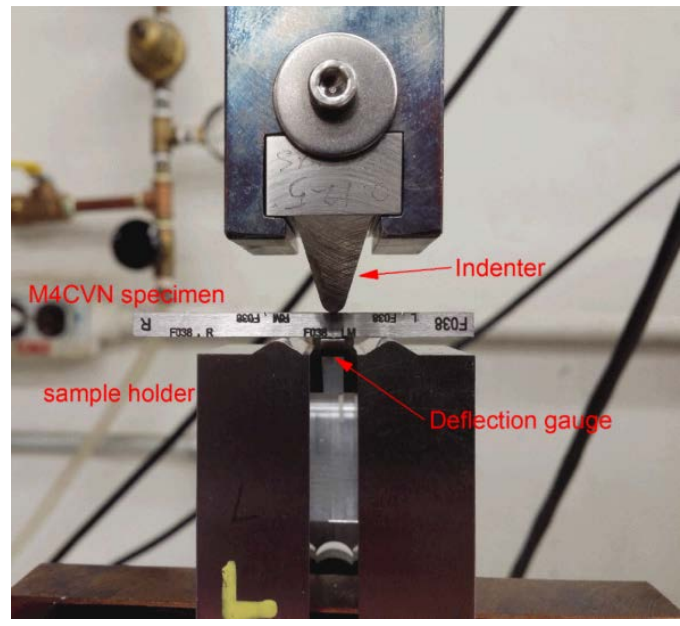

Figure 58. Fatigue pre-cracking test fixture for a M4CVN specimen.

\section{FUTURE PLANS}

Some of fatigue pre-cracked M4CVN specimens will be used in building irradiation capsules for irradiation experiments in HFIR. Remaining specimens will be used to measure material un-irradiated fracture toughness properties.

\section{REFERENCES}

[1] Fusion Materials Semiannual v.62 for January 1 - June 30, 2017. 


\section{MATERIALS ENGINEERING SUPPORTING THE FNSF CONCEPTUAL DESIGN}

\section{A.F.Rowcliffe (art.rowcliffe@gmail.com)}

\section{OBJECTIVE}

The objective of this task is to identify potential materials solutions for the Fusion Neutron Science Facility (FNSF) power core components, tritium containment and extraction systems and for lifetime components such as the vacuum vessel, structural ring and low temperature shield. In addition, the suitability of a sub-set of these structural materials as candidate substrate materials for LM-PFC concepts is being evaluated.

\section{PROGRESS AND STATUS}

A range of structural and plasma facing materials were evaluated for power core and lifetime components for the FNSF to develop a credible basis for advancing conceptual design activities. The peak blanket operating temperature and radiation damage tolerance requirements for each of the FNSF operational phases from nuclear break-in up to DEMO relevant requirements are illustrated in Figure 59.

\begin{tabular}{|c|c|c|c|c|c|c|c|c|}
\hline Phase & 1 & 2 & 3 & 4 & 5 & 6 & 7 & Power Plant \\
\hline & $\mathrm{He} / \mathrm{H}$ & DD & DT & DT & DT & DT & DT & \\
\hline years & $1-2$ & 2-3 & 2.75 & 4.5 & 5.0 & 6.5 & 6.5 & $40 \mathrm{FPY}$ \\
\hline $\mathrm{N}_{\mathrm{w}}^{\text {peak }}, \mathrm{MW} / \mathrm{m}^{2}$ & & & 1.75 & 1.75 & 1.75 & 1.75 & 1.75 & 2.25 \\
\hline Plasma on-time, \%/year & & $15-50$ & $\begin{array}{c}15 \\
55 \mathrm{~d} / \mathrm{yr}\end{array}$ & $\begin{array}{c}25 \\
91 \mathrm{~d} / \mathrm{yr}\end{array}$ & $\begin{array}{c}35 \\
128 \mathrm{~d} / \mathrm{yr}\end{array}$ & $\begin{array}{c}35 \\
128 \mathrm{~d} / \mathrm{yr}\end{array}$ & $\begin{array}{c}35 \\
128 \mathrm{~d} / \mathrm{yr}\end{array}$ & $\begin{array}{l}85 \\
310 \mathrm{~d} / \mathrm{yr}\end{array}$ \\
\hline & & & 7.2 & 19.7 & 30.6 & 39.8 & 79.6 & \\
\hline & & & 73 & 200 & 310 & 403 & 806 & $1500-2000$ \\
\hline Peak appm H & & & 327 & 894 & 1388 & 1806 & 3612 & $6800-9100$ \\
\hline Blanket structure op temp, ${ }^{\circ} \mathrm{C}$ & $<\mathbf{5 5 0}$ & $<\mathbf{5 5 0}$ & $350-550$ & $350-550$ & $400-600$ & $450-650$ & $450-650$ & 600 \\
\hline Blanket Structure material & $\begin{array}{l}\text { Gen I - } \\
\text { RAFM }\end{array}$ & $\begin{array}{l}\text { Gen I - } \\
\text { RAFM }\end{array}$ & $\begin{array}{l}\text { Gen I- } \\
\text { RAFM }\end{array}$ & $\begin{array}{c}\text { Gen I-RAFM } \\
\text { /ADV.RAFM }\end{array}$ & $\begin{array}{l}\text { ADV. } \\
\text { RAFM }\end{array}$ & $\begin{array}{l}\text { ADV.RAFM } \\
\text { /ODS }\end{array}$ & ODS & \\
\hline
\end{tabular}

Figure 59. The phased operations program for FNSF showing blanket peak operating temperatures and radiation damage requirements from nuclear break-in up to DEMO-relevant blanket conditions.

A timeline was developed linking the phased development of advanced materials to increasing levels of radiation damage tolerance coupled with improved corrosion resistance and high temperature creep strength. The timeframe to advance structural materials from the concept development phase to Technology Readiness Level (TRL) 5-6 is assumed to be of the order 15-20 years, based on assumptions on accommodating the large uncertainty in the availability of a fusion-relevant neutron source such as DONES/A-FNS/IFMIF. 
Potential opportunities for the current fusion materials program to address some of the materials-related issues directly relevant to on-going FNSF design activities were identified as follows:

- Determination of threshold He concentrations for initiation of intergranular fracture regimes in RAFMs at FNSF-relevant temperatures and dpa levels.

- Materials R\&D to advance novel high heat flux and particle management solutions for the FNSF first wall and blanket.

- Development of Al-bearing RAFMs and ODS alloys for improved compatibility with flowing PbLi.

- Neutron irradiation behavior of 3Cr-3WV vacuum vessel materials at $250-450^{\circ} \mathrm{C}$, simulating lifetime doses up to 1.0 dpa and $~ 2.0$ appm He.

- Establish response of the FNSF vacuum vessel to system loss-of-cooling events and impact of simulated thermal cycles on post-LOCA integrity.

Issues relating to the performance of advanced RAFMs and ODS alloys as substrate materials for liquid metal wall concepts were evaluated. An experimental program was started to evaluate the corrosion behavior of these materials in liquid $\mathrm{Sn}, \mathrm{Li}$ and $\mathrm{Sn}-\mathrm{Li}$. A preliminary evaluation was initiated of the corrosion behavior of F82H during 1000 hour tests at 400 to $650^{\circ} \mathrm{C}$ combined with an evaluation of the protective oxide barrier concept using a FeCrAl alloy (Kanthal alloy APMT) surrogate material. 


\title{
10. EXPERIMENTAL TECHNIQUES AND LABORATORY SYSTEMS
}

\subsection{ORNL PARTICIPATION IN THE IAEA COORDINATED RESEARCH PROJECT TOWARDS THE STANDARDIZATION OF SMALL SPECIMEN TEST TECHNIQUES FOR FUSION APPLICATIONS}

\author{
M. A. Sokolov (sokolovm@ornl.gov), X. Chen, M. N. Gussev, K. G. Field
}

\section{OBJECTIVE}

The International Atomic Energy Agency (IAEA) Coordinated Research Project (CRP) towards the standardization of small specimen test techniques (SSTT) for fusion applications aims to harmonize and coordinate world-wide development and acceptance of SSTT for fusion applications. ORNL participation in this project will contribute to three areas: tensile, fracture toughness, and fatigue crack growth rate testing.

\section{SUMMARY}

The IAEA CRP towards the standardization of SSTT for fusion applications has selected five test techniques: tensile, fracture toughness, creep, low cycle fatigue (LCF), and fatigue crack growth rate testing. ORNL will participate and make contribution in three areas: tensile, fracture toughness and fatigue crack growth rate. Analysis of SSTT results will focus on Fusion structural reference materials known as RAFM Steels. It is expected that the CRP will provide the basis for establishment of guidelines for the harmonization of SSTT practices as a first solid step towards standardization of those procedures.

\section{BACKGROUND}

Testing of small specimens play a key role in evaluating the properties of irradiated materials as a step in qualification for nuclear service in radiation environments. The use of small specimens provides several advantages. Typically, only a small volume of material can be irradiated in material test reactors at conditions simulating intended applications, conditions that include temperature, neutron flux, spectrum, and neutron dose. Small volumes of irradiated material also allow easier handling of specimens, reducing the amount of radioactive material, minimizing personnel exposures and simplifying waste disposal. However, small specimens also impose a variety of challenges. These challenges are associated with properly accounting for size effects and transferability of small specimen data to the design of structures for reactor operation. All of these issues are arguably the most extreme in developing candidate materials for fusion reactors.

The lack of common practices become critical issue when an international community is working toward the development of a new technology, as happens in the case of Fusion. To mitigate this, the IAEA has recently launched a CRP. The ultimate goal of this IAEA CRP is to harmonize and coordinate world-wide development and acceptance of SSTT for fusion applications. Initially, this CRP will focus on fusion reference structural materials, namely reduced activation ferritic martensitic steels (RAFMs). As part of the activity, a series of round robin tests will be carried out to establish best practices in the fields of fracture toughness, tensile, creep, LCF, and fatigue crack growth rate testing.

\section{DETAILED TASKS FOR THE IAEA CRP}

The detailed tasks for the five test areas the IAEA CRP will focus on is summarized in Table 12 which also shows the three areas in which ORNL will participate. 
Table 12. Detailed Tasks for the IAEA CRP

\begin{tabular}{|c|c|c|}
\hline Test areas & Tasks & $\begin{array}{c}\text { ORNL } \\
\text { participation }\end{array}$ \\
\hline Tensile & $\begin{array}{l}\text { 1. Review of the current small tensile testing methods and preparation } \\
\text { of draft testing guidelines. } \\
\text { 2. Demonstration of the small size tensile testing method based on the } \\
\text { draft guidance, followed by revision of the draft guidelines. } \\
\text { 3. Experimental demonstration of the inverse finite element method } \\
\text { and development of draft criteria for the minimum allowable } \\
\text { specimen size. } \\
\text { 4. Preliminary round robin test on the small size testing method. } \\
\text { 5. Proposal of guidelines for small size tensile testing method with } \\
\text { criteria for minimum allowable size. }\end{array}$ & Yes \\
\hline $\begin{array}{l}\text { Fracture } \\
\text { toughness }\end{array}$ & $\begin{array}{l}\text { 1. Preparation of SSTT reference guidelines and testing plan for } \\
\text { determining fracture toughness properties. Approaches: Master } \\
\text { Curve, Local Approach, Ductile Approach. } \\
\text { 2. Specimens to be used are Compact Tension, Bend Bars, Tensile } \\
\text { (smooth and notched). } \\
\text { 3. Performance and evaluation of the SSTT Round Robin plan for } \\
\text { determining fracture mechanics properties of fusion relevant } \\
\text { structural steels. }\end{array}$ & Yes \\
\hline Creep & $\begin{array}{l}\text { 1. Literature review for creep of F82H with standard size specimens } \\
\text { and creep tubes and standards for creep tests. } \\
\text { 2. Design of test matrix, including specimen size, applied stress, and } \\
\text { test temperatures. } \\
\text { 3. Uniaxial creep tests using flat type specimens. } \\
\text { 4. Uniaxial creep tests using round type specimens. } \\
\text { 5. Creep tests using creep tubes. } \\
\text { 6. Based on results of above tests, supplemental creep testing can be } \\
\text { carried out to complete the database construction. }\end{array}$ & No \\
\hline $\begin{array}{l}\text { Low cycle } \\
\text { fatigue }\end{array}$ & $\begin{array}{l}\text { 1. Literature review of effects of specimen shape, specimen size, } \\
\text { including microstructure. } \\
\text { 2. Experiment test matrix development for LCF using SSTT. } \\
\text { 3. Round robin tests of both EUROFER and F82H for different } \\
\text { specimen types (shape and size). } \\
\text { 4. Data evaluation and development of reference guideline. }\end{array}$ & No \\
\hline $\begin{array}{l}\text { Fatigue crack } \\
\text { growth }\end{array}$ & $\begin{array}{l}\text { 1. Literature review of the effect of specimen size on fatigue crack } \\
\text { growth. } \\
\text { 2. Fatigue crack growth Round Robin on EUROFER97 in both as } \\
\text { received and cold-worked conditions. } \\
\text { 3. Analysis of results and recommendations. }\end{array}$ & Yes \\
\hline
\end{tabular}




\subsection{MINIATURE MECHANICAL TESTS FOR TUNGSTEN BASED MATERIALS}

\section{Lauren Garrison (garrisonlm@ornl.gov),Emily Proehl, Xiang Chen}

\section{OBJECTIVE}

The aim of this work is to develop miniature mechanical test methods that can be used to evaluate neutronirradiated tungsten and tungsten composite materials.

\section{SUMMARY}

Because of activation concerns after irradiation, miniaturized, non-standard tungsten sample geometries are often used. Additionally, many tungsten based composites employ tungsten foils or tungsten fibers which also cannot use standard size mechanical test fixtures. A miniaturized, non-standard fracture toughness test is being developed for tungsten samples with dimensions $10 \times 4 \times 2 \mathrm{~mm}^{3}$, the geometry included in the PHENIX RB*19J HFIR irradiation capsule. Initial tests on the un-irradiated control samples are underway in preparation for irradiated sample tests.

\section{PROGRESS AND STATUS}

Fracture toughness testing will be conducted on several types of tungsten materials from the PHENIX RB*19J irradiation campaign to collect comparative fracture toughness data. The PHENIX sample size, $10 \times 4 \times 2 \mathrm{~mm}^{3}$ does not comply with the ASTM 399 or ASTM 1820-16 standards for fracture toughness testing. Therefore, a fixture with a span of $6.1 \mathrm{~mm}$ will be used to accommodate the $10 \mathrm{~mm}$ length of the PHENIX three-point bend specimens (Figure 60). A first test was successful for a tungsten specimen using the fixture in Figure 60b.
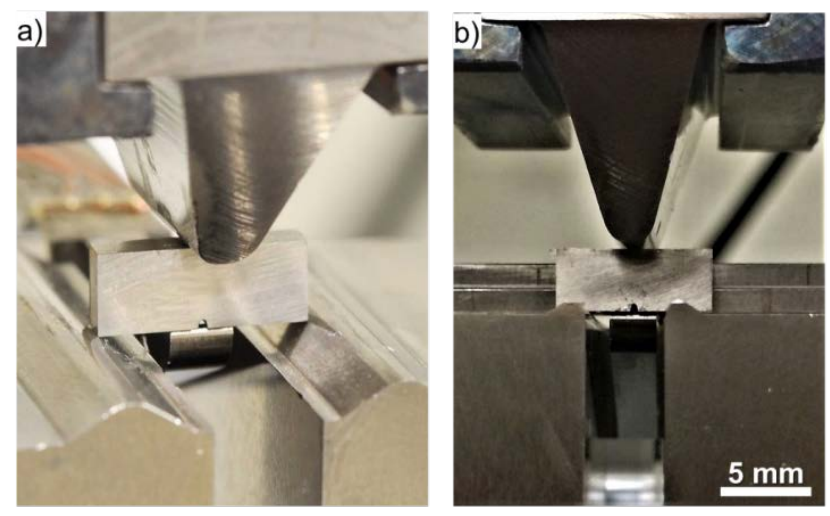

Figure 60. a) PHENIX specimen size (10 mm long) does not span the distance between support radii on a standard fixture. b) The fixture that will be used with the miniature $W$ samples has a span of $6.1 \mathrm{~mm}$.

During the applied test load cycle, the crack length was not measured accurately on the three-point bend software using the standard compliance equation. Therefore, the compliance coefficients must be altered in the fracture toughness software to match the nonstandard three-point bend specimen geometry. The load-line displacement and compliance is heavily dependent on the span to width ratio (S/W) of the specimen; the standard S/W ratio is 4 per ASTM E399-12, whereas the PHENIX samples have a S/W ratio of 1.525. Equation (1) shows the correlation between the load-line displacement, span, width, thickness, crack length, and load [1]: 


$$
E B \delta / P \cdot\left(\frac{1-a / W}{S / W}\right)=1.193-1.980 \cdot a / W+4.478 \cdot(a / W)^{2}-4.443 \cdot(a / W)^{3}+1.739 \cdot(a / W)^{4}
$$

where, $\mathrm{E}$ is Young's modulus, B is sample thickness, $\delta$ is load-line displacement, $\mathrm{P}$ is applied load, a is crack length, $\mathrm{W}$ is the width of the sample, and $\mathrm{S}$ is the span between the two points of contact on the support for the sample.

Equation (1) was re-derived using the S/W of 1.525, and the new coefficients were used in the three-point bend software. Despite this, the correct crack length was still not measured by the equipment. Additionally, pre-cracking efforts with a variety of load and amplitude parameters were unable to produce stable fatigue crack growth in the tungsten. Therefore, instead of a full J-R curve by ASTM E1820 standard, comparative critical stress intensity data, or fracture toughness, $\mathrm{K}_{\mathrm{IC}}$ may be the data procured from this study.

Multiple tests have been completed on tungsten samples with and without pre-cracking to measure the maximum load before failure instead of the full J-R curve (Table 13). Efforts to sharpen the notch have been tried and use a compressive load on the notch.

Table 13. Maximum load data for $W$ samples

\begin{tabular}{|l|l|l|l|l|}
\hline $\begin{array}{l}\text { Specimen } \\
\text { No. }\end{array}$ & Notch Treatment & $\begin{array}{l}\text { Compressive } \\
\text { Load (lbs) }\end{array}$ & Mode & $\begin{array}{l}\text { Max. load } \\
\text { (lbs) }\end{array}$ \\
\hline 1 & none & 0 & Load control & 420 \\
\hline 2 & none & 420 & K control & 150 \\
\hline 3 & none & 350 & K control & 281 \\
\hline 4 & $\begin{array}{l}\text { Sharpened with razor } \\
\text { blade }\end{array}$ & 0 & $\begin{array}{l}\text { Stroke control (load } \\
\text { rate } 0.1 \mathrm{~mm} / \mathrm{min})\end{array}$ & 300 \\
\hline 5 & $\begin{array}{l}\text { Low speed diamond } \\
\text { saw then razor blade }\end{array}$ & 0 & $\begin{array}{l}\text { Stroke control (load } \\
\text { rate } 0.1 \mathrm{~mm} / \mathrm{min})\end{array}$ & 465 \\
\hline 6 & none & 0 & $\begin{array}{l}\text { Stroke control (load } \\
\text { rate } 0.1 \mathrm{~mm} / \mathrm{min})\end{array}$ & 267 \\
\hline 7 & none & 0 & $\begin{array}{l}\text { Stroke control (load } \\
\text { rate } 0.1 \mathrm{~mm} / \mathrm{min})\end{array}$ & 265 \\
\hline 8 & none & 0 & $\begin{array}{l}\text { Stroke control (load } \\
\text { rate } 0.1 \mathrm{~mm} / \mathrm{min})\end{array}$ & 260 \\
\hline 9 & $\begin{array}{l}3 \text { min sharpening with } \\
\text { razor blade }\end{array}$ & 0 & $\begin{array}{l}\text { Stroke control (load } \\
\text { rate } 0.1 \mathrm{~mm} / \mathrm{min})\end{array}$ & 222 \\
\hline 10 & $\begin{array}{l}4 \text { min sharpening with } \\
\text { razor blade }\end{array}$ & 0 & $\begin{array}{l}\text { Stroke control (load } \\
\text { rate } 0.1 \mathrm{~mm} / \mathrm{min})\end{array}$ & 272 \\
\hline
\end{tabular}

\section{FUTURE PLANS}

The fracture toughness testing will continue on the un-irradiated specimens to determine a test plan that will be used for the irradiated PHENIX materials.

\section{REFERENCE}

[1] F. Haggag and J. Underwood, "Compliance of three-point bend specimen at the load line," International Journal of Fracture 26-2 (1984) R63-R65. 


\subsection{IN-SITU HEATING HOLDER FOR THE TALOS F200X S/TEM}

\section{M. Parish (parishcm@ornl.gov)}

A Protochips "Fusion" in-situ heating holder was purchased for use on the Talos F200X S/TEM. This system uses disposable MEMS-based devices as the heating elements, which allows very high heating and cooling rates with low drift inside the TEM. Figure 61 shows photographs of the Fusion system, which consists of a controller system, driver PC, double-tilt controller, and the holder itself.

As an example, an ion-irradiated nanostructured ferritic alloy has been prepared for in-situ heating. Figure 62a shows an image from the FIB tool of the sample being landed onto the disposable heating device; Figure 62b shows superimposed STEM-DF and STEM Ti-X ray data from the sample on the heating chip. The system has a nominal temperature limit of $1200^{\circ} \mathrm{C}$, but in the high vacuum of the TEM system $\left(\sim 10^{-7}\right.$ torr $)$ steels are limited to $\sim 500^{\circ} \mathrm{C}$ and other material limits are to be determined.

Future experiments are planned to study heating effects in structural and plasma-facing materials.

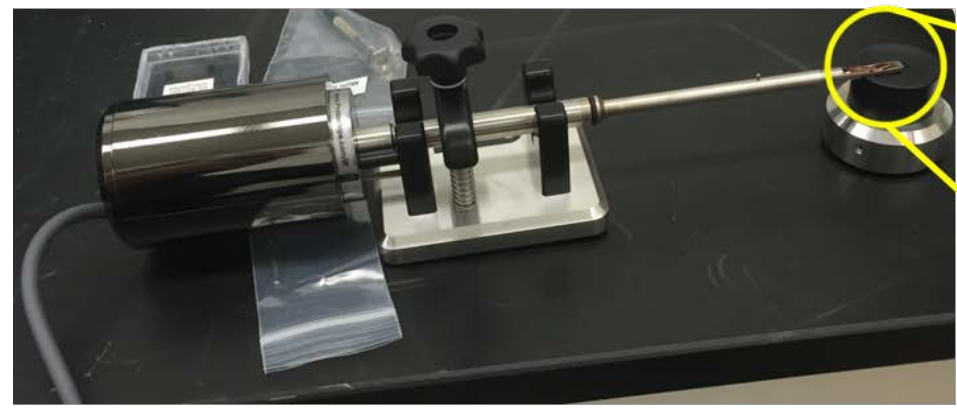

Protochips holder

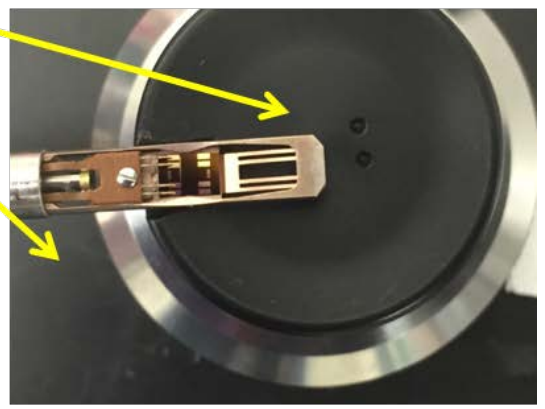

Holder tip with heating chip loaded

Figure 61. The Protochips Fusion heating TEM holder, and a detailed view of the double-tilt tip with a loaded heating chip. 

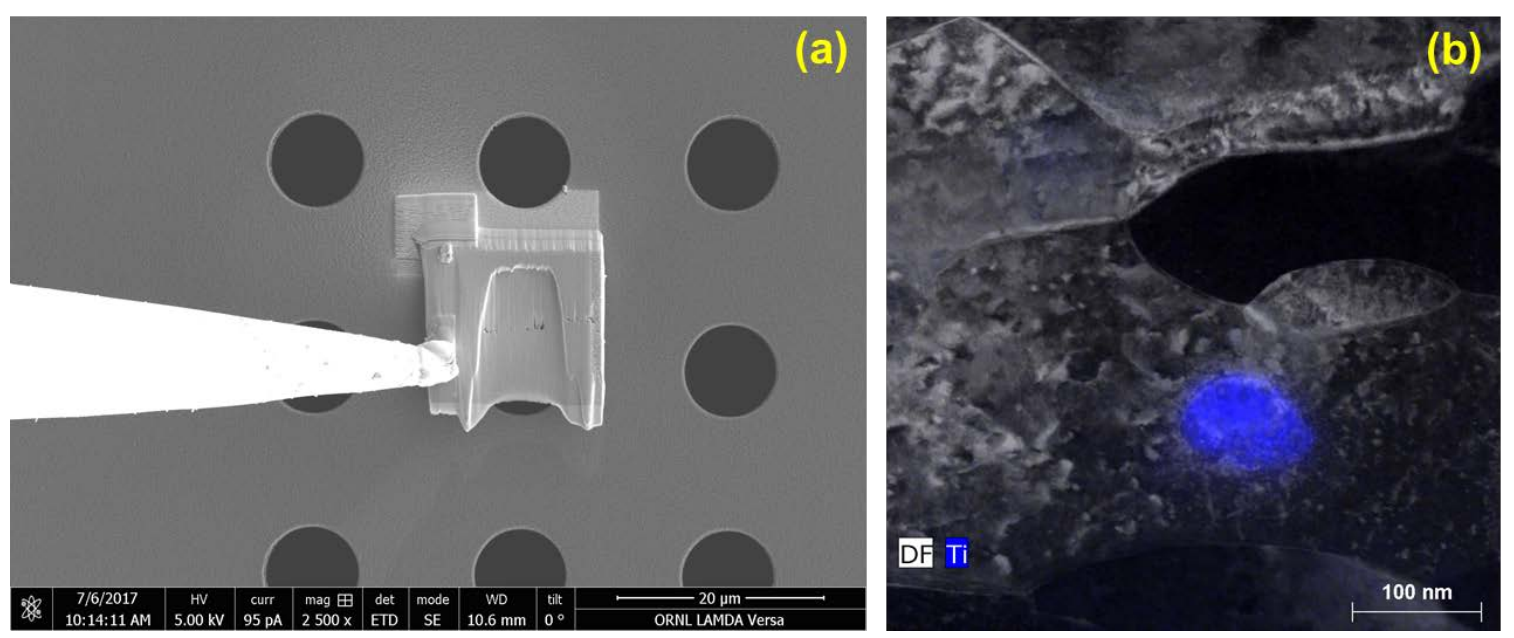

Figure 62. (a) SEM image from the LAMDA Versa3D DualBeam of a sample of ion-irradiated nanostructured ferritic alloy being landed on a heating chip. (b) STEM image $+X$-ray map of a sample in the heating holder. 


\subsection{ORNL INVENTORY SYSTEM FOR MANAGEMENT OF RADIOACTIVE SPECIMENS}

\section{Linda Hulsey (hulseylg@ornl.gov), Josh Schmidlin}

ORNL is developing a more efficient system for tracking the large and ever-growing inventory of irradiated material specimens. These specimens belong to several nuclear materials programs, come from irradiation experiments in HFIR, ATR and other reactors or accelerator-based sources, and reside in hot cells and other facilities shielded for storage of radioactive materials.

The LAMDA (Low Activation Materials Development and Analysis) lab is implementing a Laboratory Information Management System (LIMS) called LabWare. This commercial off the shelf software is highly customizable and can be used for tracking specimens, compiling irradiation history, assigning analyses and capturing test results. Currently there are over 9000 specimens in the LAMDA LIMS inventory system. As new specimens arrive in LAMDA they are barcoded and received into LIMS to track their location, including room, vault, shelf, and pig (storage cask). Barcoding of legacy specimens is an ongoing task.

Phase one of the LAMDA LIMS implementation has been completed and the core LIMS functions have been established. LabWare is being used to receive samples into LAMDA, to issue and return samples by research staff, to ship samples, and to dispose of samples. The software tracks custodianship, transaction dates, and locations. Also, it traces genealogy for specimen daughters and can record conditions.

Future phases include creating a work scheduling tool, introducing irradiation rabbit capsule tracking, and project functionality.

Implementation of LIMS is beginning in the Thermal Hydraulics \& Irradiation Engineering Group. This will allow capture of information at inception of irradiation experiments, including capsule and specimen design data, material certification records, and loading lists for specimens to be irradiated in HFIR.

The LabWare database is now connected to the HFIR database, which allows extraction of irradiation records including reactor cycles, dates, location within the reactor, positions within capsules, neutron flux, and calculated fluence. 


\title{
11. HFIR IRRADIATION PROGRAM
}

\subsection{THE MFE-RB-19J HFIR IRRADIATION EXPERIMENT}

\author{
J.W. Geringer (geringerjw@ornl.gov), C.R. Daily, J.L. McDuffee
}

\section{OBJECTIVE}

The HFIR MFE-RB-19J irradiation experiment is a collaborative effort between the US and Japan Fusion Materials programs to research tungsten for plasma facing components under divertor conditions and to evaluate blanket structural materials for DEMO and other fusion reactors.

The objective of this experiment is to irradiate tungsten and RAFM steel specimens at controlled temperatures of $300,500,800$ and $1200^{\circ} \mathrm{C}$ in the Removable Beryllium (RB) position of the High Flux Isotope Reactor (HFIR). The capsule has a gadolinium shield inside the capsule housing to reduce thermal neutron flux and thus reduce transmutation rates in specimen materials. The expected radiation damage levels for the originally planned six cycles of HFIR operation are 2.5 to 3 dpa for the steel and $\sim 1.0$ to 1.5 dpa for the tungsten.

\section{SUMMARY}

This experiment required a thermal neutron shield to modify the fast/thermal neutron ratio over the life of the experiment. Previous experiments used an external $\mathrm{Eu}_{2} \mathrm{O}_{3}$ shield for thermal neutron suppression, but that design is no longer feasible due to both fabrication difficulties with the $\mathrm{Eu}_{2} \mathrm{O}_{3}$ inserts and the HFIR management decision not to allow the replacement of the RB experiment liners. Therefore, a new design has been established that uses a gadolinium metal cylinder encased between an inner aluminum sleeve and the outer experiment tube. During normal operation, differential thermal expansion will press the aluminum sleeve and gadolinium shield against the outer tube, minimizing gaps between the parts and the temperature difference across those gaps. To minimize reductions in the nominally 25 day HFIR cycle length (due to the presence of the neutron shield, the irradiation period was spread over two fiscal years (three cycles in 2016 and one cycle in 2017).

The HFIR RB-19J irradiation experiment contains six cylindrical holders (four temperature zones) which house 1300 tungsten and steel specimens. The capsule and shield is design to be centered about the HFIR mid-plane, but the holders are shifted slightly upward from the mid-plane. The assembly of the RB19J capsule was completed in May 2016 and installed in HFIR in June 2016. The first irradiation cycle, 466, started June 142016 and the last irradiation cycle, 469, finished on December 9, 2016. The reported operating temperatures were on average $400^{\circ} \mathrm{C}, 550^{\circ} \mathrm{C}, 800^{\circ} \mathrm{C}$ and $1100^{\circ} \mathrm{C}$ for the four zones. During the four irradiation cycles eleven of the fourteen thermocouples malfunctioned and were subsequently disconnected. Temperature control was maintained by keeping the gas concentration similar to the recorded operating history.

After evaluation of the calculated Gd-shield burnout, it was decided to remove the experiment after four irradiation cycles. Based on the isotopic content from the activation analysis, the RB-19J capsule was categorized as a Hazard Category 3 shipment. A Transportation Safety Document (TSD) was prepared and submitted for DOE approval. The strategy for the onsite shipment to disassembly hot cells was approved in September 2017. 


\section{PROGRESS AND STATUS}

\section{Experiment Design and Specimen Matrices}

Thermal and Neutronics Analysis and Mechanical Design of the RB-19J experiment have been reported in detail in the Fusion Materials Semiannual Progress Report for the Period Ending June 30, 2016, report DOE-ER-0313/60, available in Pages 205-214.

The Specimen Matrices for the experiment are documented in the same Semiannual Progress Report in Pages 215-233.

\section{Operating History}

The capsule completed four irradiation cycles, three in FY16, cycle 466, 467 and 468 and one in FY17, cycle 469. Due to malfunctioned thermocouples, temperature during the last few cycles were maintained by controlling the $\mathrm{He} / \mathrm{Ar}$ gas concentration to match all zones according to operating history and by monitoring the remaining thermocouples in the $1200^{\circ} \mathrm{C}$ and $500^{\circ} \mathrm{C}$ zones. The reported operating temperatures were on average $400^{\circ} \mathrm{C}, 550^{\circ} \mathrm{C}, 800^{\circ} \mathrm{C}$ and $1100^{\circ} \mathrm{C}$ for the four zones.

Initial cycle reduction trends indicated faster than expected Gd-shield burnout. For the experiment to meet the objectives, it was determined that transmutation of $\mathrm{W}$ to Re and Os must remain below 1\%. A detailed neutronic analysis model of $800^{\circ} \mathrm{C}$ zone sub-holder section was created which is conceptually shown in Figure 63. The results summarized in Table 14 indicated that Re transmutation was expected to increase above the 1\% criteria by end of cycle (EOC) 470 and that a rapid increase would start to occur during the fifth cycle (Figure 64). The decision was made to remove the experiment after four cycles of irradiation.

The experiment finished irradiation with accumulated reactor operation of 8001 MWD.

(a)

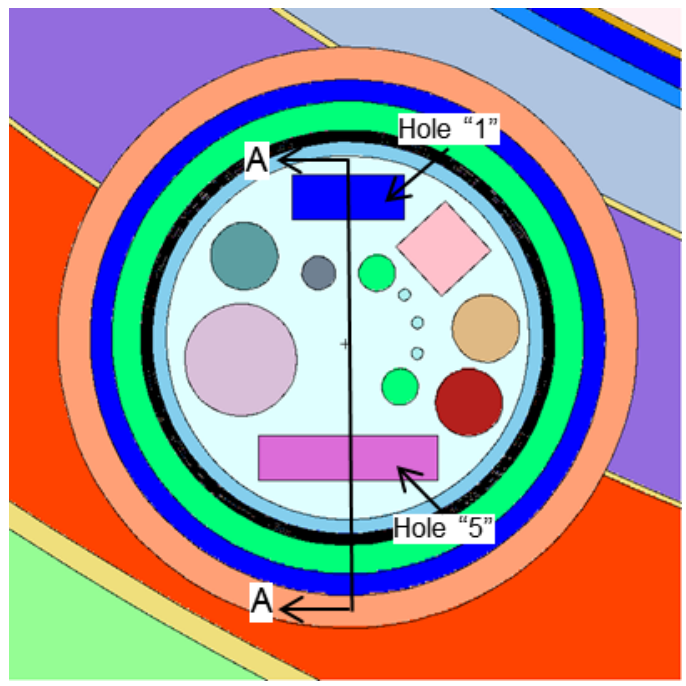

(b)

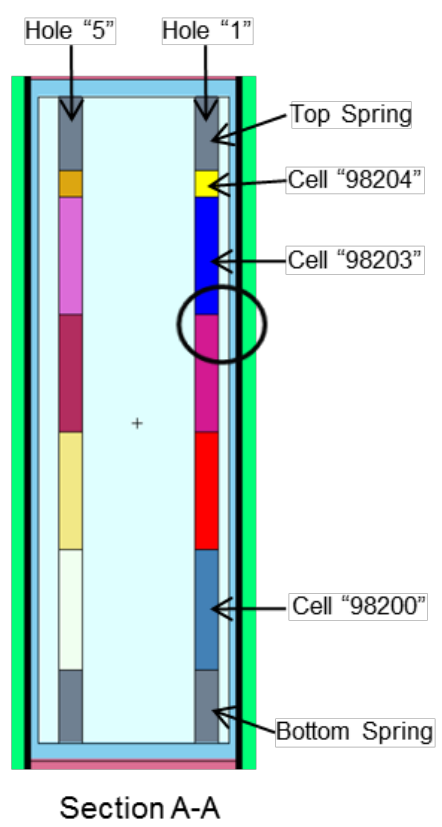

Section A-A

Figure 63. The $800^{\circ} \mathrm{C}$ zone analysis model overview: (a) Top view and (b) side view section cut A-A. 
Table 14. Accumulation of Rhenium by HFIR Cycle*

$\left({ }^{185} \mathrm{Re}+{ }^{187} \mathrm{Re}\right) /$ Initial W load $\left({ }^{180} \mathrm{~W}+{ }^{182} \mathrm{~W}+{ }^{183} \mathrm{~W}+{ }^{184} \mathrm{~W}+{ }^{186} \mathrm{~W}\right) * 100$

\begin{tabular}{|c|c|c|c|c|c|}
\hline & \multicolumn{5}{|c|}{ Cycle } \\
\hline Cell & EOC & EOC & EOC & EOC & EOC \\
& 466 & 467 & 468 & 469 & 470 \\
\hline 98200 & $0.11 \%$ & $0.24 \%$ & $0.38 \%$ & $0.52 \%$ & $0.74 \%$ \\
\hline 98203 & $0.12 \%$ & $0.24 \%$ & $0.39 \%$ & $0.54 \%$ & $0.93 \%$ \\
\hline 98204 & $0.13 \%$ & $0.27 \%$ & $0.44 \%$ & $0.61 \%$ & $1.06 \%$ \\
\hline
\end{tabular}

* This is a lower bound estimate for \% bulk transmutations. Does not include transmutations leading to any isotopes other than ${ }^{185,187}$ Re (including "new" stable W isotopes).

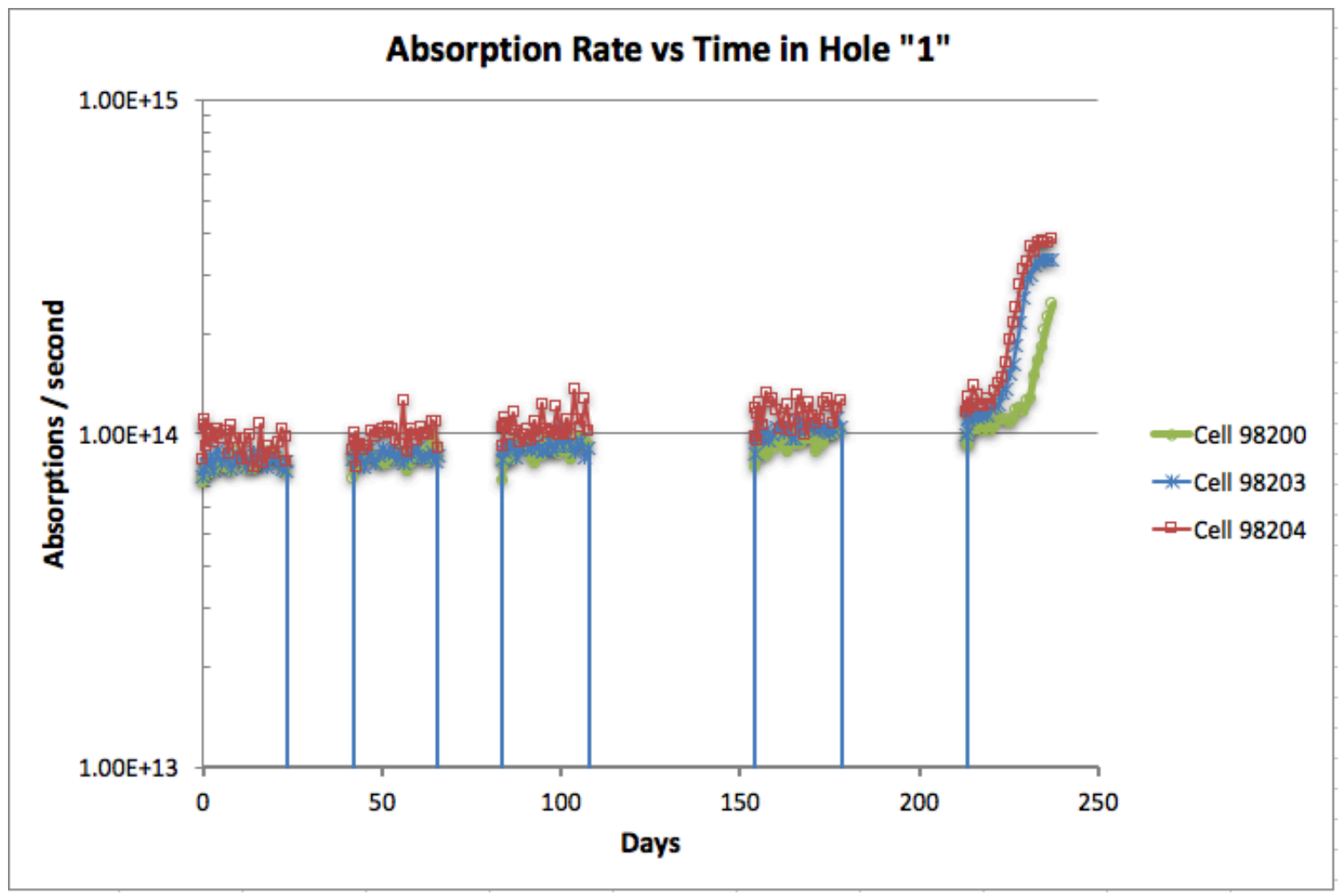

Figure 64. Absorption rate to produce ${ }^{185,187}$ Re over time for a representative section of the HFIR RB 19J irradiation capsule. 


\section{Shipping and Disassembly}

Activation calculations that determined the curie content for shipping were completed during February 2017, just after the last irradiation cycle. The radioactive material quantities in the RB-19J after irradiation constituted a Hazard Category-3 categorization. This categorization level required DOE approval. A Transport Safety Document (TSD) together with the Technical Safety Requirements (TSR) that documents the onsite transportation method, process and shipping content to move the RB-19J from the HFIR facility to 3525E hot cell facility, was submitted on May 5, 2017 for DOE review and successfully approved without conditions to the proposed strategy on September 25, 2017.

The RB-19J remained connected to the Material Irradiation Facility (MIF) to maintain gas pressure, Figure 65, but was successfully disconnected during August 2017 to prepare for site shipment. The internal pressure was maintained by inserting a steel plug into the flexible hose connection which was then clamped with at least two hose clamps to provide a positive seal against leakage.

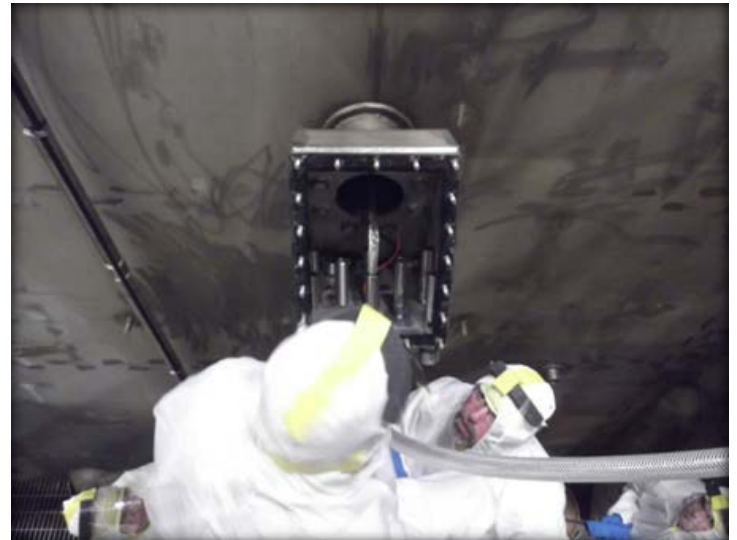

(a)

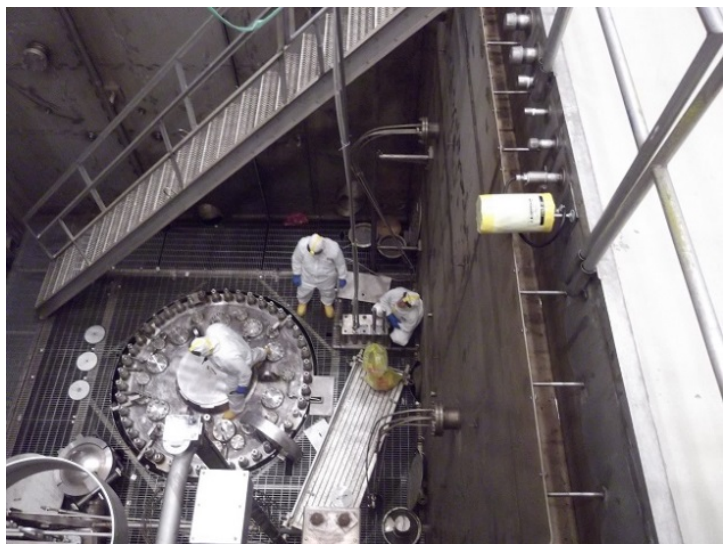

(b)

\section{Figure 65. Capsule RB-19J (a) MIF connection port and (b) capsule storage location while connected to the MIF.}

\section{FUTURE PLANS}

The next pending actions are to have the TSD implemented over the first few weeks of FY18 and then to have RB-19J transported with the use of a lead loop cask container, shown in Figure 66, to the 3525E hot cell facilities where the housing, sleeves and TCAT's will be removed. After that the sub-holders will be removed and separately transported to the 3025E hot cell facilities where the specimens will be removed from the holders and inventoried to start with post irradiation examination (PIE).

First testing and PIE of the specimen materials is expected to start during April 2018 or the second half of FY18. 

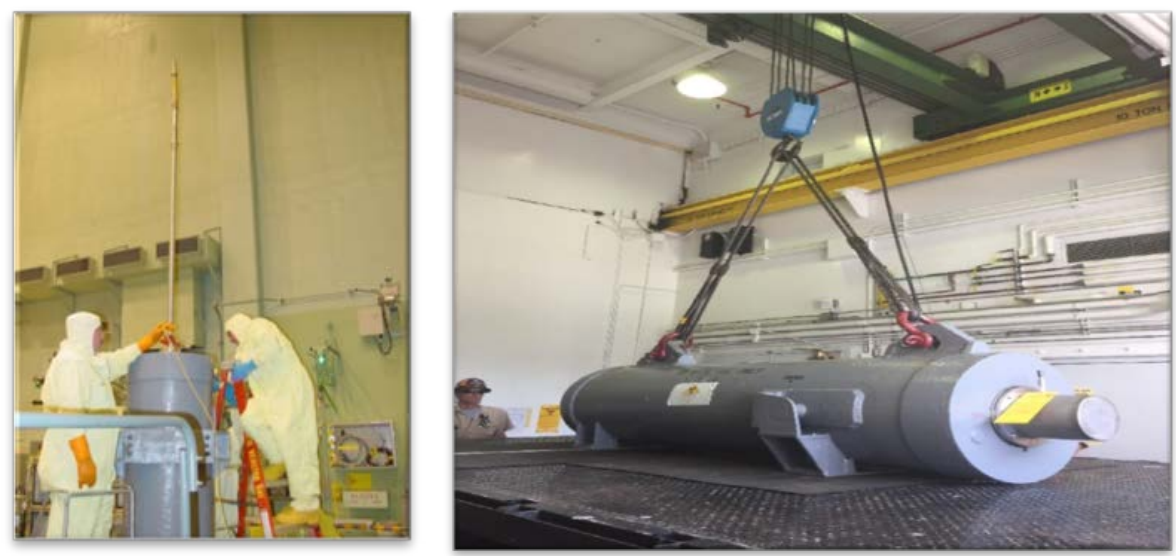

(a)

(b)

Figure 66. Shipping cask that will be used for RB-19J capsule (a) Handling of the loop cask container and (b) loading of the loop cask container. 


\subsection{HFIR IRRADIATION EXPERIMENTS}

Y. Katoh (katohy@ornl.gov), J.L. McDuffee, C. Bryan, J.P. Robertson

\section{SUMMARY}

Neutron irradiation experiments were performed in support of the fusion materials program using various materials irradiation facilities in the High Flux Isotope Reactor (HFIR). The HFIR reactor operated for seven cycles in FY-2017, cycles 469 through 475, accumulating a total of 14,737.76 MWD.

During FY-2017, 4 target zone rabbit capsules completed HFIR irradiation, achieving the target neutron fluences. Those capsules are listed in Table 15 along with condensed information on material, specimen type, temperature, fluence, and period of irradiation. At the end of FY-2017, 7 target zone rabbit capsules are continuing irradiation in HFIR toward their target neutron fluences. Those capsules are listed in Table 16 along with the information on materials, specimen types, and irradiation parameters.

The full length capsule RB-19J was installed in the removable beryllium of the reactor with the start of Cycle 466, in June 2016. It contains tungsten and F82H alloys in various specimen configurations, operating at $250 / 300,500,800$, or $1200^{\circ} \mathrm{C}$. The experiment used a Gd thermal neutron shield. It was in the reactor for four cycles, completing irradiation at the end of Cycle 469. It has been removed from the control facility at the HFIR, and is scheduled for hot cell disassembly in early calendar year 2018.

Table 15. Fusion materials program rabbits that completed HFIR irradiation in FY-2017

\begin{tabular}{|c|c|c|c|c|c|c|c|c|}
\hline $\begin{array}{l}\text { Experiment } \\
\text { Designation }\end{array}$ & $\begin{array}{c}\text { Primary } \\
\text { Materials }\end{array}$ & $\begin{array}{c}\text { Specimen } \\
\text { Types }\end{array}$ & $\begin{array}{c}\text { Irradiation } \\
\text { Temperature } \\
\left({ }^{\circ} \mathrm{C}\right)\end{array}$ & $\begin{array}{c}\text { Max } \\
\text { Exposure } \\
\text { (dpa) }\end{array}$ & $\begin{array}{l}\text { Number of } \\
\text { Reactor } \\
\text { Cycles }\end{array}$ & \multicolumn{3}{|c|}{$\begin{array}{l}\text { HFIR Cycles } \\
\text { Start - End }\end{array}$} \\
\hline IMR8 & various & MD specimens & 600 & 11 & $\begin{array}{c}5 \\
\text { (out Cycle 468) }\end{array}$ & 466 & - & 471 \\
\hline IMR10 & various & MD specimens & 1000 & 11 & 5 & 466 & - & 470 \\
\hline IMR11 & various & MD specimens & 1000 & 11 & 5 & 466 & - & 470 \\
\hline SCF7 & $\mathrm{SiC} / \mathrm{SiC}$ & Bend bars & 600 & 31 & 14 & 457 & - & 470 \\
\hline
\end{tabular}

Table 16. HFIR fusion materials program rabbit capsules continuing irradiation beyond FY-2017

\begin{tabular}{|c|c|c|c|c|c|c|c|c|}
\hline $\begin{array}{l}\text { Experiment } \\
\text { Designation }\end{array}$ & $\begin{array}{l}\text { Primary } \\
\text { Materials }\end{array}$ & $\begin{array}{l}\text { Specimen } \\
\text { Types }\end{array}$ & $\begin{array}{c}\text { Irradiation } \\
\text { Temperature } \\
\left({ }^{\circ} \mathrm{C}\right)\end{array}$ & $\begin{array}{c}\text { Max } \\
\text { Exposure } \\
\text { (dpa) }\end{array}$ & $\begin{array}{l}\text { Number of } \\
\text { Reactor } \\
\text { Cycles }\end{array}$ & \multicolumn{3}{|c|}{$\begin{array}{c}\text { HFIR Cycles } \\
\text { Start - End }\end{array}$} \\
\hline F13A6 & $\begin{array}{l}\text { FeCrAlY } \\
\text { Steel }\end{array}$ & Bend bar & 300 & 47 & 28 & 451 & - & 478 \\
\hline JCR11-05 & SiC/SiC & bend bars & 950 & 50 & 25 & 444 & - & 470 \\
\hline JCR11-07 & $\mathrm{SiC} / \mathrm{SiC}$ & Mini bend bars & 950 & 100 & 47 & 444 & - & 490 \\
\hline JCR11-08 & $\mathrm{SiC} / \mathrm{SiC}$ & Mini bend bars & 950 & 200 & 85 & 444 & - & 528 \\
\hline SCF8 & $\mathrm{SiC} / \mathrm{SiC}$ & Bend bars & 600 & 100 & 45 & 457 & - & 501 \\
\hline SCF9 & $\mathrm{SiC} / \mathrm{SiC}$ & Bend bars & 600 & 200 & 90 & 457 & - & 546 \\
\hline SCF11 & $\mathrm{SiC} / \mathrm{SiC}$ & Bend bars & 950 & 30 & 14 & 458 & - & 471 \\
\hline
\end{tabular}




\section{PUBLICATION AND PRESENTATION RECORD}

\subsection{PAPERS PUBLISHED IN FY 2017}

\section{(Alphabetical by first $\underline{\text { ORNL author) }}$}

C. Ang, C.M. Parish, C. Shih, C. Silva and Y. Katoh, "Microstructure and mechanical properties of titanium aluminum carbides neutron irradiated at 400-700 C,” J. Eur. Ceram. Soc. 37 (2017) 2353-63.

C. Ang, S.J. Zinkle, C. Shih, C. Silva, N. Cetiner, and Y. Katoh, "Phase stability, swelling, microstructure and strength of $\mathrm{Ti}_{3} \mathrm{SiC}_{2}$-TiC ceramics after low dose neutron irradiation,” J. Nucl. Mater. 483 (2017) 4453.

Mark Bannister, Fred Meyer, Hussein Hijazi, Kinga Unocic, Lauren Garrison, Chad Parish. "Surface morphologies of He-implanted tungsten," Nuclear Instruments and Methods in Physics Research B 382 (2016) 76-81.

J.B. Caughman, R.H. Goulding, T.M. Biewer, T.S. Bigelow, I.H. Campbell, J. Caneses, S.J. Diem, A. Fadnek, D.T. Fehling, R.C. Isler, E.H. Martin, C.M. Parish, J. Rapp, K. Wang, C.J. Beers, D. Donovan, N. Kafle, H.B. Ray, G.C. Shaw, M.A. Showers, "Plasma Source Development for Fusion-relevant Material Testing,” J Vacuum Science \& Technology A: Vacuum, Surfaces, and Films, 35 (2017) 03E114.

D. Donovan, D. Buchenauer, J. Whaley, G. Wright, C.M. Parish, X. Hu, "Characterization of He-Induced Bubble Formation in Tungsten due to Exposure from an Electron Cyclotron Resonance Plasma Source," Fusion Science and Technology 72 (2017) 337-346.

J. Reiser, Lauren Garrison, H. Greuner, J. Hoffmann, T. Weingärtner, U. Jäntsch, M. Klimenkov, P. Franke, S. Bonk, C. Bonnekoh, S. Sickinger, S. Baumgärtner, D. Bolich, M. Hoffmann, R. Ziegler, J. Konrad, J. Hohe, A. Hoffmann, T. Mrotzek, M. Seiss, M. Rieth, A. Möslang, "Ductilisation of tungsten (W): Tungsten laminated composites," International Journal of Refractory Metals and Hard Materials 69 (2017) 66-109.

Xunxiang Hu, Kevin Field, Stephen Taller, Yutai Katoh, Brian Wirth, "Impact of neutron irradiation on thermal helium desorption from iron,” Journal of Nuclear Materials, 489 (2017) 109-117.

Xunxiang Hu, Takaaki Koyanagi, Yutai Katoh, Brian D. Wirth, "Positron annihilation spectroscopy investigation of vacancy defects in neutron-irradiated 3C-SiC,” Physical Review B, 95 (2017) 104103.

Y. Katoh, D. Clark, Y. Ueda, Y. Hatano, M. Yoda, A.S. Sabau, T. Yokomine, Lauren Garrison, W. Geringer, A. Hasegawa, T. Hino, M. Shimada, D. Buchenauer, Y. Oya, T. Muroga, "Progress in the US/Japan PHENIX project for the technological assessment of plasma facing components for DEMO reactors," Fusion Sci. Technol. 72 (2017) 222-232.

D.J. Sprouster, T. Koyanagi, E. Dooryhee, S.K. Ghose, Y. Katoh, L.E. Ecker, ”Microstructural evolution of neutron irradiated 3C-SiC,” Scripta Materialia 137, (2017) 132-136.

T. Koyanagi, N.A.P.K. Kumar, T. Hwang, L.M. Garrison, X. Hu, L.L. Snead, Y. Katoh, "Microstructural evolution of pure tungsten neutron irradiated with a mixed energy spectrum," Journal of Nuclear Materials 490 (2017) 66-74. 
T. Koyanagi, N.A.P.K. Kumar, T. Hwang, Lauren Garrison, X. Hu, L.L. Snead, Y. Katoh, "Microstructural evolution of pure tungsten neutron irradiated with a mixed energy spectrum," J. Nucl. Mater. 490 (2017) 66-74.

F.W. Meyer, L. Han, H. Hijazi, M.E. Bannister, K.A. Unocic, C.M. Parish, P.S. Krstic, "Energy dependence of He-ion-induced tungsten nanofuzz formation at non-normal incidence angles," Nuclear Materials and Energy, http://dx.doi.org/10.1016/j.nme.2017.01.013.

Jeremy Moon, Lauren Garrison. "Tungsten Foils and Composites for Fusion Applications - Mechanical Testing” Transactions of the American Nuclear Society, 116 (2017) 435-437.

C. M. Parish, K. A. Unocic, L. Tan, S. J. Zinkle, S. Kondo, L. L. Snead, D. T. Hoelzer, and Y. Katoh, "Helium sequestration at nanoparticle-matrix interfaces in helium + heavy ion irradiated nanostructured ferritic alloys," Journal of Nuclear Materials, 483 (2017) 21-34.

C. M. Parish, K. Wang, R. P. Doerner, and M. J. Baldwin, "Grain orientations and grain boundaries in tungsten nanotendril fuzz grown under divertor-like conditions," Scripta Materialia, 127 (2017) 132-135.

C.M. Parish, K. Wang, P.D. Edmondson, K.A. Terrani, X. Hu, R.L. Seibert, Y. Katoh, "Combining Transmission Kikuchi Diffraction and Scanning Transmission Electron Microscopy for Irradiated Materials Studies," Microscopy and Microanalysis, 23-Supplement 3 (2017) 2218-2219.

C.M. Parish, T. Koyanagi, S. Kondo, Y. Katoh, Irradiation-induced $\beta$ to $\alpha$ SiC transformation at low temperature, Scientific Reports 7 (2017) 1198.

S. Kondo, C.M. Parish, T. Koyanagi, Y. Katoh, "Equilibrium shapes and surface selection of nanostructures in 6H-SiC,” Applied Physics Letters 110 (2017) 142106.

D. Donovan, D. Buchenauer, J. Whaley, G. Wright, C.M. Parish, \& X. Hu, "Characterization of HeInduced Bubble Formation in Tungsten due to Exposure from an Electron Cyclotron Resonance Plasma Source," Fusion Science and Technology 72 (2017): 337-346.

Steven J. Pawel, Kinga A. Unocic, “Compatibility of an FeCrAl alloy with flowing Pb-Li in a thermal convection loop,” Journal of Nuclear Materials, 492 (2017) 41-51.

A. F. Rowcliffe, L. M. Garrison, Y. Yamamoto, L. Tan, Y. Katoh, "Materials Challenges for the Fusion Nuclear Science Facility," Fusion Engineering and Design July 2017 DOI: 10.1016/j.fusengdes.2017.07.012.

L. El-Guebaly, L. Mynsberge, A. Davis, C. D’Angelo, A. Rowcliffe, B. Pint, and the ARIES-ACT Team, "Design and Evaluation of Nuclear Systems for ARIES-ACT2 Power Plant with DCLL Blanket" Fusion Science and Technology 72 (2017) 17-40.

K. Wang, M. E. Bannister, F. W. Meyer, and C. M. Parish, "Effect of starting microstructure on helium plasma-materials interaction in tungsten," Acta Materialia, 124 (2017) 556-567.

K. Wang, R.P. Doerner, M.J. Baldwin, F.W. Meyer, M.E. Bannister, A. Darbal, R. Stroud , C.M. Parish, "Morphologies of tungsten nanotendrils grown under helium exposure," Scientific Reports, 7 (2017) Article 42315. 
S.J. Zinkle, K.A. Terrani and L.L. Snead, "Motivation for Utilizing New High-performance Advanced Materials in Nuclear Energy Systems" (invited), Current Opinion in Solid State and Materials Science, $20^{\text {th }}$ anniversary special issue, 20 (2016) 401-410. doi:10.1016/j.cossms.2016.10.004.

C.L. Tracy, S. Park, D.R. Rittman, S.J. Zinkle, H. Bei, M. Lang, R.C. Ewing, and W.L. Mao, "Formation of a hexagonal close-packed phase of the high-entropy alloy CrMnFeCoNi at high pressure," Nature Communications (May 25, 2017) 16634 (6pp); DOI: 10.1038/ncomms15634.

D. Stork and S.J. Zinkle, "Introduction to the Special Issue on Technical Status of Materials for a Fusion Reactor,” Nuclear Fusion 57 (2017) 092001 (9 pp).

H. Tanigawa, E. Gaganidze, T. Hirose, M. Ando, S.J. Zinkle, R. Lindau, E. Diegele, "Development of Benchmark Reduced Activation Ferritic/Martensitic Steels for Fusion Energy Applications”, Special Issue on Materials for a Fusion Reactor, Nuclear Fusion 57 (2017) 092004.

S.J. Zinkle, J-L Boutard, D.T. Hoelzer, A. Kimura, R. Lindau, G.R. Odette, M. Rieth, L. Tan, H. Tanigawa, "Development of Next Generation Tempered and ODS Reduced Activation Ferritic/Martensitic Steels for Fusion Energy Applications”, Special Issue on Materials for a Fusion Reactor, Nuclear Fusion 57 (2017) 092005.

S. M. González de Vicente, J.-L. Boutard, S. J. Zinkle, H. Tanigawa, "Materials Testing Facilities and Programmes for Fission and Ion implantation damage”, Special Issue on Materials for a Fusion Reactor, Nuclear Fusion 57 (2017) 092011.

D. Stork, J-L Boutard, S. Gonzalez, R. Heidinger, A. Moslang, A. Ibarra, M.J. Porton, and S.J. Zinkle, "Towards a programme of testing and qualification for structural and plasma-facing materials in 'fusion neutron' environment”, Special Issue on Materials for a Fusion Reactor, Nuclear Fusion 57 (2017) 092013. 


\subsection{PAPERS SUBMITTED IN FY 2017}

(Currently awaiting publication)

Charles Kessel, James P Blanchard, Andrew Davis, Laila El-Guebaly, Lauren M Garrison, Nasr M Ghoniem, Paul W Humrickhouse, Yue Huang, Yutai Katoh, Andrei Khodak, Edward P Marriott, Siegfried Malang, Neil B Morley, G H Neilson, Juergen Rapp, Marvin E Rensink, Thomas D Rognlien, Arthur F Rowcliffe, Sergey Smolentsev, Lance L Snead, Mark S Tillack, Peter Titus, Lester Waganer, Greg M Wallace, Stephen J Wukitch, Alice Ying, Kenneth Young, Yuhu Zhai, "Overview of the Fusion Nuclear Science Facility, a Credible Break-in Step on the Path to Fusion Energy,” submitted to Fusion Engineering and Design.

Lauren Garrison, F. W. Meyer, M. E. Bannister. "The Influence of Microstructure on Deuterium Retention in Polycrystalline Tungsten,” accepted by Fusion Science and Technology.

Lauren M. Garrison, Gerald L. Kulcinski, Greg Hilmas, William Fahrenholtz, and Harry M. Meyer III. "The Response of ZrB2 to Simulated Plasma-Facing Material Conditions of He Irradiation at High Temperature,” submitted to Journal of Nuclear Materials.

F. Meyer, L. Han, H. Hijazi, M. Bannister, K. Unocic, C. Parish, P. Krstic, "Energy dependence of Heion-induced tungsten nanofuzz formation at non-normal incidence angles," Nuclear Materials and Energy, in press.

C.M. Parish, K. Wang, P.D. Edmondson, "Viewpoint: Nanoscale chemistry and crystallography are both the obstacle and pathway to advanced radiation-tolerant materials," Scripta Materialia, in press.

L. Tan, B.K. Kim, G.S. Was, "Evolution dependence of vanadium nitride nanoprecipitates on directionality of ion irradiation," Journal of Nuclear Materials, https://doi.org/10.1016/j.jnucmat.2017.09.001.

S.J. Zinkle and L.L. Snead, "Opportunities and limitations for ion beams in radiation effects studies: Bridging critical gaps between charged particle and neutron irradiations," invited viewpoint paper in press for Scripta Materialia, doi.org/10. 1016/ j. scriptamat. 2017. 06. 041. 


\subsection{PRESENTATIONS (INCLUDES ONLY OFES-FUNDED ORNL PRESENTING AUTHORS, BY DATE PRESENTED)}

Lauren Garrison “Fusion Energy: Is it still 30 years away?” graduate student seminar. University of

Illinois, Nuclear, Plasma, and Radiological Engineering Department. October 4, 2016.

Lauren Garrison. "Building an extraordinary career in research with Oak Ridge National Lab" student ANS section meeting at University of Illinois. October 4, 2016.

At the Appalachian Regional Microscopy Society (AReMS) Fall Meeting, Knoxville, TN, USA, October 6-7, 2016:

C. M. Parish, "Having a hot time: analyzing highly radioactive materials with electron microscopy".

At 26th IAEA Fusion Energy Conference, October 17-22, 2016, Kyoto, Japan:

R. E. Stoller, D.W. Clark, N. M. Ghoniem, Y. Katoh, R. J. Kurtz, J. Marian, G. R. Odette, B. D. Wirth, T. Yamamoto, and S. J. Zinkle, "Recent Advances in Radiation Materials Science from the US Fusion Reactor Materials Program”, paper MPT/1-1.

At Materials Science \& Technology 16, October 23-27, 2016, Salt Lake City, Utah:

Yutai Katoh, Takaaki Koyanagi, Takashi Nozawa, Hiroyasu Tanigawa, "Microstructures and Strength of Early Nuclear Grade SiC/SiC Composite after Very High Fluence Neutron Irradiation".

C. Ang, S. Zinkle, C. Parish, C. Shih, Chinthaka Silva, P. Edmondson, Y. Katoh, "Neutron irradiation of $\mathrm{Ti}_{3} \mathrm{AlC}_{2}-\mathrm{Ti}_{5} \mathrm{Al}_{2} \mathrm{C}_{3}$ and $\mathrm{Ti}_{3} \mathrm{SiC}_{2}$ materials - recovery and annealing at elevated temperature”.

At the 13th International Workshop on Spallation Materials Technology, Oct. 31-Nov. 4, 2016, Chattanooga, Tennessee:

S.J. Zinkle, G.R. Odette and T. Yamamoto, "Impact of $\mathrm{H}$ and He transmutation products on radiation effects in materials".

At NuMat 2016: The Nuclear Materials Conference, November 7-11, 2016 Montpellier, France:

A.A. Campbell, Y. Katoh, M.A. Snead, "Post-irradiation tensile strength of fine-grained nuclear graphite".

C. M. Parish, P. D. Edmondson, R. L. Seibert, T. J. Gerczak, Y. Katoh, and K. A. Terrani, "Smaller, faster, better: Applying advanced microscopy to irradiated fuels and materials".

S.J. Zinkle and R.E. Stoller, "On the importance of correlated defect recombination in radiation effects studies”.

At the Materials Research Society annual meeting, Nov. 27-Dec. 2, 2016, Boston, in Symposium MB3 on High-Entropy Alloys:

T. Yang, S. Xia, C. Li, Y. Zhang, Y. Wang and S.J. Zinkle, “A Promising New Class of Irradiation-tolerant Alloys: High-Entropy Alloys”. 
At the 41st International Conference and Expo on Advanced Ceramics and Composites, Jan 22-27, 2017, in Daytona Beach:

C. Ang, C. Parish, C. Shih, S. J. Zinkle, C. Silva, P. Edmondson, N. Cetiner, Y. Katoh, "Fracture behavior of $\mathrm{Ti}_{3} \mathrm{AlC}_{2}-\mathrm{Ti}_{5} \mathrm{Al}_{2} \mathrm{C}_{3}$ and $\mathrm{Ti}_{3} \mathrm{SiC}_{2}$ after neutron-irradiation at elevated temperatures"

T. Koyanagi, M. Lance, Y. Katoh, "Probing structural disorder in neutron irradiated silicon carbide by Raman spectroscopy”.

X. Hu, T. Koyanagi, Y. Katoh, "Positron Annihilation Spectroscopy Investigation of Vacancy Clusters in Neutron-irradiated 3C-SiC”.

At TMS 2017 - Annual Meeting \& Exhibition, February 26 - March 2, 2017, San Diego, California: Lauren M. Garrison, Xunxiang Hu, Chad M. Parish, Taehyun Hwang, Takaaki Koyanagi, Makoto Fukuda, Jens Reiser, Lance L. Snead, and Yutai Katoh. "Microstructure and mechanical properties of neutron-irradiated tungsten foil for laminate composites".

Xunxiang Hu, Kevin Field, David Woodley, Yutai Katoh, "Impact of neutron irradiation on helium desorption behavior in iron”.

T. Koyanagi, M. J. Lance, Y. Katoh, “Quantification of irradiation defects in silicon carbide using Raman spectroscopy”.

C. M. Parish, X. Hu, L. Garrison, P. Edmondson, K. Wang, L. Snead, and Y. Katoh, "Microstructural processes in neutron-irradiated tungsten".

Lauren M. Garrison, Xunxiang Hu, Chad M. Parish, Taehyun Hwang, Takaaki Koyanagi, Makoto Fukuda, Jens Reiser, Lance L. Snead, and Yutai Katoh. "Microstructure and mechanical properties of neutron-irradiated tungsten foil for laminate composites".

K. Wang, C.M. Parish, Y. Katoh, F.W. Meyer, M.E. Bannister, R.P. Doerner, M.J. Baldwin, and D. Donovan, "Microstructural effects on helium plasma-materials interaction in tungsten".

S.J. Zinkle, Y. Yang and L.L. Snead, "Design of Creep-Resistant Copper Alloys” (invited keynote).

S.J. Zinkle, "Microstructure of Irradiated Materials" (Robert Franklin Mehl Award/ Institute of Metals Lecture).

Lauren Garrison. "Materials for Fusion Reactors.” undergraduate student seminar . University of Illinois, Nuclear, Plasma, and Radiological Engineering Department. March 28, 2017.

Lauren Garrison. "Neutron Irradiation Effects in Tungsten.” graduate student seminar. University of Illinois, Nuclear, Plasma, and Radiological Engineering Department. March 28, 2017.

Lauren Garrison. "Building an extraordinary career in research with Oak Ridge National Lab.” seminar for Society of Women Engineers at University of Illinois, March 28, 2017.

At MRS Spring Meeting, Phoenix, Arizona, April 17-21, 2017:

C. Li, X. Hu, G.M. Stocks, B.D. Wirth, S.J. Zinkle, "Evaluating Irradiation Effects and Defect Kinetics in a Co-Free High Entropy Alloy”, Symposium ES5 on Advances in Materials, Experiments and Modeling for Nuclear Energy. 
At the16th International Conference on Plasma-Facing Materials and Components for Fusion Applications, Neuss/Düsseldorf, Germany, May 16-19, 2017:

L.M. Garrison, F.W. Meyer, M.E. Bannister, K. Unocic. "Effects of Machining and Polishing on the Near-Surface Region of Tungsten for Use as a Plasma-Facing Component.” (best poster award).

C.M. Parish, L.M. Garrison, X. Hu, K. Wang, P.D. Edmondson, L.L. Snead, R.P. Doerner, M. J. Baldwin, M. E. Bannister, F. W. Meyer, and Y. Katoh, "Neutron Irradiation and PMI Effects on Microstructure and Mechanical Properties of Tungsten," (poster presentation).

Third International Workshop on Models and Data for Plasma-Material Interaction in Fusion Devices (MoD-PMI 2017), Forschungszentrum Jülich, Jülich, Germany, May 22-24, 2017:

C.M. Parish, L.M. Garrison, X. Hu, K. Wang, P.D. Edmondson, L.L. Snead, and Y. Katoh, "Neutron Irradiation Effects on Microstructure of Tungsten," (invited).

Lauren Garrison, Y. Katoh, M. Bannister, P. Edmondson, X. Hu, N. A. P. Kiran Kumar, T. Koyanagi, F. Meyer, J. Moon, E. Ohriner, C. Parish, A. Sabau. "Research on tungsten for fusion reactors at Oak Ridge National Laboratory.” IPP-Garching, Garching, Germany. May 23, 2017.

27th IEEE Symposium on Fusion Engineering, Shanghai, China. June 4-8, 2017:

Lauren M. Garrison, Jeremy Moon, Yutai Katoh, Mark Norfolk, Justin Wenning, Evan Ohriner. "Tungsten-steel composites fabricated by roll bonding and ultrasonic welding for structural use in plasma-facing components”.

Xunxiang Hu, Chad Parish, Kun Wang, Yutai Katoh, “Transmutation-induced precipitation in neutron-irradiated tungsten”.

S.J. Zinkle, “Application of Materials Science Advances to Fusion Energy” (invited),

L. M. Garrison, Y. Katoh, M. Bannister, P. Edmondson, X. Hu, N. A. P. Kiran Kumar, T. Koyanagi, F. Meyer, J. Moon, E. Ohriner, C. Parish, A. Sabau. "Research on Tungsten for Fusion Reactors at Oak Ridge National Laboratory.” ASIPP, Hefei, China. June 9, and University of Science and Technology, Hefei, China. June 12, 2017.

At American Nuclear Society Annual Meeting, San Francisco, California, June 11-15, 2017:

Jeremy Moon and Lauren Garrison. "Tungsten Foils and Composites for Fusion Applications Mechanical Testing”.

Xunxiang Hu, "Fusion Materials Science Research at ORNL", seminar at Fusion Safety Group of Idaho National Laboratory, July 12, 2017.

At Microscopy and Microanalysis, St. Louis, Missouri, August 7-10, 2017:

C.M. Parish, K. Wang, P.D. Edmondson, K.A. Terrani, X. Hu, R.L. Seibert, Y. Katoh, "Combining Transmission Kikuchi Diffraction and Scanning Transmission Electron Microscopy for Irradiated Materials Studies".

At $13^{\text {th }}$ International Symposium on Fusion Nuclear Technology, Kyoto, Japan, September 25-29, 2017:

M. Akiyoshi, R. Kasada, Y. Ishibashi, L.M. Garrison, J.W. Geringer, W.D. Porter, and Y. Katoh. "Validation of Miniature Test Specimens for Post-Irradiation Thermal Diffusivity Measurement.”. 
M. Shimada, Y. Oya, W.R. Wampler, Y. Yamauchi, C.N. Taylor, L.M. Garrison, D.A. Buchenauer, and Y. Hatano. "Deuterium Retention in Neutron-Irradiated Single-Crystal and Polycrystalline Tungsten”. 